\title{
ESSENCE OF SOCIAL EXCHANGE THROUGH ALUMNI ENGAGEMENT OF MILLENNIALS AND THEIR ALMA MATER
}

A Dissertation
Presented to
the Faculty of the Graduate School
at the University of Missouri-Columbia

In Partial Fulfillment

Of the Requirements for the Degree

Doctor of Education

by

ROBERT J. MACHOVSKY

Dr. Nissa Ingraham. Dissertation

December, 2020 
The undersigned, appointed by the dean of the Graduate School, have examined the dissertation entitled

\section{ESSENCE OF SOCIAL EXCHANGE THROUGH ALUMNI ENGAGEMENT OF MILLENNIALS AND THEIR ALMA MATER}

Presented by Robert J. Machovsky, a candidate for the degree of doctor of education and herby certify that, in their opinion, it is worthy of their acceptance.

Dr. Nissa Ingraham

Dr. Timothy J. Wall

Dr. Dan Gordon

Dr. Everett Singleton 


\section{DEDICATIONS}

This dissertation is dedicated to my amazing wife, Katie Machovsky, without her I would not have been able to make it through this journey. Her continued support, and love throughout is truly the best gift of all. I would also like to thank the rest of my family for their love and support throughout this process. 


\section{ACKNOWLEDGEMENTS}

I would like to thank all the amazing faculty in this program but especially my

Dissertation Chair Dr. Nissa Ingraham. Your patience, guidance and humor through the entire process is what kept me going. You are an amazing educator and feel blessed that I you were able to help me through this journey. I would also like to thank Dr. Tim Wall for all your support direction and encouragement over the years, you are truly a great person and educator. 


\section{TABLE OF CONTENTS}

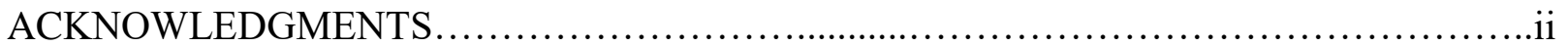

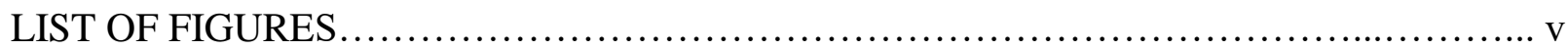

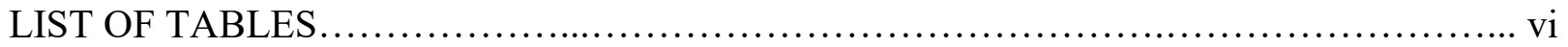

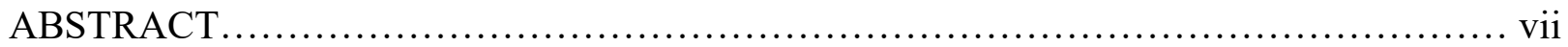

\section{SECTION}

1. INTRODUCTION TO THE BACKGROUND OF THE STUDY $\ldots \ldots \ldots \ldots \ldots \ldots \ldots \ldots \ldots \ldots . . \ldots$

Background

Statement of the Problem

Purpose of the Study

Research Questions

Conceptual Underpinnings

Design of the Study

Definition of Key Terms

Limitation, Delimitations, Assumptions, and Design Controls

Significance of the Study

Summary

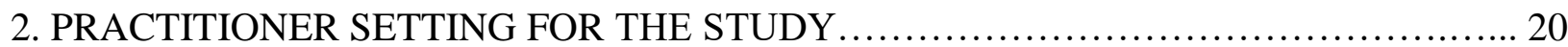

History of the Organization

Organizational Analysis

Leadership Analysis

Implications for Research in the Practitioner Setting

Summary

3. SCHOLARLY REVIEW FOR THE STUDY.

Social Exchange

Alumni Engagement

Millennial Characteristics

Summary

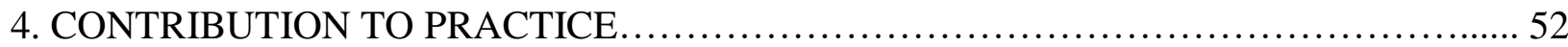

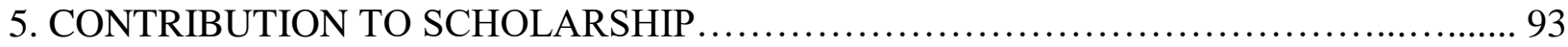

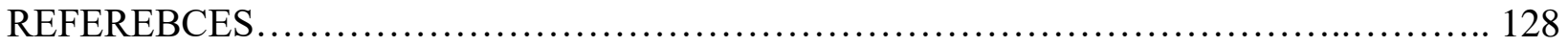

6. PERSONAL REFLECTION ........................................................ 132 
APPENDIXES

A. PARTICIPANT CONSENT FORM FOR ONLINE SURVEY $\ldots \ldots \ldots \ldots \ldots \ldots \ldots . \ldots \ldots$

B. ONLINE SURVEY ................................................. 155

C. PARTICIPANT CONSENT FORM FOR FOCUS GROUP ......................162

D. FOCUS GROUP QUESTIONS......................................... 163

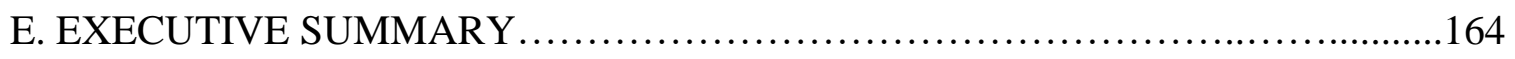

F. IRB APPROVAL FROM UNIVERSITY OF MISSOURI ..........,..........166

G. IRB APPROVAL FROM NORTHWEST MISSOURI STATE UNIVERSITY .....167

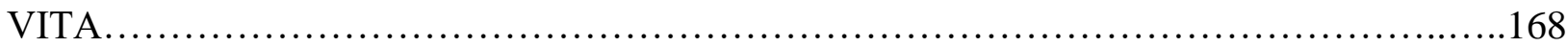




\section{LIST OF FIGURES}

FIGURE

1. Conceptual Underpinnings $\ldots \ldots \ldots \ldots \ldots \ldots \ldots \ldots \ldots \ldots \ldots \ldots \ldots$

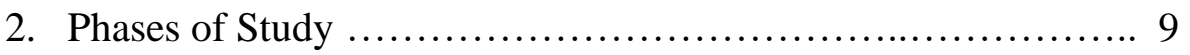

3. Data Collection Tool \& Analysis for Each Research Question ... 13

4. Organization Structure of Midwest University Leadership Team. 23

5. Organization Structure of University Advancement............. 24

6. Conceptual Underpinnings................................ 36

7. Millennials and Seniors by Race Ethnicity................... 48

8. Conceptual Underpinnings...............................97

9. Millennial Alumni Who Gave vs Those That Did Not Give........ 111

10. Millennial Donor Gifts by Area............................112

11. Average Gift of Millennials of Two Birth Groups..................113

12. Average Gift of Millennials That Were In Organizations vs Millennials Who were Not In Organizations. 115

13. Average Gift of Donors Based On Number of Organizations Involved

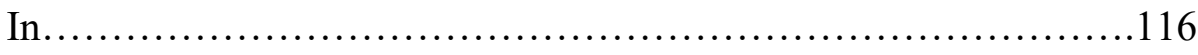

14. Average Gift Based on Type of Degree.........................117

15. Average Gift by Gender...................................118

16. Average Gift of Athlete Donors Compared Donors Who Were Not An Athlete 


\section{LIST OF TABLES}

TABLE

1. Alumni Gender Breakdown.................................. 108

2. Ethnicity of Participants.................................. 108

3. Early and Late Born Millennial Breakdown......................109

4. Alumni Degree Codes........................................ 109

5. Data by Fiscal Year....................................... 110

6. Millennial Alumni Who Give..................................111

7. Donor Gift Area Breakdown................................. 112

8. $t$-Test - Largest Gift by Early or Late Millennial..................113

9. $t$-Test - Largest Gift by Those That Were In Organizations......... 114

10. Mean Largest Gift by Number of Organizations In................116

11. $t$-Test - Largest Gift by Degree Code..........................117

12. $t$-Test - Largest Gift by Gender.............................118

13. $t$-Test - Largest Gift by Athletics Organization.................119

14. Coding Themes........................................... 120 


\begin{abstract}
This study investigated the donor and alumni engagement and perceptions of the "Millennial" generation and descriptive statistics of the population (born between 1980-2004) at a rural Midwest University. Data were obtained from a University database containing demographic (i.e., gender, race, birth year, donor status, donation amount, activities involved in while in school), on Millennial alumni at the University. Data were analyzed by a variety of techniques that included descriptive statistics, Independent $t$-Test, deployment of a survey, and focus group. The quantitative findings concluded that Millennials who were born from 1980 to 1989 contributed larger average gifts then Millennials who were born from 1990 to 2004 . Additionally, the research discovered that Millennials who were involved in organizations gave larger donations than those who were not in student organizations. The qualitative findings concluded that the Millennial population provided evidence of areas and reason on why they support the institution when connected to making a donation and the various aspects that affect one's ability due to communication preferences, affinity, areas to support, and financial ability. An understanding for professionals and researchers to be educated on how to better fundraise/engage with the Millennial generations within higher education will allow for universities and colleges to rely on this generation in the years to come.
\end{abstract}

Keywords: millennial generation, donor, alumni, affinity and alumni engagement 


\section{SECTION ONE}

\section{INTRODUCTION TO THE BACKGROUND OF THE STUDY}

State higher education institutions have had to increase their efforts in raising private funding from alumni to help offset the declining revenue from the state and national governments (Knapp, 2000; Caboni \& Proper, 2007; Li \& Zumeta, 2015; Zhang, Ning, \& Barnes, 2016). Fundraising programs of higher education institutions have been exploring methods to engage better with their various generations of constituent alumni and friends to generate the increase in private support (Osborn, Alkezweeny, \& Kecskes, 2015). This study sought to help fill a gap in literature and knowledge for the scholars and practitioners working with Millennial engagement and to increase engagement and, ultimately, private support to institutions of higher education.

\section{Background of the Study}

The history of private support in the form of donations to the higher education sector was not a new trend. Educational philanthropy goes back to medieval times in Europe, where some of the first institutions received gifts to help with budgetary needs to remain open and functioning (Cobban, 1975). For example, Harvard College received credit for the early fundraising activities in the states in the year 1638, when John Harvard left his estate to the school (Frank, 2014). Fundraising and the need for alumni engagement has evolved a great deal since 1638. University fundraising and engagement efforts found themselves competing with more non-profit charities than ever before (Cha \& Neilson, 2001).

The average cost of university tuition over the last 20 years has increased at an annual rate more significant than the United States Consumer Price Index (Harvard University Factbook, 2005-2006), due to a shift in university funding models. The change in practice required schools to aggressively increase efforts of securing private support to continue to offer 
quality and affordable education (Gottfried \& Johnson, 2006). In 2016, the Council for Aid to Education's annual Voluntary Support of Education survey (VSE) of colleges and universities reported that the combined public and private higher education sectors received a record of $\$ 41$ billion in private support due to the decreased funding from state government from previous years (Kaplan, 2018). Because of the decreased state funding for higher education from 2009 to 2011 in the United States, schools increased the cost of tuition to fill the gap (Oliff, Palacios, Johnson, \& Leachman, 2013), which required that they put more efforts in raising private dollars. The cost of university tuition increased drastically from 1990 to 2015, not only at fouryear institutions but at two-year institutions and community colleges as well (Kim \& Ko, 2015; Lee, Lim \& Kim, 2017). The steady increase in university tuition was due to the decrease in funding for higher education by government agencies (Oliff et al., 2013; Weerts, 2014). According to Oliff et al. (2013), "During the Great Recession of 2008, state spending nationwide dropped 28\%; every state except North Dakota and Wyoming cut funding for higher education" (p. 1). Thirty-six states decreased funding for higher education by at least $20 \%$; while, 11 states cut funding by more than one-third (Oliff et al., 2013). Deep cuts in government funding left university administrators on their own to raise funds for the construction of new facilities and improved infrastructures on university campuses (Oliff et al., 2013). The demographic of alumni constituents also continued to change as the largest population of university constituents was represented by the Millennial Generation (Lewis, 2019). This generation became three times larger than Generation $\mathrm{X}$ and was considered the next generation of donors to non-profit organizations (Connor, Shaw \& Fairhurst, 2008). Not only were they larger than Generation X, but they were even more massive than the generation known as "The Baby Boomers," individuals born between 1946-1964 (Rainer \& Rainer, 2011, p. 2). It was because of this fact, 
fundraisers needed to take advantage of this new generation to fill the gap in donating that previous generations such as "The Baby Boomers" would leave behind (Dagher, 2014).

\section{Statement of the Problem}

Each year, fundraising professionals at universities developed fundraising and engagement activities with a range of constituents who engaged with universities in the past or have yet to continue that relationship (Weerts \& Hudson, 2009). At the time of this study, there was a lack of research regarding information that determined the specific alumni engagement practices needed when considering future fundraising campaigns and segmentation criteria towards individuals born from 1980 to 2004, known henceforth as “Millennials.” Definitions for this group included additional years within 1980 to 2004. For this study, Millennials were categorized by being born from 1980 to 2004 (Stein, 2013; Feiertag \& Berge, 2008; Howe \& Strauss, 2000; Rainer \& Rainer, 2011). With limited time and budget, institutions alumni relations professionals needed to strategically look at who and how they were messaging to younger alumni to improve engagement activity (Drezner \& Huehls, 2014). As Millennials became the next generation of givers and volunteers at the Midwest University studied (Hanley Semelbauer, 2015), the lack of institutional knowledge in fundraising, engagement practices, personal preference with this population, and demographics needed to be evaluated.

\section{Purpose of the Study}

This study sought to fill the gap about what Millennial engagement looked like within higher education. The university studied will be referred to as "Midwest University" throughout the remainder as the study. This study provided demographic information about whom from the Millennial alumni generation from the Midwest University was giving back, and provided a blueprint about which engaged alumni the institution should have communicated and 
concentrated on differently in future communications pieces, such as direct mail solicitations and individual approaches like personalized fundraising asks. The significance of this study was to minimize the scholarship gap in the literature and professional practice of alumni engagement to Millennials.

Current and past donors, such as (alumni, friends, parents, and students who have demonstrated financial interest in engaging with the Midwest University will be referred to as "donors" for the remainder of the study) from fiscal years 2015 through 2019 from the Midwest University was the main focus of this research. The researcher looked at variables, such as total giving history, age, class year, and gender. Additionally, this study identified perceptions of why Millennials engaged with Midwest University. The research question that guided this study was, “What does Millennial alumni engagement look like at a rural Midwest university?”

This study intended to fill the gap in knowledge and research by building a better understanding of what was needed for Millennials to stay engaged with Midwest University when looking at financial resources (Saratovsky, 2013 McAlexander, Koenig \& DuFault, 2016; McCELLAN, 2016). Connolly and Blanchette (1986) identified additional economic variables such as job, age, grandchildren, and spouse's career as other factors that influenced engagement for those born from 1980-2004. However in this study, the only institutional data collected was class year, gift amount, age, gender, and selected fiscal years. Additionally, qualitative research methods were conducted to help understand the Millennial perception of why and how they chose to engage with higher education institutions. 


\section{Research Questions}

Due to the necessity of higher education intuitions need to rely more on private sources of funding and higher levels of engagement among their alumni (Oliff et al.,2013), it was pertinent to understand emerging constituents. This explanatory sequential mixed-methods study sought to answer the overarching question: What does Millennial alumni engagement look like at a rural Midwest university?

Probing questions driving this study included:

1) Who are the Millennials who give at the University?

2) Why do these Millennials give to the University?

To understand the qualitative nature of the phenomenon, a survey and semi-structured focus group (see Appendix A) was used answer the overarching research question of how do Millennial alumni prefer to stay engaged with Midwest University. (See Appendix A) for additional probing questions that assisted in answering this question.

\section{Conceptual Underpinnings}

This explanatory sequential mixed-methods study was guided by the conceptual underpinnings of the social exchange perspective, alumni engagement, and Millennial characteristics. When looking at demographics that identified Millennials who chose to engage with the university in which they graduated from, one must first understand why alumni and friends would want to connect with the institution by making a philanthropic gift or any additional engagement possibilities. Understanding a person's social exchange needs allowed the researcher to understand why individuals chose to give back and/or engage with this school (Radcliffe, 2011; Dodge, 2016). Additionally, understanding typical alumni engagement and Millennial characteristics were imperative in guiding this study. 


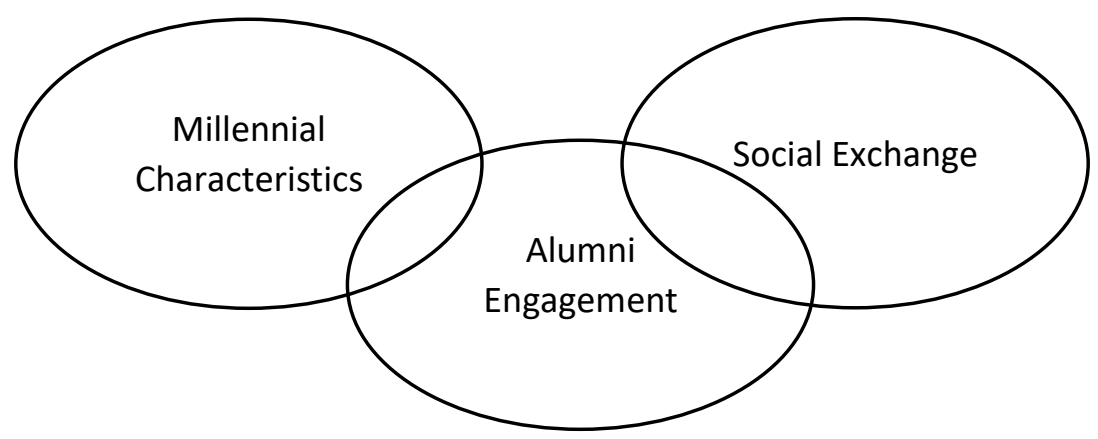

Figure 1. Conceptual Underpinnings

\section{Social Exchange}

Blau (1964) defined the social exchange theory, as a concept of exchanging relationships, as a social exchange phenomenon in which the product of exchanged relationships, with each other and a social reward environment that established trust and social bonds. Additionally, this theory provided the following assumption: Individuals engaged in activities to achieve goals with the understanding that there was a cost for the continued relationship (Blau, 1964). Blau's development of the social exchange theory (SET) provided insight on organizational behavior and integrated a variety of frames, references, and methods that explained or debunked the phenomenon of social satisfaction and interaction (Emerson, 1976). Blau's (1964) simple definition of social exchange was "limited to action that was contingent, and mutually rewarding processes involving 'transaction' or simply 'exchange.'” (Emerson, 1976, p. 336). To provide an even more simplistic lens on SET.

This study was further supported by the works of researchers Weerts and Ronca (2007), to substantiate social exchange and its importance as a critical conceptual underpinning. In their research, Weerts and Ronca (2007) used the social exchange concept to explain why alumni stayed connected to their alma mater based on the attitudes and characteristics that people had towards their institutions. This further confirmed the reasoning of using the social exchange 
concept in this study and understanding why a specific population chose to engage and develop a continued relationship with an entity in which they are associated (Weerts \& Ronca, 2007).

\section{Alumni Engagement}

Many factors could have had an effect on alumni engagement and ranged from a variety of approaches and reasons (Drew-Branch, 2011). Factors, such as student engagement, alumni satisfaction, and affinity towards the institution, emerged as identifiers for more significant alumni engagement in the study. When considering alumni participation further, one study determined that there was a variety of different methods that made an individual connected to his or her alma mater (Osborn et al., 2015). Another study found that alumni who received university publications and materials had a higher probability of making a gift than those who did not accept or receive similar information (Taylor \& Martin, 1995). An additional study reported that the most significant predictor of alumni engagement potential was institutional programming that focused on alumni activities, along with further communication aspects including a multiple alumni affinity programs, such as alumni chapters and volunteer opportunities (Harrison, 1995). Global financial stability was another area that revealed several vital findings that supported its effect on alumni engagement predictability (Davis, 2019). A survey conducted in 2008 reported that $22 \%$ of individuals over the age of 60 did not make a gift due to the downturn of the economy (Hall, 2008). This $22 \%$ represented a large population of the Baby Boomers who were hit the hardest with decreases to retirement and investment portfolios (Hall, 2008). Specifically, this study identified three areas: donor engagement, global financial stability, and alumni loyalty.

\section{Millennial Characteristics}


Understanding the Millennial population by looking at the characteristics most exhibited was essential when considering this generation (Oblinger, 2003; Purani, Kumar, \& Sahadev, 2019). A wealth of information existed regarding this population and its characteristics. The work of Farrel and Hurt (2014) provided a variety of features that accounted for this population, such as multi-tasking abilities, poor communication skills, and the requisite of technology (Feirtag \& Berge, 2008). Additional characteristics such as generous, optimistic, structured, and collaborative were cited by the works of Elam, Stratton \& Gibson, (2007). Looking at the literature available on this population allowed additional framework about connecting with this population from a philanthropic stand-point.

\section{Design of the Study}

This explanatory sequential mixed-methods study explored the demographics of Millennials who chose to engage with the alumni program at a moderately selective rural Midwest university and understood the phenomenon of Millennial giving. The mixed-methods study design combined quantitative and qualitative data within the study that allowed the researcher to understand the aspects under review (Creswell, 2014). The researcher relied on both numerical data (Charles \& Mertler, 2002), and "an inquiry process of understanding the meaning of individuals or groups" (Creswell, 2014, p. 4). The researcher collected the data in phases, which allowed him to continually reflect and sort comments into themes and categories known as the constant comparative method (Kruger \& Casey, 2015; Merriam \& Tisdell, 2015). This gave the researcher the opportunity to consider changes in the data to increase the quality of the data being collected (Krueger \& Casey, 2015). Figure 2 provides the order of phases the mixed-methods study evaluated during the collection and study of data. 


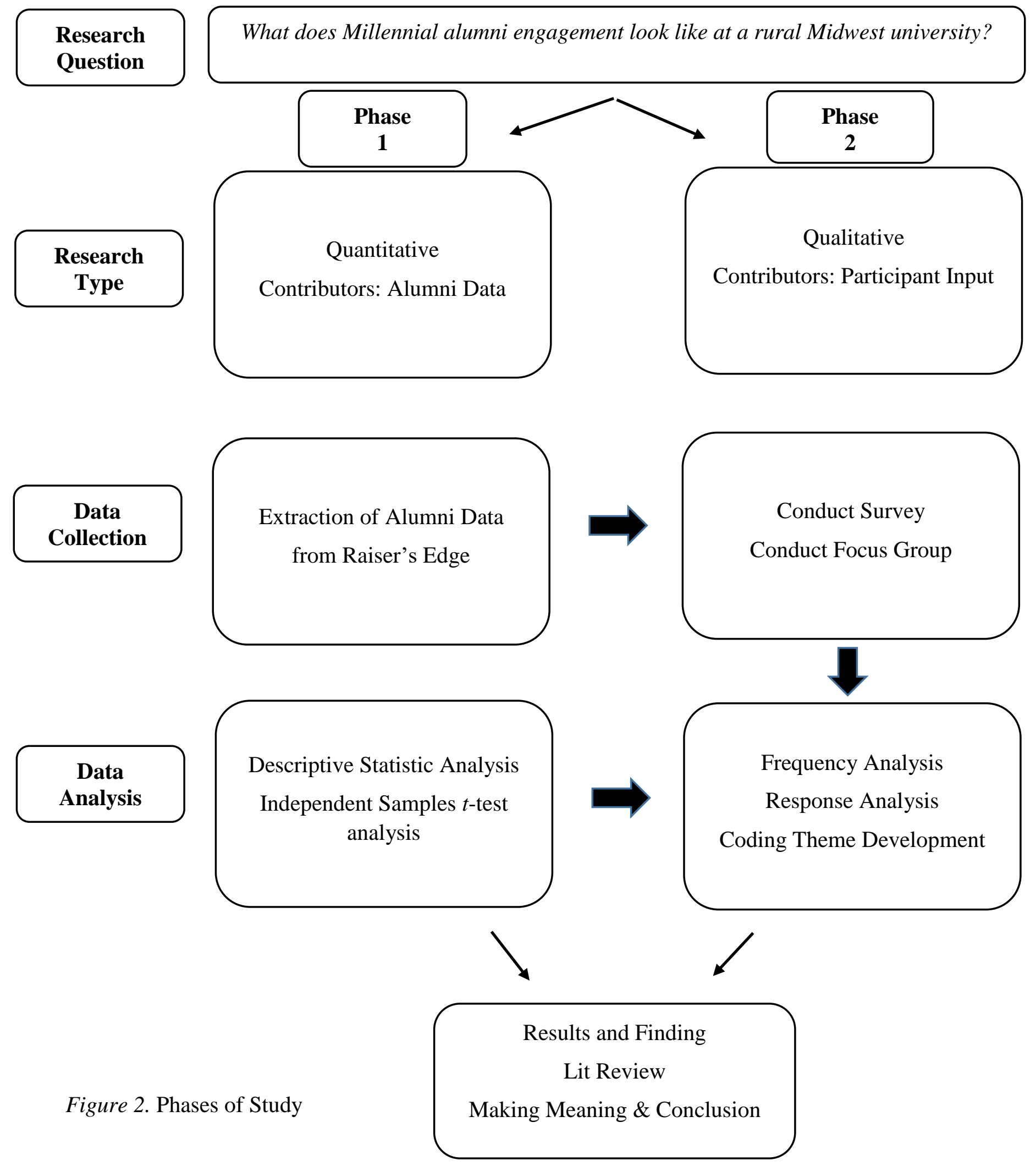




\section{Setting}

Midwest University was a rural public university located in a city of less than 15,000 residents (Midwest University, 2020). Due to its rural location, students came from a variety of backgrounds that included rural, city, and urban environments during their high school years (Midwest University, 2020, Fact sec.). Midwest University was approximately 100 miles from a large metropolitan city center with a population of more than one million. Midwest had an enrollment of approximately 7,000 students that consisted of a traditional student body with a large concentration of Caucasian students at more 88\% (Midwest University, 2020, Student demographic sec.). The $12 \%$ of minority student population ethnicities included Black, Asian, and Hispanic as the recognized primary minority groups (Midwest University, Student demographic sec.). Additionally, the average class size at Midwest University was 27, the student-to-faculty ratio was 22-to-1, and laptops and textbooks were included in the tuition (Midwest University, 2020, facts sec.). From an alumni perspective, Midwest University reported more than 70,000 alumni and friends, and an endowment of \$25.6 million that provided more than $\$ 900,000$ in scholarships, as published in 2018 on the Midwest University facts website. Midwest University's Foundation reported more than 5,600 donors in 2018 (Midwest University, 2020, Midwest Facts, Facts sec.).

Midwest University prided itself on "student success - every student, every day" (Midwest University, Mission sec., para. 1). Additionally, it identified student retention as one of the main areas of focus due to a decline in enrollment over the past few years (Midwest University, 2018). University programs and services, such as the Student Success Center, were charged in assisting students with their needs to help keep retention strong at Midwest University and the graduation rate above peer institutions (Midwest University, 2018, Facts sec.). 
Midwest University was associated with a separate nonprofit organization that worked through the vice president of external relations and the executive director of the Midwest Foundation. The Foundation did not report to the Board of Regents, university president, or the vice president of external relations and executive director of the Midwest Foundation (Midwest University, 2020). Instead, the Foundation was comprised of a group of alumni and friends of the University and served as Board of Directors and governed itself. The Foundation was again a separate entity from the University but operated in the benefit of the University by raising private dollars for various university initiatives and projects.

\section{Participants}

The participants for this study are graduates of Midwest University who were born from 1980-2004 and known as the Millennial Generation. A random sampling approach was utilized to shorten the list of alumni reviewed in the study and allowed the researcher to establish a controlled setting "so that the true influence of the independent variable on the dependent can be determined" (Creswell, 2014 p. 53). The list of participants was pulled from a database known as Raiser's Edge, a constituent management software used within the Midwest University Advancement division that stored and tracked records. Names were removed from the list and replaced with a unique numeric identifier and then randomly selected to be included in the study (Creswell, 2014). The data information consisted of: a) Gender, b) Giving Amount, C) Fiscal Year, d) Activities, e) Email Address, f) Type of Degree, g) Race, and h) Age. Additionally, the participants donated to the intended institution within the fiscal years of (FY19, FY18, FY17, FY16, and FY15) and engaged with the university by taking advantage of one or more of its many volunteer opportunities. 


\section{Data Collection Tools}

The following data collection tools were used to collect data for this explanatory sequential mixed-methods study. First, the researcher received approval from the Institutional Review Board (IRB) at The University of Missouri (Creswell, 2014). As Creswell (2014) indicated, obtaining IRB approval helped to ensure the trustworthiness of the study by having an outside review of the research design and protocols. When permission was granted from the IRB, the researcher requested IRB approval from Midwest University to extract the data from the Office of University Advancement at Midwest University that gathered the data from Raiser's Edge, their a constituent management system (CRM) used by the university and its Advancement Office that stored and tracked constituent information.

The data was requested and accessed in an archival manner by extracting the information in an Excel file format with the following headers: a) Gender, b) Giving Amount, c) Fiscal Year, d) Activities, e) Email Address, f) Type of Degree, g) Race, and h) Age. To protect the participants and allow for complete anonymity, the researcher coded each participant with a unique individual number that was not aligned or distinguishable to personal records or any identifiable information that would determine the participants' identities (Creswell, 2014). This anonymity protected the participants from political repercussions on important ethical pieces of

research, as denoted by (Seidman, 2013). Additionally, the researcher stored data on a password protected server that was locked in an office when the researcher was not present.

Additionally, the researcher organized and distributed a survey that randomly selected Millennials from the Midwest University pool of available participants by email, dispersing through the Midwest University email system. In selection of participants and design, the researcher followed design and measurement validity to insure the selection and distribution of 
the survey adhered to a trustworthiness of followed protocols (Fink, 2017). The study was used to obtain or secure a series of engagement questions with the university, (see Appendix A). The survey was conducted through Qualtrics, a recognized and trusted vendor in survey production and deployment (Molnar, 2019). Fink (2017) explained that surveys were used when researchers wanted to understand answers about people from people. However, Fink (2017) went on to say that surveys should not be the only method used when extracting information from human participants. For triangulation, a semi-structured focus group was also organized and conducted during the data collection process to collect deeper and richer data (Kruger \& Casey, 2015).

Participants in the focus group were randomly selected by an odd number in the original data set of alumni Millennials from Midwest University. Additionally, the focus group consisted of four participants (Kruger \& Casey, 2015) being asked a series of questions, (see Appendix B for participant consent form structure and questions of the focus group.)

\begin{tabular}{|l|c|c|}
\hline \multicolumn{1}{|c|}{ Research Question } & Data Collection Tool & Data Analysis \\
What did Millennial alumni & Focus Group and Survey & Axial Coding and Constant \\
rural Midwest university? & Comparative Method \\
\hline Who are Millennial's that & Midwest University's & SPS \\
& Raiser's Edge date of & Independent Samples $t$-test \\
& Focus Group \& Survey & analysis \\
\hline Why do Millennials give? & Midwest University's & SPS \\
& Raiser's Edge date of & Independent Samples $t$-test \\
& Millennials & analysis \\
\hline
\end{tabular}




\section{Focus Group \& Survey}

Figure 3. Data Collection Tool \& Analysis for Each Research Question

\section{Data Analysis}

To answer the research questions, the researcher conducted the following analysis of the data that was compiled from both methodologies of quantitative and qualitative study approaches by using what the Explanatory Sequential Mixed-Methods approach (Creswell, 2014). From this approach, the researcher conducted quantitative research first and analyzed the results. Creswell (2014) affirmed that a mixed-methods approach allowed for the investigation to combine or integrate the research collected from qualitative and quantitative study approaches to build a deeper and richer understanding of the subject being reviewed. To answer the overarching research question, the researcher compiled descriptive statistics that provided a summary on the following demographics: a) gender, b) giving amount, c) graduation year, d) activities, e) email address, f) type of degree, g) race, and h) age.

The researcher then conducted the qualitative portion of the study to build on the findings and results uncovered from the quantitative collection (Creswell, 2014). The dependent variables for this were: a) gender, b) giving amount, c) activities, d) email address, e) type of degree, f) race, and g) age, and the independent variable was : a) graduation year. Finally, the researcher used Microsoft Excel to randomly select participants who were used in the descriptive statistics and Independent Samples $t$-test analysis portion of the study.

Additionally, a survey was conducted to help determine why Millennial-born alumni form Midwest University preferred to stay engaged with the university. The survey taken by Midwest University Millennial alumni consisted of a series of open and closed questions along 
with the inclusion of questions that the respondent answered by using a Likert Scale (see Appendix B, ques. 9). In the data analysis part of research, the researcher created themes or categories from the survey and focus group data, along with using an Axial coding method, that allowed for themes and coding structures to be constructed and used for implementation (Merriam \& Tisdell, 2015). This approach would also meet the needs and standards to be reviewed in an organized qualitative study. Additionally, this led to an open coding practice that allowed the researcher to categorize words and themes (Merriam \& Tisdell, 2015; Picardi \& Masick, 2013).

\section{Definition of Key Terms}

For clarification and educational purposes, terms used in this study have been defined. The following terms are:

Fiscal Year $(F Y)$. Fiscal year operated from July 1 to June 30 and was a year as reckoned for taxing or accounting purposes (Midwest University, 2020).

Current Donor. Anyone who made a gift within the fiscal year (Midwest Foundation, 2020).

Past Donor. Anyone who has made a gift in previous fiscal years but not current fiscal year (Midwest Foundation, 2020).

Segments. Organization of constituent records for solicitation using a variety of fundraising approaches (Midwest University, 2020).

Designation. In a selected area, the donations were directed for a specific project (Midwest University, 2020).

Annual Fund. A division within the institutional advancement department that organized all annual solicitation appeals to restricted and unrestricted designations. 
Institutional Advancement. A division within a university that directed and coordinated all fundraising efforts (Midwest University, 2020).

Alumni. A graduate or former student of a specific school, college, or university (Dictionary.com, 2020).

Friends. Anyone who donated to the university and were not alumni (Midwest University, 2020).

Average Gift. To calculate the average gift amount, two numbers were needed: total donation revenue and total gifts received. Divide donation revenue (x) by the number of gifts (y), and average gift was generated (Fundraising Report Card, 2016).

Affinity. Liking to a specific group or university representation (Merriam-Webster, n.d.).

Alumni Engagement. The level of attraction, connection, affection, and influence an alumnus had with their alma mater over time (Toyn, 2020).

Millennials. Individuals born from 1980 to 2004 (Howe \& Strauss, 2012).

\section{Limitations of Study}

Limitations for the study included the fact that the data only analyzed the past three years of giving of Millennials at Midwest University within the uncontrolled group of participants at the time of this study. Additionally, the data was not always revealing the correct primary donor, as many alumni, friends, and spouses would make gifts on alumni's behalf, which resulted in the donor credit being assigned to the spouse and not to the actual alumnus which led to inaccurate donor coding. Another limitation was that the data was only pulled from one university, which limited the ability to find national trends. 


\section{Delimitations of Study}

There was a delimitation associated with the study: This study only examined one school, Midwest University. The economy and financial health of the country impacted the data during the past three years. Additionally, this study took place during the COVID-19 Pandemics which could have altered participants responses while taking the survey and participating in the focus group session. An additional factor that could have had an impact on giving results was that the national trend consisted of the majority of higher-end donors who were over the age of 65 and represented $17 \%$ of all donors below age 50 (Sargeant \& McKenzie, 1999). These individuals were the highest age group within the last recession and could have affected financial contributions during 2017, 2018, and 2019 fiscal years (Sargeant \& McKenzie, 1999).

\section{Assumptions}

Findings from this research would be beneficial to practitioners at the participating institution along with provide insight and knowledge to higher education fundraising alumni engagement progression. Staff would benefit from knowing the breakdown between genders and about how their donor base was represented. Knowing donor demographics would allow for the strategic approaches to be the benchmark against peer institutions, along with providing a matrix that established accountability for performance and best practice.

Fundraising professionals, especially annual giving staff, needed to review marketing and segmenting strategies moving forward. Targeted segmenting strategies with age, graduation year, last gift amount, and gender would provide more reliable and higher yields when reviewing performance and return on investment.

Finally, practitioners at the participating institution should have considered expanding this research by identifying other donor parameters, such as academic major, involvement, donor 
wealth capacity, and occupation. When reviewing additional information, practitioners would make a better estimate on proper dollar amounts to be solicited from potential donors, along with a metric for finding and reviewing potential donors.

\section{Design Controls}

The researcher implemented design controls to keep the focus of research and result in a narrow focus (Creswell, 2014). This was done by only looking at a sample set of Millennial data that encompassed the following demographics: a) gender, b) giving amount, c) fiscal year, d) activities, e) email address, f) type of degree, g) race, and h) age.

\section{Significance of the Study}

\section{Practice}

The proposed research allowed advancement practitioners and fundraising professionals within higher education, to better understand how to effectively engage with Millennial alumni. This-information could then be used when analyzing fundraising efforts. Additionally, it provided greater understanding and knowledge of university advancement divisions and practitioners, to utilize towards building better engagement plans with this subgroup. It also gave advancement and fundraising professionals an opportunity to identify best practices on engaging with the Millennial population and provided a stronger foundation for alumni engagement and fundraising efforts for years to come.

\section{Scholarship}

Based on research for this study, contributions to institutional fundraising had limitless and undefined opportunities. This research provided a better understanding of Millennial alumni who engaged with newly defined best practices when working with this segment of alumni at Midwest University. Findings from this study expanded existing knowledge about how 
Millennials and how they preferred to stay engaged, while also providing clarity about who to target, specifically in the Millennial population. This information should have an impact on the advancement and alumni relations engagement efforts moving forward with the Millennials population.

\section{Summary}

The findings from this study guided fundraising professionals at Midwest University when considering segmenting approaches and creating program plans for their Alumni Association engagement opportunities. This practice allowed individuals to stretch budgetary dollars to maximize further return on investment, securing increased dollars for the Alumni Association, along with closing the existing gap that existed on Millennials giving back to their alma mater. 


\section{SECTION TWO}

\section{INTRODUCTION OF PRACTITIONER SETTING FOR THE STUDY}

Alumni engagement looks different from one school to the next (Coolman, 2011; Osborn, et al., 2015). While universities and colleges offered a wide range of engagement opportunities, financial engagement continued to be the leading source of engagement activity from alumni and friends so that universities continue to invest resources and time to increase participation and dollars (Drezner 2011; Grace, 1997).

The University Advancement Division at Midwest University offered a wide range of engagement opportunities for alumni and friends to stay connected with the school and was prepared for a mixed methods research. The next section of the paper includes an analysis of the history of the organization, the organizational structure, mission, and leadership analysis.

\section{History of Organization}

\section{Midwest University}

The Office of University Advancement at Midwest University was the fundraising arm and constituent engagement facilitator for alumni, parents, friends, corporations, foundations, and other entities that had an affinity for the direct benefit and financial support for the University. This office consisted of three units, including advancement services, alumni relations, and development that supported the office in its fundraising and engagement activities. The first section of the organizational analysis paper focused on Midwest University, the Office of University Advancement, Midwest Leadership Team, and the Board of Regents organization structure and provided supporting background information for each of the units mentioned. 


\section{Organization Missions}

Midwest University, Midwest Foundation. Inc., The Midwest Alumni Association, and the Office of University Advancement had mission statements that helped drive each area to benefit Midwest University collectively.

Midwest University Mission: Focused on "student success - every student, every day" (Midwest University, 2020, Mission sect., para. p. 1).

The Midwest Foundation, Inc. Mission: The Midwest Foundation, Inc. "develops and stewards philanthropic resources for the benefit of Midwest University and its students" (Midwest Foundation, Inc. By-Laws, 2017 p. 1).

The Midwest Alumni Association Mission: "The Midwest Alumni Association fosters lifelong relationships through the giving of time, talent and funds to initiatives and opportunities that advances the University, its alumni, future alumni, and friends" (Midwest Alumni Association By-Laws, 2020 p.1).

Office of University Advancement Mission: "Is to encourage, receive, invest, manage, steward, and disburse private support on behalf of the donors of Midwest, for the benefit of the university, its students, faculty, staff, and alumni. Additionally, this office supports the mission of fostering lifelong relationships through initiatives and opportunities that advance the university, current and future alumni, parents, and friends" (Midwest Foundation, Inc., 2017; p. 1 Midwest Alumni Association, 2017 p. 1).

\section{Organizational Analysis}

The organizational structural design was not traditionally developed overnight, as it took time for leaders and the organization to work as a team to decide what was needed for the organization to effectively operate (Bolman \& Deal, 2013). Organizational structure was defined 
as the "formal configuration between individuals and groups regarding the allocation of tasks, responsibilities, and authority within the organization" (Lunenburg, 2012, p.1). The organization under review in this section included Midwest University, The Division of University Advancement, and the Midwest Foundation, Inc.

\section{Midwest University}

Midwest University was a public four-year state institution that was governed by a Board of Regents (BOR) (Midwest University, 2020, Midwest Board of Regents sec., 1st para.). The university president reported to the BOR regarding the budget and the overall operation of the university. The president of the university oversaw the entire university organization and had a group of leaders who made up his Midwest Leadership Team (MLT). This team consisted of the following positions: a) provost, b) vice president of finance and administration, c) chief of university police and vice president of culture, d) vice president of student affairs, e) director of athletics, and f) vice president of external relations and executive director of the Midwest Foundation, Inc. (Midwest University, 2020, MLT sec.).

\section{Midwest Foundation, Inc.}

Midwest University was associated with a separate nonprofit organization that worked through the vice president of external relations and the executive director of the Midwest Foundation. The Foundation did not report to the BOR, university president, or the vice president of external relations and executive director of the Midwest Foundation. Instead, the Foundation consisted of a group of alumni and friends of the university and served as Board of Directors and governed itself. The Foundation was again a separate entity from the University but operated in the benefit of the university by raising private dollars for various university initiatives and projects. 


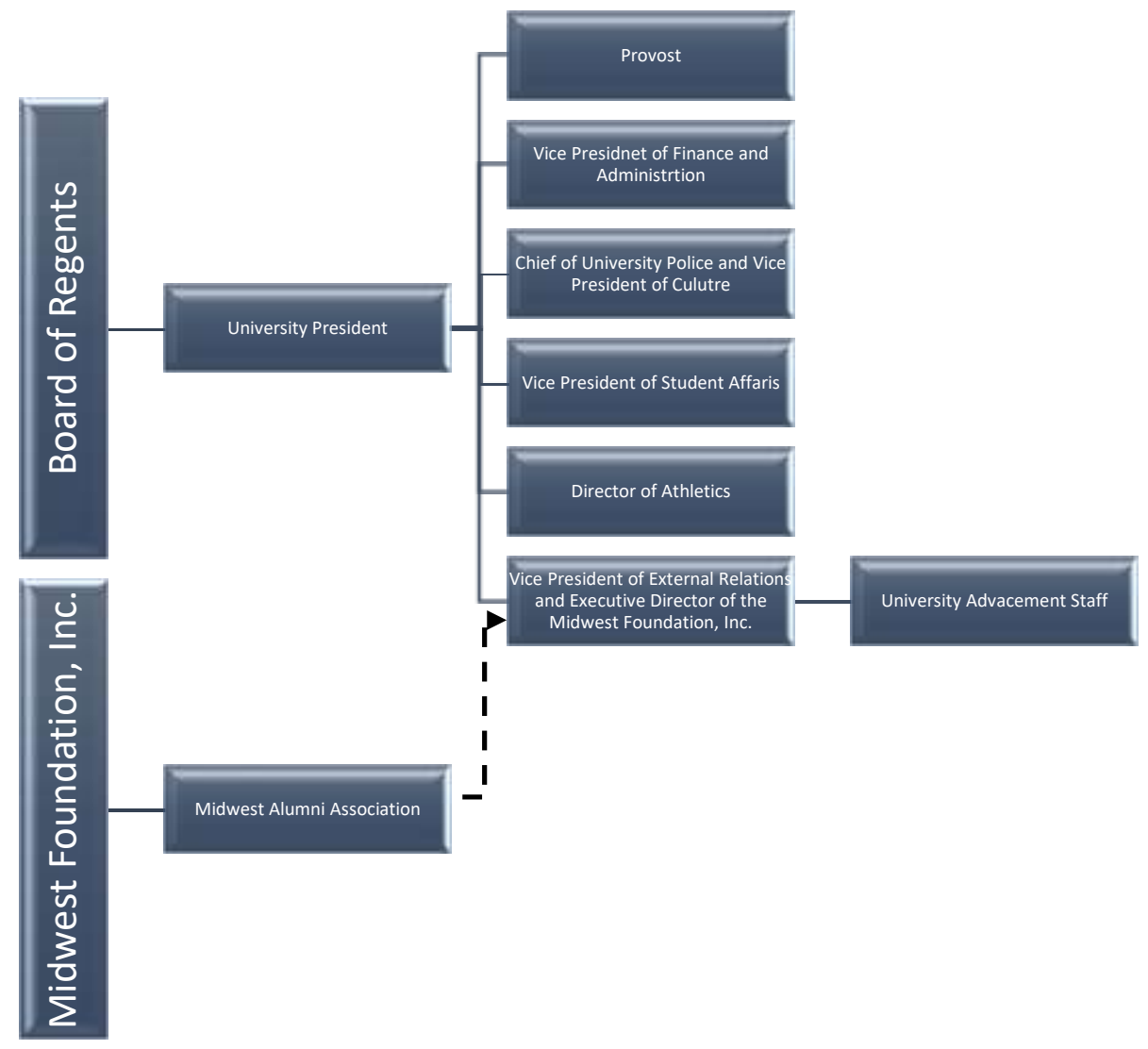

Figure 4: Organization Structure of Midwest University Leadership Team in connection with reference and hierarchy of the Board of Regents and Midwest Foundation, Inc. Advancement Staff (Midwest University, 2020)

The Midwest University Division of University Advancement had several divisions within the structure of the office. The divisions included alumni relations, development, and advancement services. Each division assisted and worked independently from the other two divisions at any given time. However, for the most part, all three divisions worked collectively to advance Midwest University.

The advancement division was led by the vice president of external relations and executive director of the Midwest Foundation, who was responsible for leading the advancement 
team. The executive director of advancement and chief finance officer for the Midwest

Foundation assisted the vice president with managing the Office of University Advancement.

This person had two directors reporting to her who oversaw the areas of alumni relations, which

included annual giving and development, along with two additional staff members who also reported to the executive director and made up the advancement services, a department this person solely managed before being promoted to executive director. The directors were responsible for additional staff who reported directly to them.

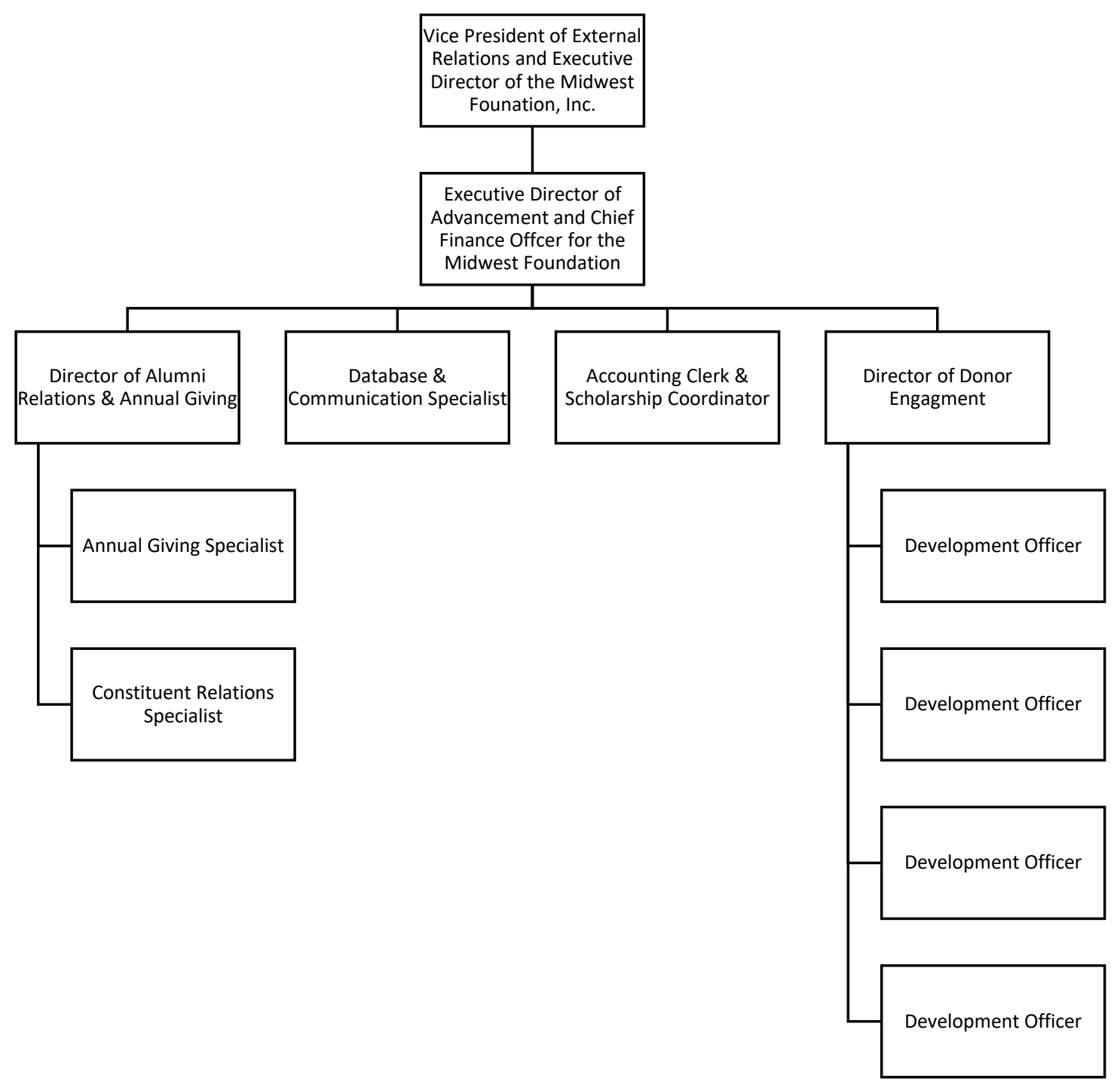


Figure 5: Organizational Structure of Midwest University Office of University Advancement Staff (Midwest University, Office of University Advancement, 2020)

Alumni Relations Engagement. The alumni relations division at Midwest University provided a variety of engagement efforts that kept alumni and friends connected to the institution. These efforts were organized by the director of alumni relations and annual giving and included, but are not limited to, direct mail, events, services, social media/electronic, organization of regional chapters, affinity groups, and volunteer opportunities.

Distribution of Direct Mail. One example of direct mail that was distributed from this office was the Alumni Magazine: Distribution of the magazine was mailed three times per year. The alumni magazine reached more than 30,000 households per distribution and provided updates and news about the University and its alumni and friends (Midwest University, 2020).

Event Invitations. The alumni relations program sent invitations to alumni and friends for a variety of activities such as Homecoming, reunions, and donor events. Invitations can come from the alumni relations office, development office, or advancement services. Invitations are pulled based on the type of event and included alumni from different segments who were connected to that event or activity.

Donor Stewardship. University Advancement produced and sent a variety of pieces that allowed donors to be acknowledged and thanked, and to see how their contributions benefited the University.

Events. At Midwest University, events focused on building participation and engagement among its alumni and friends. Alumni relations events included a variety of programming that allowed alumni and friends to come together throughout any given year. Marquee events for the alumni relations program included the following: 
Alumni Awards Banquet: Annual event that recognized alumni and friends of the University in the following categories: Distinguished Alumni Award, Distinguished Faculty Award, Distinguished Faculty Emeritus Award, Honorary Alumni Award, Public Service Award, Turret Service Award, and Young Alumni Award.

Homecoming: Homecoming was held annually in the fall and provided an opportunity for alumni and friends to come back to the institution to connect with friends and attend a variety of events such as the Homecoming parade, Alumni Open House, tailgating, and the Homecoming football game.

Reunions: A variety of class years and affinity groups such as athletic teams, black alumni, and Golden Years Reunion for those who celebrated 50 years or more since graduating from Midwest University.

Donor Events: Donor events allowed alumni to come back, be thanked for their generosity, meet students, and celebrate projects and initiatives they helped accomplish at the university.

Athletics Events: Midwest University competed at the Division II level for all sports. Marquee sports that allowed alumni and friends to engage with the university included: men's and women's basketball, women's volleyball, and football. In total, Midwest University offered 14 collegiate teams (Midwest University Athletics, 2020).

Socials: A variety of socials offered alumni and friends an opportunity to gather on and off campus. Socials were hosted at pubs, restaurants, homes of alumni and friends, and any place that allowed for gathering to commence.

Tailgating Events: Before University athletic games, alumni and friends gathered in the parking lots to socialize. Traditionally, football was the only sport in which alumni tailgated as 
the weather is much milder compared to sports that competed during the winter and spring months.

Golf Tournaments: Golf tournaments provided an opportunity for alumni and friends to come together, play golf, and network with each other. Traditionally, these events were organized and purposed for fundraising efforts that benefit Midwest University.

Travel Programs: This alumni program provided vacation trips to various locations for alumni and friends to travel together. The alumni travel program gave an opportunity for alumni to engage with each other and the University while on vacation to the various destinations on an annual basis.

Graduation: Graduation was held two times per year, at the end of the spring and fall academic semesters. The Alumni Relations Office provided an alumni welcome address to the graduating student and organized an event called Grad Fest to educate all the graduates about how to stay engaged with Midwest University and take advantage of various services and programs.

Services. The Midwest Alumni Association offered a variety of services to its alumni and friends. The following services were provided:

Transcripts: Alumni could request official and unofficial transcripts.

Midwest News: Links to various news connected to Midwest University.

Bearcat License Plate: Alumni and friends could showcase their affinity decal issued on their license plate in the state.

Bearcat Bookstore: Alumni and friends could shop for University apparel at the campus bookstore. 
Career Services: Alumni and friends learned about programs, events (Mock Interview Day, information sessions, etc.) and various services offered throughout the year.

University Facts: Provided a list of common questions alumni friends had about Midwest University.

Midwest Archives: Access to online museums and information regarding University archival artifacts.

Electronic Yearbooks: Midwest University published annual yearbooks that dated back to 1917. Yearbooks could be viewed in a chronological order by year.

Social Media/Electronic Communication. The alumni relations program utilized a variety of social media outlets and email communication that kept alumni engaged with Midwest University. The following social media platforms were utilized for engagement efforts: Facebook, Twitter, and LinkedIn. Additionally, the University sent emails to communicate with alumni weekly.

Regional Alumni and Friends Chapters and Affinity Groups. At the time of the study, alumni relations had 22 organized chapters and affinity groups. Chapters and affinity groups met throughout the year in their geographical locations and at Midwest University to stay engaged with the University and other alumni who lived in their areas or were involved in similar activities while in school. The following alumni chapter and affinity groups were (in order of formation): a) Kansas City Chapter, b) Arizona Chapter, c) Band Alumni Chapter, d) Maryville Chapter, e) St. Joseph Chapter, f) Central Iowa Chapter, g) Western Iowa/Eastern Nebraska Chapter, h) Colorado Chapter, i) Southern California Chapter, k) Japan Chapter, 1) Southern Iowa Chapter, m) Dallas Chapter, n) Mid-Missouri Chapter, o) Chicago Chapter, p) St. Louis 
Chapter, q) Springfield Chapter, r) Eastern Iowa Chapter, s) Twin Cities Chapter, t) Gridiron Chapter, u) Washington DC Chapter, v) Black Alumni Chapter, and w) Theatre Alumni Chapter. Annual Giving Engagement. The Midwest Annual Giving Program was the foundation for annual giving for the Office of University Advancement. This program raised annual dollars for the Midwest Fund and other established funds in which alumni and friends of the institution were interested in donating. Annual giving used a variety of fundraising approaches to engage and fundraise from alumni and friends such as direct mail, social media, call center, and an annual giving day.

Development Engagement. The Office of University Advancement focused on securing major gifts that consist of $\$ 10,000$ or more annually. Development engagement consisted of four development staff who engaged with potential and current donors to cultivate a relationship with Midwest University and its priorities to raise major gifts for projects and initiatives.

Volunteer Engagement. The alumni program at Midwest University provided a variety of volunteer engagement opportunities for alumni friends. Notable volunteer opportunities included:

Alumni Board of Directors: The Alumni Board of Directors consisted of up to 18 volunteer board of director positions and one current volunteer student director. The Alumni Board of Directors oversaw the engagement efforts of the Midwest Alumni Association. The alumni board operated under the Midwest Foundation and had a representative from the Board sit on the Foundation Board of Directors to report the business of the alumni association.

Midwest University Foundation Board of Directors: The Midwest Foundation was made up of a 40-person volunteer board who were alumni and friends of the University. The board members were recruited to the Board for their expertise and giving potential. The Midwest 
Foundation oversaw all the fundraising efforts that benefited the University. All Midwest University Advancement staff who worked with the Foundation Board were University employees and reported to the vice president of external relations and executive director of the Midwest Foundation. It was essential to understand that the Foundation Board oversaw the Midwest University Alumni Association along with provided funding to the organization to operate.

Alumni Chapter and Affinity Leadership Positions: Each of the 22 alumni chapters was led by a group of volunteers associated with that group. Volunteer leadership positions included a president, vice president, treasurer, and secretary.

New Student Recruitment: Alumni and friends of Midwest University assisted in the recruitment efforts of future students by attending college fairs, hosting new student send-offs, writing a welcome postcard to newly accepted students, or working at one of the state fair booths to engage with prospective students and their families.

Speaker at University Event or Classes: Midwest University provided a variety of opportunities for alumni and friends to come back for volunteer-speaking opportunities. Some of those speaking opportunities consisted of an alumni welcome to the new graduates at graduation ceremonies, in various classes, career-ready events, and interviewing students.

Academic Advisory Boards: Midwest University had Academic Advisory Boards associated with many of its academic Schools and Departments. Advisory boards allowed the Schools and Departments to connect with alumni and friends of Midwest University based on education disciplines that drove future curriculum along with keeping graduates engaged with the academic programs. 
Midwest University volunteer engagement opportunities provided a variety of options for alumni and friends to consider. The Millennial population had the opportunity to participate in all-volunteer efforts. However career networking volunteer engagement, such as serving on Academic Advisory Boards or speaking opportunities, allowed Millennials to engage with the University within their profession.

\section{Leadership Analysis}

Midwest University and the Midwest Foundation, Inc. had similar and different leadership structures and styles that embodied the organizations and the professionals within them. Northouse (2016) defined leadership as, "As a process whereby an individual influences a group of individuals to achieve a common goal" (p. 6). In this section, the researcher examined the various leadership styles that both organizations used to help achieve their missions and purposes and addressed how both organizations used their leadership to make decisions and accomplish organizational effectiveness and goal achievement. McCaffery (2010) defined performance management as "a strategic and integrated approach to developing the capabilities of individuals and teams in order to increase organizational effectiveness" (p. 162).

\section{Midwest University}

Midwest University leadership embodied a variety of leadership styles and approaches that individuals in the organization used to operate the University. According to Northouse (2016), the administration leadership had a variety of components that made up the leadership phenomenon. These themes included that "leadership is a process, involves influence, occurs in groups, and has shared goals among team members" (Northouse, 2016 p. 6). Midwest University was led by the president of the University, who was governed by the Board of Regents. The BOR oversaw the president's role along with the overall well-being of the University. 
The BOR along with the University president made decisions for the University based on the evaluation and performance of the overall organization. To effectively evaluate the University, the BOR and president utilized analytics to review budgets, enrollment, graduation rates, and a variety of other key metrics to keep informed on the health and stability of the organization (BOR BYLAWS, 2020, Powers of the Board of Regents sec.). It is from here the president made decisions with the MLT to keep the cost of tuition down, increase enrollment, improve infrastructure, and predict and avoid risks for the institution (Gagliardi, Parnell \& Carpenter-Hubin, 2018).

Northouse (2018) described the leadership power of the BOR, University president, and the MLT as "position" and "personal" leadership influence (p. 16). Both types of leadership powers allowed individuals at Midwest University to make decisions and provide direction based on the position they held and the expertise or skill sets that made them qualified to be in that role (Northouse, 2018). It was from these roles and positions that the University leadership created what Levi (2017) explained as the purpose of teams. He went further to explain that teams allowed the organization to deal with specific areas of experiences, problems, or issues. Elam, C., Stratton, \& Gibson (2007) explained that it was essential for organizations and leaders to allow for the teams they created to have an environments where everyone was working toward shared goals and processes that encouraged leaders to learn from each other and about the organization they served.

\section{Midwest Foundation, Inc.}

The Midwest University Foundation's main objective was to provide private funding for the University's projects and initiatives and keep alumni and friends engaged that advance the University (Foundation Bylaws, 2020, mission and purpose sec). Just like the University 
leadership, the Foundation Board of Directors used analytics to drive their decision-making and problem-solving to operate as an efficient and productive nonprofit organization (Gagliardi et al., 2018). Gill (2010) explained that for nonprofit boards to be effective, they needed to implement what he called the "Strategic Board Model" (p. 30). This model was implemented into four processes: a) developing a leader plan, b) defined delegation of work, c) prioritization of tasks, and d) evaluating and monitoring progress and expectations.

Since the Midwest University Foundation Board was organized and structured as a volunteer board, current board members needed to be thoughtful and strategic about who they invited to come and serve on the Board. Board members were expected to lead by example by making monetary donations and being an engaged board member (Midwest Foundation Bylaws, 2020, Expectations sec.). Northouse (2016) described this type of leader as a person who wanted to serve and served first by making sure that other people's needs were met to allow for growth and development known as "Servant Leadership" (p. 226). Additionally, board members collectively needed to be aware of the areas in which board membership was weak in regards to skill sets and expertise development. Goffee and Jones (2011) explained that leaders needed to rely on instincts and know weaknesses and differences of board members to continue to be influential leaders for their organizations they served. Levi (2017) articulated that disturbing coleading around team members allowed members to facilitate their area of strength which would strengthen the entire team.

\section{Implications for Research in the Practitioner Setting}

The proposed research allowed advancement practitioners and fundraising professionals within higher education an opportunity to understand how to engage with Millennial alumni more effectively and efficiently in the future when analyzing fundraising efforts. This research 
provided a greater understanding and knowledge that university advancement divisions and practitioners can utilize toward building better engagement plans with this subgroup population. The ability for advancement and fundraising professionals to identify best practices on engaging with the Millennial population could provide a stronger foundation for alumni engagement and fundraising efforts for years to come (Lewis, 2019).

Based on the research for this study, contributions to intuitional fundraising had limitless and undefined opportunities as research provided a better understanding of Millennial alumni. This segment engaged with newly-defined best practices when working with Millennial alumni at the Midwest University. Findings from this study expanded existing knowledge about how Millennials preferred to stay engaged while providing clarity about who to target within this population. This study had an impact on the advancement and alumni relations practice, engagement efforts, and professions while leveraging the Millennials population to engage with their university.

This study had the opportunity to provide other university advancement and alumni relation divisions to use the information learned from this study about how to best engage with the Millennial population. The fundraising and alumni engagement professions were influenced to work smarter instead of harder when learning what made this population engage with their alma mater.

\section{Summary}

Understanding the background and the organizational structure of both the Midwest University and the Midwest Foundation, Inc. was vital as it provided the context of who the organizations were and how they operated interdependently and independently from each other. Additionally, the information in this section explained Midwest University and the Midwest 
Foundation, Inc., organization's mission and purpose, which provided the connection about why alumni engagement was essential to both organizations.

Leadership styles of these organizations varied based on what group or individuals one evaluated. However, Servant Leadership and Transformational Leadership were the two leadership styles that provided an overcharging connection between the two organizations as both involved shared vision and goals for the origination, and the leaders to follow (Bass \& Riggio (2006). 


\section{SECTION THREE}

\section{SCHOLARLY REVIEW FOR THE STUDY}

Section Three focused on three conceptual underpinnings that were utilized to guide this research: Social exchange theory, alumni engagement, and Millennial characteristics. The social exchange theory and its ability to provide a more in depth understanding of one's motivations was reviewed. Additionally, literature regarding factors that were affected by alumni engagement, both approaches and best practices in higher education were illuminated. Finally, the Millennial Generation and those born within these constraints and the characteristics that constituted this population were expounded upon. Previous research about how these concepts impacted higher education advancement professionals were reviewed. Galvan and Galvan (2017) explained that conceptual underpinnings offered the writer in the literature review section an opportunity to link facts with consideration, ultimately leading to a well-developed understanding assisting with explaining the phenomenon under review.
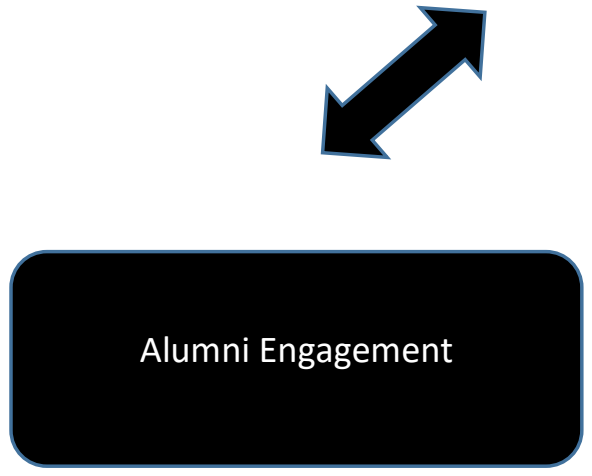

Figure 3. Conceptual Underpinnings

\section{Millennial Characteristics}

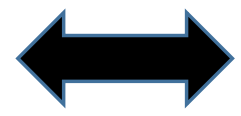


In this section, several conceptual underpinnings were analyzed. The concepts of social exchange, alumni engagement, and Millennial characteristics highlighted the elements needed when understanding what alumni engagement looked like for the people, culture, and the case for support by the institution that assists in building a culture of philanthropy (see Figure 3). Most importantly, these underpinnings provided an existing structure of evidence that aided in answering the overarching research question of: What does Millennial alumni engagement look like at a rural Midwest University?

\section{Review of Existing Literature}

\section{Social Exchange}

Social interaction and connections provided evidence that there was a connection with alumni engagement (Scott \& Seglow, 2007). The social exchange theory (SET) was a concept that was utilized in various research to aid in the understanding of one's motivations to act and continue a relationship known as pure altruism (Keller, 1982; Monks, 2003; Weerts \& Ronca, 2007). In this study, it was imperative to refine and define what social exchange meant as a concept and how it pertained to this study. SET, for the purpose of this study, was defined as: "limited to actions that are contingent, and mutually rewarding process involving 'transaction' or simply 'exchange.”' (Emerson, 1976, p. 336.). To further strengthen social exchange relevance concerning this study, a combination of research such as "A Study of Alumni Engagement and Its Relationship to Giving Behaviors" used the SET concept to explain why alumni felt motivated to give back to their university (Radcliffe, 2011). Another study revealed that those who received scholarships were more inclined to stay engaged with their university while looking through the lens of social exchange (Diehl, 2007). 


\section{Creation of Social Exchange Theory}

The creation of the social exchange theory, or SET, had multiple contributors (Homans, 1961; Blau, 1964). First, Homans (1961) defined social exchange as an "exchange between two people that encompasses a give and take in the relationship" (Homans, 1961 p. 13). Peter M.

Blau and Richard M. Emerson (1976) continued research on the theory by providing insight that social exchange along with the relationship and interaction of others was influenced by a variety of propositions that rewarded actions with receiving awards. This further developed research explained a series of propositions that included:

1) When rewarded, the person repeated the action.

2) A person who chose to engage expected to receive an award.

3) The more a person received an award; the less they desired to receive the award again. (Emerson, 1976).

Blau's additional work to the theory was similar to Emerson's, but focused more on small group social structures and the exchange of power connected with economic transactions and advantages (Roeckelein, 2018).

Social Exchange and Connection to Perceptions on Value. Numerous studies have used the SET to provide evidence of how alumni engagement was connected to past and current experiences with how one saw and valued their institution (Thomas \& Smart, 2005; Radcliffe, 2011; Skari, 2014). In one study, the research found that student satisfaction coupled with their overall experiences while attending school increased the likelihood of that individual staying engaged with the university by making a financial gift (Skari, 2014). Another study with similar findings recognized four identifiers of: a) years since graduation, b) social, c) campus leadership, and d) academics experiences as highlights to those who perceived value with engagement at the 
university as compared with those who were not active at the institution (Thomas \& Smart 2005). However, another study found that there was no connection between those who had received a specific type of degree, scholarships, or participation in campus involvement compared with non-traditional alumni who responded to the survey (Hurst, 2008).

The social exchange theory provided this research the ability to understand the connection and relationship between the individual and the institutions they attended (Cook \& Lasher, 1996; Liu, 2006; Weerts \& Ronca, 2008). The concept of SET recognized the connection between individuals who engaged with their alma mater and received benefits of an ongoing partnership (Emerson, 1976; Kennett, 1980).

\section{Alumni Engagement}

There were a variety of factors that affected alumni engagement (Hummel, 2010; Barber, 2013; Volin, 2016), but in this section, the researcher looked at the following: a) alumni loyalty, b) global financial stability, and c) donor engagement practices.

Donor engagement practices were carried out in a variety of approaches to make an individual feel closer to his or her alma mater. One study found that alumni who received alumni publications and materials had a higher probability of making a gift than those who did not review or accept similar information (Taylor \& Martin, 1995). Another study reported that the most significant predictor of fundraising potential was institutional programming that focused on alumni activities along with additional communication pieces, including a variety of alumni affinity programs (Harrison, Mitchell, \& Petterson, 1995).

Further refining this idea of donor engagement, Duncan (2004) explained a model of altruism called the Impact Philanthropy Theory. Duncan (2004) detailed that this theory focused on the reason that a person chose to donate was their desire to make a difference. He went a step 
further by saying that this theory explained that donors and organizations can work interconnected with each other and that a donor's main desire was to have all their funds go directly toward the area in need to make the most significant impact (Duncan, 2004). The organization's role was to fulfill the donor's request with limiting or eliminating the percentages of the gift that was taken out for administration cost for the organization (Duncan, 2004). Additionally, Duncan's (2004) theory of Impact Philanthropy went on connecting why individuals chose to have alumni loyalty.

In higher education today, financial uncertainty required colleges and universities to explore best practices to solicit and engage alumni in the most cost-effective and efficient ways (Coolman, 2011). Approaches to interactions with students and young alumni were beneficial to future successful engagement efforts (Atchely, 1989). This next section examined cultural elements and best practices implemented in a variety of engagement approaches while providing evidence of industry standards that yielded high participation performance for alumni engagement programs.

The importance of various engagement connection strategies found in one study identified communication, relationship building, events, and opportunities to volunteer increased motivations of alumni to be engaged (Barber, 2013). However, another study explored these connection strategies further and found adverse effects on the engagement with social media, such as Facebook, with younger alumni in the Millennial Generation (Horsemen, 2011). The study found that Millennials were not likely to be engaged through volunteering or giving back to the institution with an increased connection through social media. However, the study further revealed that young alumni were willing to provide a recommendation to prospective students and had the desire to make a financial commitment in the future. 


\begin{abstract}
Alumni Loyalty
Alumni loyalty was defined as an individual who had the desire to make a financial gift, stayed updated with university news, attended university events, and had interest in being a member of the alumni association (Snijders, Wijnia, Rikers \& Loyens, 2019). Various studies showed the different reasons why these individuals had heightened loyalty as compared to those who do not.
\end{abstract}

One study found that those who received academic scholarships were more likely to increase their gift size than those who did not (Dugan et al. 2000). Financial aid was also recognized in a study as a predictor for future donors compared to those who did not receive financial assistance to assist in paying for school (Monks, 2003). However, another study analyzed the success of an athletic team that had a strong alumni fan base and determined that winning records, contrary to popular beliefs, did not increase alumni giving in dollars or number of gifts (Baade and Sundberg, 1996). This finding alone was a crucial fact to remember when analyzing the target population at Midwest University.

Explaining one's affinity towards people or places was what Swift (1999) described as cultural affinity theory. One's ability to feel close to their institution was ingrained subconsciously after spending time on the campus and with the people who made up that campus. Swift (1999) further explained that cultural affinity was something that no organization traditionally considered when identifying communication strategies to their constituency base. Cultural affinity was defined as the bias one felt toward something because they had a personal connection (Swift, 1999). According to Swift (1999), many individuals spent years on their college campuses building up this cultural affinity towards the school and the community. It was when they graduated that the universities needed to use creative marketing approaches and 
tactics to connect back with these individuals who held the institution and community in high regard (Remley, 1996; Garvey \& Drezner, 2013; Drezner, 2018).

Size of School and Culture. When looking at the size of the institution, one study found that the size of a school, along with academic degrees offered, affected the overall dollars raised (Baade \& Sundberg, 1993). However, the report also stated that annual gifts were $25 \%$ less than that of much smaller liberal arts institutions (Baade \& Sundberg, 1993). University fundraising departments needed to be informed on the makeup of their alumni base before segmenting and selecting people to whom they sent appeals and solicitations (Kanady, 2015). Knowing vital benchmarks helped fundraising teams conduct and organize direct appeals and various engagement efforts that targeted their alumni base with appropriate messaging, marketing and program planning while keeping in mind the demographic factors that made up the alumni base (Kanady, 2015).

The type of climate and culture a school offered also shaped and affected alumni giving back to the school (Cates, 2011). Rankin (2005) defined campus climate as "cumulative attitude, behaviors, and standard of employees and students concerning access for, the inclusion of, and level of respect for individual and group needs, abilities and potential" (p. 17) (Vervoort, \& Gasman, 2016). One study researched gay men and their preference for giving back to the university. The study found that those who gave within this population only gave because they felt their overall experience was enjoyable and that they felt supported as an individual (Vervoort \& Gasman, 2016). Specter (2012) also conducted a study that analyzed the importance of culture and its ability to have a positive effect on alumni engagement. In the research, the study found that a variety of factors that helped build pride and traditions in the campus community. The study found that for campus traditions to have a positive effect on the university community, the 
institution must have a strong mission, an understanding of first impressions with prospective students, a variety of alumni engagement efforts, and an understanding that everyone within the university community was responsible for embracing the tradition and utilizing technology to build attention and effectiveness (Specter, 2012).

\section{Global Financial Stability}

Global financial stability provided several significant findings that supported its effect on alumni engagement (Tindall, 2011; Hrywna, 2013; Hohouser, 2020). Global financial stability, for the purpose of this study, was defined as: "a state in which the financial system, i.e., the key financial market and the institutional financial system, was resistant to economic shocks and fit to fulfill its basic functions" (Magyar Nemzeti Bank, 2020, Defining Financial Stability, $1^{\text {st }}$ para.). A survey conducted in 2008 reported that $22 \%$ of individuals over the age of 60 did not make a gift due to the downturn of the economy (Hall, 2008). The $22 \%$ represented a large population of Baby Boomers who were greatly impacted with decreases to retirement and investment portfolios. A study in Giving USA also reported that it has taken nearly eight years for fundraising levels to pick up to the same levels since before 2008, representing a $22 \%$ increase prior to the recession (Hrywna, 2013). These studies further refined the importance of global financial stability as an essential factor in alumni engagement.

During times of global financial uncertainty, universities understood the importance of continuing to build strong relationships with current donors and potential donors (Waters, \& Tindall, 2011; Holhouser, 2020). Universities did this by providing a variety of needs for funding that were beneficial for their donor bases to support (Wedgeworth, 2000). The social exchange theory (Drezner, 2009) allowed institutional fundraising arms and their donors to come together to connect the interest and needs from one another then determine methods to support a project 
or an initiative the allowed the university to prosper. Drezner (2009) went on and explained that donors traditionally gave because they get something in return, which further supported this research using the social exchange theory as part of its theoretical framework.

The satisfaction in getting something in return for a donor who made a gift was done in a variety of common practices such as receiving gifts, annual stewardship reports, membership to giving societies, or possibly the potential of having a building or physical space named in their honor (Underwood, 2014). The most common type of benefits donors had when making a gift was one which the Internal Revenue Service provided when filing of their annual taxes (IRS, 2020). This practical motivation that taxable benefits offered was a great deal of motivation to donors when taking advantage of some of the tax breaks that exist when substantial monetary donations were made to a nonprofit organization such as a university (Tsiotsou, 2007). However, one study found that alumni who received various types of stewardships from their institution only slightly affected their desire to stay involved with the school (Harrison, 2018). This type of financial incentive further substantiated the notion of global financial stability as a key factor in alumni engagement.

Increasing Cost of Higher Education. State funding for higher education in the United States has dropped significantly in recent years_-leading to increased tuition to adjust for institutions' reliance on state funding (Oliff et al., 2013). The cost of university tuition increased drastically over the past 25 years, not only at four-year institutions, but at two-year institutions and community colleges as well (Kim \& Ko, 2015; Lee et al., 2017). The steady increase in university tuition was due to the decrease in funding for higher education by government agencies (Oliff et al., 2013; Weerts, 2014). However, the global financial and health crises within the last 15 years continued to add pressure to institutions to increase the overall cost to students. 
Great Recession of 2008. "During the Great Recession of 2008, state spending nationwide dropped 28\%; every state except North Dakota and Wyoming cut funding for higher education" (Oliff et al., 2013, p. 1). Thirty-six states decreased funding for higher education by at least 20\%; while, 11 states cut funding by more than one-third. Deep cuts in government funding left universities on their own to raise funds for the construction of new facilities and improved infrastructures on university campuses (Oliff et al., 2013).

Covid-19 Pandemic of 2020. The Covid-19 Pandemic of 2020 shocked higher education by requiring campuses to cancel in-person classes while moving classes online and forcing students to move back to their permanent residences (Foreman, 2020). Due to schools requiring students to move off campus, many schools had to refund students for room and board that universities already accounted for in their fiscal year budget (Whitford, 2020). Whitford (2020) continued by providing examples of how the University of Minnesota campuses lost more than \$27.8 million, and the University of Wisconsin Madison estimated revenue losses to be more than $\$ 100$ million when all refunds were issued to students. These significant financial losses to higher education impacted universities abilities to pay for faculty and staff in the current academic year and had a ripple effect on future budgets requiring schools to continue to increase costs while facing concerns for lower enrolments in the fall 2020 semester (The Change Leader, 2020).

\section{Millennial Characteristics}

Strauss and How (1991) coined the term "Millennial" in their book Generations: The History of America's Future (p. 14). After its publication, the term millennial resonated with the generation as it gained attention and general acceptance (Morgan, 2014). When analyzing the composition of the Millennial Generation, definitions varied from the years that encompassed 
this population. For example, Strauss (2005) first identified individuals who were born from 1982 to 2001 as the Millennial population; however, other studies isolated different birth-years (Monaco \& Martin, 2007; Chou, 2012). For this study, Millennials were categorized as being born from 1980 to 2004 (Stein, 2013; Feiertag \& Berge, 2008; Howe \& Strauss, 2000; Rainer \& Rainer, 2011).

With 60 million Millennials, this population was three times larger than Generation X, one of the youngest in the workforce, and classified as "digital natives" (Connor, Shaw \& Fairhurst, 2008 p. 2) as they were exposed to technology as small children. As products of a very high-tech environment, their attitudes and behaviors were shaped (Hobbs, 2017) to be comfortable with the fast-paced world and access to instant information along with content on social networking due to social media platforms like Facebook and Twitter (Rosentiel, 2010).

This generation also experienced events that impacted the world such as Columbine High School and Virginia Tech shootings, September 11, 2001 terrorist attacks, and the Oklahoma City bombing, to name a few. This generation was labeled as "emotionally needy" (Crumpacker \& Crumpacker, 2007) and "high maintenance" (Hira, 2007), as they were continually seeking high praise, validation, and entertainment at school and in the workplace (Jonas-Dwyer \& Pospisil, 2004). Further research was done that explored Millennial's preference in communication with additional information about demographics of age and gender that provided a better understanding of this generation.

\section{Preference in Communication}

A common characteristic among Millennials was their comfort levels with current and new technology that became available to aid in sending and receiving communication (Oblinger, 2003). In fact, some researchers feared that Millennials were using too much technology and lost 
the value of face-to-face social skills that previous generations developed (Elam, Statton \& Gibson, 2007). One study expanded upon the topic of Millennials' abilities to communicate and receive information explained the importance of keeping these groups interested in topics by finding a way to draw personal interest and connect back to the individual (Kotz, 2016). The study also revealed that Millennials were very social and exceled when they could interact with others collaboratively (Kotz, 2016).

When soliciting this generation, a study conducted in 2018 found Millennials preferred a more direct strategy compared to an indirect approach as personal approaches from each fundraising campaign conducted in the study consistently generated more fundraising dollars than those who received an indirect solicitation (Austin, Clark, \& Sigmar, 2018). Experts also agreed that the importance of focusing on the persuasive marketing strategy known as Attention, Interest, Desire, Action or (AIDA) were also essential to embrace in any marketing and communications pieces to any audience Cardon's Business Communication: Developing Leaders for a Networked World (2018).

Additional characteristics of Millennials were that they believed in the future and the idea that they would be able to do something great for the world (Monaco \& Martin, 2007). Being relational was another key trait that was common in this generation as they maintained their friendships and were very close to their parents (Elam et al., 2007). Learning was also an important characteristic to this generation as parents stressed the importance of an education to get them where they wanted to go (Pyoria, Ojala, Saari \& Jarvinen, 2017). Religion was not cited as big of a priority as it was in past generations. Only $31 \%$ of Millennials believed Jesus was the only way to get to heaven (Rainer \& Rainer, 2011). 


\section{Gender and Diversity}

The gender for the Millennial Generation increased with diversity compared to other generations as more individuals became aware of their sexual identity as this generation has increased the number of individuals identifying as lesbian, gay, and bisexual (Broido, 2004). Another study found when looking at gender that $25 \%$ more women in the Millennial Generation were getting their bachelor's degree or higher compared to their male counterparts. Additionally this study revealed that Millennials were getting married later in life as the average age for men was close to 30 and 27 for women compared to those who were getting married in the ' 70 s and '80s (Eppli, 2015). Their average age was 23 for men and 22 for women (Eppli, 2015).

When researching diversity, Millennials were the most diverse when comparing diversity from past generations (Frey, 2018). For example, Frey points out in his research that the Millennial population made up more than $55 \%$ white ethnicity compared to those ages 55 and older whose percentage of white ethnicity was $75 \%$. He goes on to explain that this was due to the immigration increases the U.S. experienced in the ' 80 s and '90s influencing the diversity of the demographics that made up this generation. Figure 4 provides a breakdown in race compared to those 55 years and older.

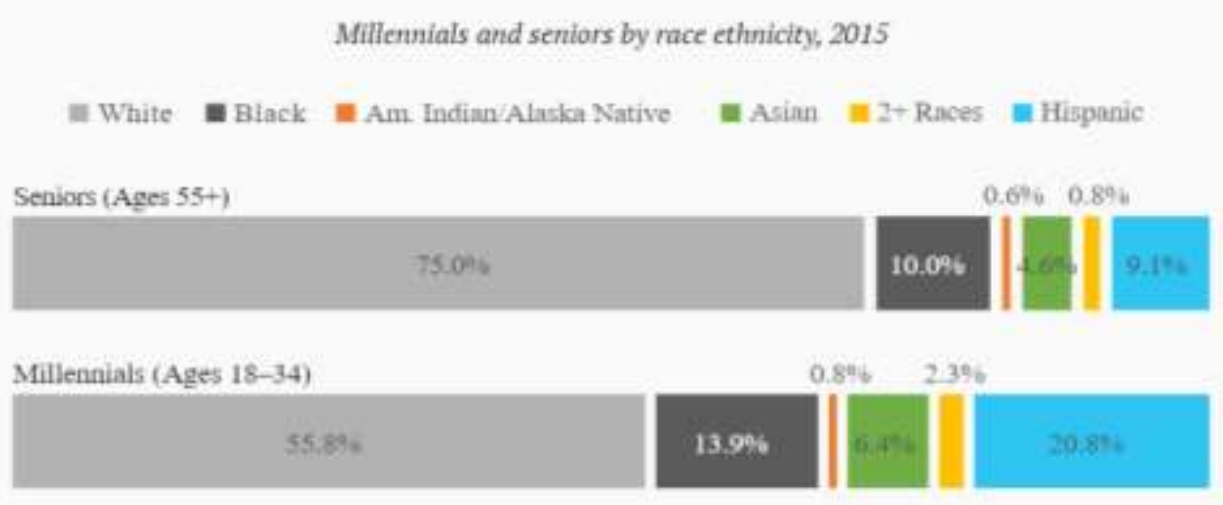


Figure 4.Millennials and Seniors by Race Ethnicity, 2015. Retrieved from:

https://www.brookings.edu/research/millennials/ Received approval to use graph by Brookings Institution on 7.29.2020.

Gender was cited as influencing whether a person will give or not. A study reported that women owned half of the wealth in the United States and account for $58 \%$ of undergraduates enrolled at colleges today (Strout, 2007). This finding required institutions to think critically about messaging along with the segmenting processes to solicit for a gift as women gave for different reasons than men. According to one study, women were more likely to give to an organization while men gave larger amounts (Wiepking \& Bekkers, 2012). The report stated that women, at almost every income level, were better donors. Finally, women gave to many charities throughout a year, while men gave to only a select few (Mesch, Rooney \& Denton. 2011), leaving fundraising professionals to consider how often to solicit women compared to men. Age

To understand the ages of the Millennial Generation, it was first essential to revisit the years that made up this population. Michael Dimock (2019) provided insights on this as he explained that anyone born from 1981 to 1997 was considered to be a part of this generation. To help put in context, the ages of this generation ranged from 23 to 38 years old in 2019. He went on to explain that there were differences in the generations based on when they were born. For example, those born from 1986 to 1992 entered the job market at the end of the recession that began in the fall of 2008, while Millennials born since 1992 may still be in college.

Additionally, this generation made up more than 77 million Millennials (Taylor \& Keeter, 2010) and was larger than Generation X and the Baby Boomer generation (DeVaney, 2015). However, Tulgan (2013) argued that this generation was too large to be inclusive of the 
years 1981 to 1997 when Millennials were born. He explained that this generation should be divided into two generations as the individuals born in 1990's and 2000's grew up experiencing different technological advancements Tulgan (2013).

When studying the years Millennials were born, 1990 represented the largest birth year out of all the years represented in this generation (Sweeney, 2006). After the year 1990, this generation's population started to drop over the remaining years, leaving a declining trend in the population (Sweeney, 2006). Another interesting fact about this generation in terms of when they were born was that generation before them, i.e. the Baby Boomers and Generation X, would start to retire over the next 25 years, leaving Millennials with a lucrative and open job market to take advantage of during their career (Statistics Canada, 2007).

When looking at age, a study conducted examined when donations were made based on the connection to the age of the donor. The study revealed that at the age of 52, gifts started decreasing at one particular university (Taylor \& Martin, 1995). Another study conducted in 1997 found that older alumni donated more to universities when comparing class year giving percentages. Classes from 1955-1961 gave at 26.1\% participation rate compared to the younger class years of 1972-1981 at an 18.8\% (Okundade, 1997). However, a different study found that a person's giving increased only as their earnings increased, and not due to their age (Watsyn, 2009). When analyzing the leading indicator of giving, the class year was attributed to alumni engagement with one study (Okunade, Wunnava \& Walsh, 1994). However, another study found that when financial loans are paid off, the desire to stay connected or engaged with the university decreased (Langley, 2010). 


\section{Summary}

Institutions used a wide range of techniques to keep alumni engaged. The main focus was concentrated on building relationships and staying connected while using marketing approaches such as printed publications like an alumni magazine, direct mail fundraising appeals, or annual events that included class reunions and regional alumni chapter gatherings that created positive feelings toward their alma mater (Hunter et al., 1999; Weerts \& Ronca, 2008). It was from these positive feelings and a personal connection to the constituent that individuals saw the value in engaging with the institution.

However, gender, age, and global financial stability were proven to have an effect on individual charitable giving and overall engagement to higher education institutions. Understanding the variables that could affect one's giving was essential to recognize for institution fundraising arms who relied more on alumni and friends to remain connected and make recurring contributions. Additionally, university fundraising professionals needed to look at the type of culture that surrounded the makeup of their university to understand why individuals chose to make gifts to their institutions. The case for support that was marketed and how that need drove one's decision to make a monetary donation back to the university should consistently be refined and tailored to meet the segmented population.

Finally, the need to understand why and how Millennials chose to engage with their alma mater assisted higher education advancement offices in finding those supporters who were most likely to donate. Merging research and information on the various demographic characteristics that made up the Millennial Generation aided in helping fundraising practitioners be better prepared and ultimately more successful with their fundraising efforts when engaging with Millennials. 


\section{SECTION FOUR}

\section{CONTRIBUTION TO PRACTICE}

Who: MIAA Advancement Conference

When: June 3, 2021

How: Face-to-Face, Email

Presentation of study will be presented at the 2021 MIAA Advancement Conference through Power Point and executive summary handout. The researcher will provide the visual and handouts along with take questions at the end of the presentation. Attendees will receive the PowerPoint presentation by email for future reference.

\section{Type of Document}

In person presentation by Power Point slides will be provided to the 2021 MIAA Advancement Conference organizers. The full Power Point will be provided in a clear and organized fashion and will be the version that is used during the conference presentation.

\section{Rational for this Contribution Type}

Information that is shared from the presentation is intended for alumni relations and annual giving professionals who are looking for insight on how to better communicate, fundraise and engage with the Millennial population. The Power Point presentation format will provide an overview of problem along with findings and recommendations. From information shared, attendees will be able to take information back to their programs and to apply knowledge to future programming. 


\section{ESSENCE OF SOCIAL EXCHANGE THROUGH ALUMNI ENGAGEMENT OF MILLENNIALS AND THEIR ALMA MATER}

Robert J. Machovsky

University of Missouri Educational Leadership Policy Analysis Program

Dr. Nissa Ingraham, Dissertation Supervisor

2021 MIAA Advancement Conference

June $4^{\text {th }}, 2021$ 


\section{Problem Statement}

- Lack of Knowledge

- Lack of research regarding information that determined the specific alumni engagement practices needed when considering future fundraising campaigns and segmentation criteria towards individuals born from 1980 to 2004, known henceforth as "Millennials"

- With limited time and budget, institutions alumni relations professionals needed to strategically look at who and how they were messaging to younger alumni to improve engagement activity (Drezner \& Huehls, 2014)

- As Millennials have become the next generation of givers and volunteers at the Midwest University studied (Hanley \& Semelbauer, 2015), the lack of institutional knowledge in fundraising, engagement practices, personal preference with this population, and demographics needed to be evaluated.

A lack of information and research regarding the lack of knowledge (Merriam \& Tisdell, 2015).The have been no studies that specifically researched alumni engagement with a segmentation criteria toward individuals born between 1980 to 2004 (Stein, 2013; Feiertag \& Berge, 2008; Howe \& Strauss, 2000; Rainer \& Rainer, 2011) Overall, descriptive statistics and perceptions of Millennials at Midwest University are unknown and need to be explored and analyzed.

Existing literature explored a wide range of findings connected to Millennials and the importance to understand this population due to declining budgets and need to understand better and more effective engagement practices along with better understanding demographics of this population (Weerts \& Hudson, 2009; Drezner \& Huehls, 2014). 


\section{Purpose of Research}

- The main purpose of this research was to fill the gap in knowledge about what Millennial engagement looked like within higher education.

- This mixed-methods study included demographic information about whom from the Millennial alumni generation from the Midwest University was giving back, and provided a blueprint about which engaged alumni the institution should have communicated and concentrated on differently in future communications pieces, such as direct mail solicitations and individual approaches like personalized fundraising asks.

- The significance of this study was to minimize the scholarship gap in the literature and professional practice of fundraising to Millennials in a higher education setting.

The purpose of the research provided an understanding to the readers on what this research was about (Creswell, 2014). The research purpose was to fill the gap in knowledge about what Millennial engagement looked like within higher education settings. The research sought to find demographic facts and trends along with collected perceptions of Millennials on how to better engage with them by understating who they were, along with what motivated them to be engaged. 


\section{Research Questions}

- Overarching Research Question

- What does Millennial alumni engagement look like at a rural Midwest university?

- Probing Sub-questions

- Who are Millennials who give at the University?

- Why do these Millennials give to the University?

Due to the necessity of higher education intuitions needed to rely more on private sources of funding and higher levels of engagement among their alumni (Oliff et al., 2013), it was pertinent to understand emerging constituents.

The probing sub-questions were needed to help the researcher target specific areas of focus that allowed the researcher direction when creating the focus group and interview structure and questions (Creswell, 2014). 


\section{Conceptual Framework}

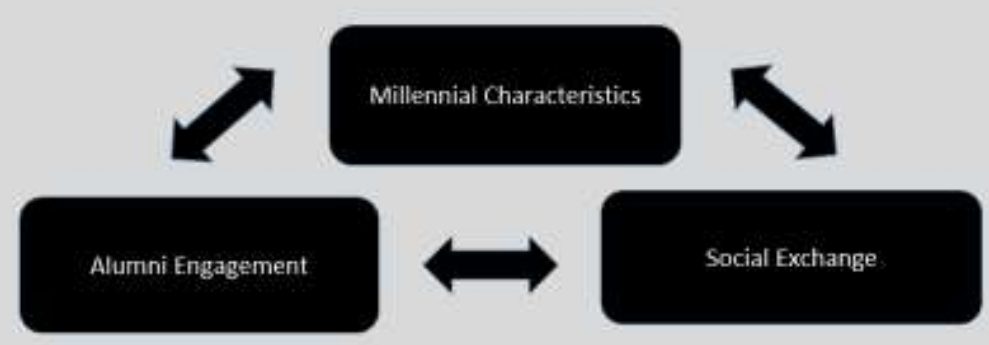

When looking at demographics that identified Millennials who chose to engage with the university in which they graduated from, one needed to first understand why alumni and friends would-wanted to connect with their institutions by making a philanthropic gift or any additional engagement possibilities. Understanding a person's social exchange needs allowed the researcher to understand why individuals chose to give back and/or engage with this school (Radcliffe, 2011; Dodge, 2016). Additionally, understanding typical alumni engagement and Millennial characteristics were imperative in guiding this study. 


\section{Social Exchange}

- The social exchange theory (SET) was a concept that was utilized in various research to aid in the understanding of one's motivations to act and to continue a relationship known as pure altruism (Keller, 1982; Monks, 2003; Weerts \& Ronca, 2007).

- Social interaction and connections provided evidence that there was a connection with alumni engagement (Scott \& Seglow, 2007).

- Defined as: "limited to actions that are contingent, and mutually rewarding process involving 'transaction' or simply 'exchange", (Emerson, 1976, p. 336). 


\section{Alumni Engagement}

- Variety of factors that affected alumni engagement (Hummel, 2010; Barber, 2013; Volin, 2016)

- The importance of various engagement connection strategies found in one study identified communication, relationship building, events, and opportunities to volunteer increased motivations of alumni to be engaged (Barber, 2013).

- Alumni loyalty was defined as an individual who had the desire to make a financial gift, stayed updated with university news, attended university events, and had interest in being a member of the alumni association (Snijders, Wijnia, Rikers \& Loyens, 2019).

- The cost of university tuition increased drastically over the past 25 years, not only at four-year institutions, but at two-year institutions and community colleges as well (Kim \& Ko, 2015; Lee et al., 2017). 


\section{Millennial Characteristics}

- Strauss and How (1991) coined the term "Millennial" in their book, Generations: The History of America's Future (p. 14).

- Strauss (2005) first identified individuals who were born from 1982 to 2001 as the Millennial population; however, other studies isolated different birth-years (Monaco \& Martin, 2007; Chou, 2012).

- With 60 million Millennials, this population was three times larger than Generation X, one of the youngest in the workforce, and classified as "digital natives" (Connor, Shaw, \& Fairhurst, 2008, p. 2) as they were exposed to technology as small children.

- When researching diversity, Millennials were the most diverse when comparing diversity from past generations (Frey, 2018). 


\section{Research Design}

- A mixed-methods study design combined quantitative and qualitative data within the study that allowed the researcher to understand the aspects under review (Creswell, 2014).

- Relied on both numerical data (Charles \& Mertler, 2002) and "an inquiry process of understanding the meaning of individuals or groups" (Creswell, 2014, p. 4).

- Used phases in collecting data that allowed the researcher to continually reflect and to sort comments into themes and categories known as the constant comparative method (Kruger \& Casey, 2015; Merriam \& Tisdell, 2015).

- Phase 1: Analyzed quantitative data.

- Phase 2: Deployment of survey, focus group and analyze data.

This explanatory sequential mixed-methods study explored the demographics of Millennials who chose to engage with the alumni program at a moderately selective rural Midwest university and understood the phenomenon of Millennial giving.

The mixed-methods study design combined quantitative and qualitative data within the study that allowed the researcher to understand the aspects under review (Creswell, 2014).

The researcher relied on both numerical data (Charles \& Mertler, 2002), and "an inquiry process of understanding the meaning of individuals or groups" (Creswell, 2014, p. 4).

The researcher collected the data in phases, which allowed to continually reflect and to sort comments into themes and categories known as the constant comparative method (Kruger \& Casey, 2015; Merriam \& Tisdell, 2015). This gave the researcher the opportunity to consider changes in the data to increase the quality of the data being collected (Krueger \& Casey, 2015). 


\section{Participants}

\section{Research Participants}

- Quantitative data of Millennials born from 1980 to 2004 and FY16-19

- N Valid: 72,672

- Survey Group

- 500 random sample surveys sent out

- 129 completed survey

- $26 \%$ Response rate

- Focus Group

- Recruited by email advertisement to 500 random sample individuals

- Four individuals participated

- Three males

- One female 


\section{Millennial Population}

Table 1

Alumni Gender

\begin{tabular}{lcc}
\hline Gender & Frequency & Percentage of Total \\
\hline Female & 40,644 & 55.9 \\
Male & 31,992 & 44 \\
Unknown & 28 & 0 \\
\hline Total & 72672 & 100 \\
\hline
\end{tabular}

Gender breakdown between male and female participants

Table 1 above provided descriptive statics on the Millennial population. 


\section{Millennial Population}

Table 2

Alummi Ethmicity

Ethnicity Frequency

284

1,488

Asian

Black, Non-Hispanic

Hispanic

1,964

352

Multi-race

244

Native Hawaiian or Pac. Isl.

Non Resident Alien

Unknown

36

1,488

572

White, Non-Hispanic

55,064

Percentage of Total

0.46

2.42

3.19

0.57

0.40

0.06

2.42

0.93

89.55

Ethnicity breakdown of research participants

When looking at Millennial donors from a demographic perspective, 71,531 or $98.4 \%$ were considered not donors, as they had not ever made a gift to the University during the time spam of FY16-FY19. However, 1,141 individuals in this study had made a donation representing $1.5 \%$ of the population. To further breakdown the 1,141 donors, the researcher analyzed the type of areas the donor Millennial population was contributing also. The following were the designation themes donors were giving too; scholarships had 135 donors representing $11.8 \%$ of the donors, athletics had 261 donors representing $22.9 \%$ of the donors, unrestricted designations had 536 donors representing $47 \%$ of donors, academics had 56 donors, representing $4.9 \%$ of the donor base, and other had 153 donors, representing 13.4\%. The other designation category included designations of student organizations and areas that donors participated in as students. 


\section{Millennial Population}

Table 3

Ahumi as Early or Late Millemials

\begin{tabular}{lcc}
\hline Millennial Status & Frequency & Percentage of Total \\
\hline Bom From 1980-1989 & 39,568 & 54.45 \\
Bom From 1990-2004 & 33,104 & 45.55 \\
\hline
\end{tabular}

Breakdown of research participants born from 1980-1989 and 1990-2004

Table above provided descriptive statics on the Millennial population.

\section{Millennial Population}

Table 4

Alumni Degree Codes

\begin{tabular}{clc}
\hline Type of Degree & Frequency & Percentage of Total \\
\hline Undergraduate Degree & 58,956 & 81.3 \\
Masters or Higher Degree & 13,572 & 18.7 \\
Total & 72.528 & 100 \\
\hline
\end{tabular}

Type of degree breakdown of research participants

Table above provided descriptive statics on the Millennial population. 


\section{Millennial Population}

Table 5

Fiscal Year of Data

\begin{tabular}{rcc}
\hline Fiscal Year & Frequency & Percentage of Total \\
\hline FY16 & 18,168 & 25 \\
FY17 & 18,168 & 25 \\
FY18 & 18,168 & 25 \\
FY19 & 18,168 & 25 \\
Total & 72,672 & 100 \\
\hline
\end{tabular}

Breakdown of research participants in each fiscal year

Table above provided descriptive statics on the Millennial population.

\section{Results by Research Questions}




\section{Findings - What does Millennial alumni engagement look like at a rural Midwest university?}

- Probing Sub-Question: Who are Millennials who give at Midwest University?

\begin{tabular}{|c|c|c|c|}
\hline \multicolumn{4}{|c|}{ 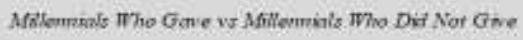 } \\
\hline & Frequency & Petoent & $\begin{array}{l}\text { Comidative } \\
\text { Peroent }\end{array}$ \\
\hline NoGhe & 71531 & 98.4 & 95.4 \\
\hline Gave & 1141 & 1.5 & 1:57 \\
\hline Total & 72672 & 100 & \\
\hline
\end{tabular}

Millennial population who gave vs. those who had not made a gift. $1.5 \%$ of the Millennial population had made a gift vs $98.4 \%$ who had not.

Table above provided descriptive statistics on the Millennial population who gave vs. those who had not made a gift.

\section{Findings - What does Millennial alumni engagement look} like at a rural Midwest university?

- Probing Sub-Question: Who are Millennials who give at Midwest University?

\begin{tabular}{|c|c|c|}
\hline \multicolumn{3}{|c|}{ Donar Gut Area Brendiown } \\
\hline Desaranation Asea & Frequensy & Percen \\
\hline Scholurslips: & 135 & $\mathrm{tt} .8$ \\
\hline Adileties & 261 & 22.9 \\
\hline Umestricted & 536 & 47 \\
\hline Acondemics & 56 & 49 \\
\hline Other & 153 & 13.4 \\
\hline Total & 1141 & 100 \\
\hline
\end{tabular}

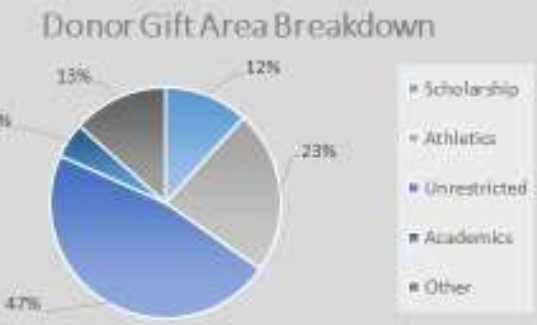

Donor gift by designation breakdown of research participants. Unrestricted and Athletics designation were the two highest. 
FY16-FY19. However, 1,141 individuals in this study had made a donation, representing 1.5\% of the population. To further breakdown the 1,141 donors, the researcher analyzed the type of areas the donor Millennial population was giving too. The following are the designation themes donors were giving too: scholarships had 135 donors representing $11.8 \%$ of the donors, athletics had 261 donors representing $22.9 \%$ of the donors, unrestricted designations had 536 donors representing $47 \%$ of donors, academics had 56 donors, representing $4.9 \%$ of the donor base, and other had 153 donors representing 13.4\%. The other designation category included designations of student organizations and areas that donors participated in as students.

\section{Findings}

- Probing Sub-Question: Who are Millennials who giveat Midwest University?

Table 8

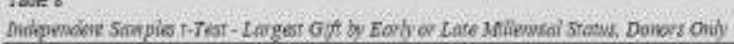

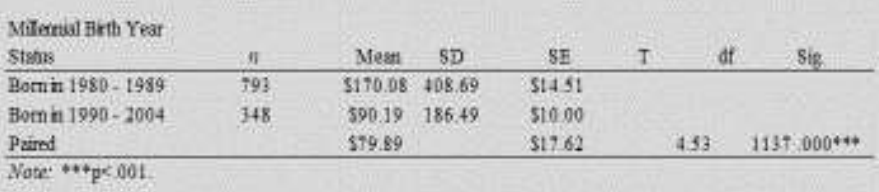

targest Gitt by Early or Late Millennial Status, Donors Only

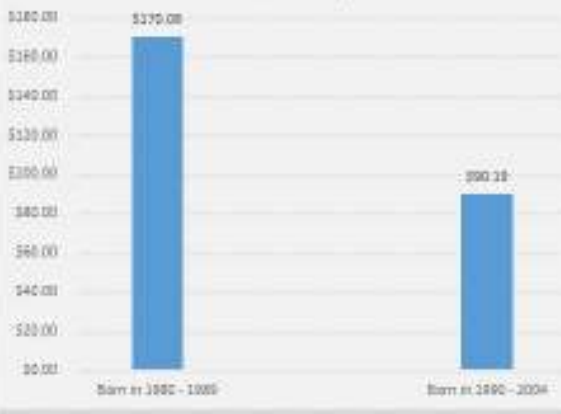

These results suggested that individuals bon from 1980 to 1989 had the potential to give a higher average than those born from 1990 to 2004.

A paired samples $t$-test was conducted for the two groups of birth years of donors subtest. The test compared average donation among the two groups and found, on average, individuals born from 1990 to 2004 gave a lower average gift $(M=\$ 90.19, S E=\$ 10.00)$ than did individuals born from 1980 to $1989(M=\$ 170.08, S E=\$ 14.51), t(1137)=4.53, p<.05$, resulting in a statistical significant difference among average donations when comparing the two birth year groups. These results suggested that individuals born from 1980 to 1989 had the potential to give a higher average than those born from 1990 to 2004. 


\section{Findings}

- Probing Sub-Question: Why do Millennials give at Midwest University?

Table 9

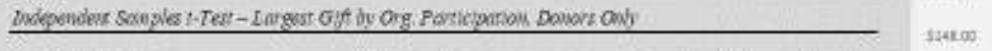

\begin{tabular}{|c|c|c|c|c|c|c|c|}
\hline Parbinated in Org & $n$ & Mean & SD & SE & I & & \\
\hline Org & 520 & $\$ 15050$ & 333.4 & $\$ 16.81$ & & & \\
\hline NoOrg & 6321 & $5: 41.70$ & 335.01 & $\$ 13.44$ & & & \\
\hline Pared & & $\$ 8.80$ & & 521.27 & 0.414 & 1139 & 0.679 \\
\hline
\end{tabular}

Nove. Not Stshiticaly sgnisearit

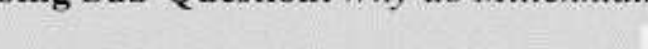

Largest Avg. Gift by Donor Who Were in Orgs.

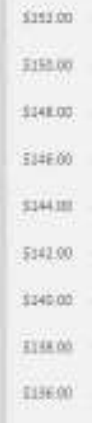

siso.se:

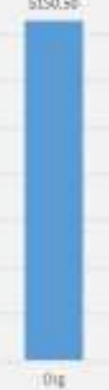

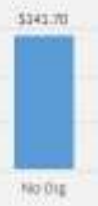

Although not significant, these results suggested that individuals who were in organizations as students gave larger gifts than those who were not in student organizations.

A paired samples $t$-test was conducted for donors who were organizations versus those donors who were not in an organization subtest. The test compared average donation among the two groups and found, on average, individuals who gave and were not in student organizations, while in college had a lower average gift $(M=\$ 141.70, S E=\$ 13.44)$ than did donors who were in organizations as student $(M=\$ 150.50, S E=\$ 16.81), t(1139)=0.414, p>.05$ resulting in not a statistical significant difference among average donations when comparing the two groups. Although not significant, these results suggested that individuals who were in organizations as students gave larger gifts than those who were not in student organizations. 


\section{Findings}

- Probing Sub-Question: Why do Millennials give at Midwest University?
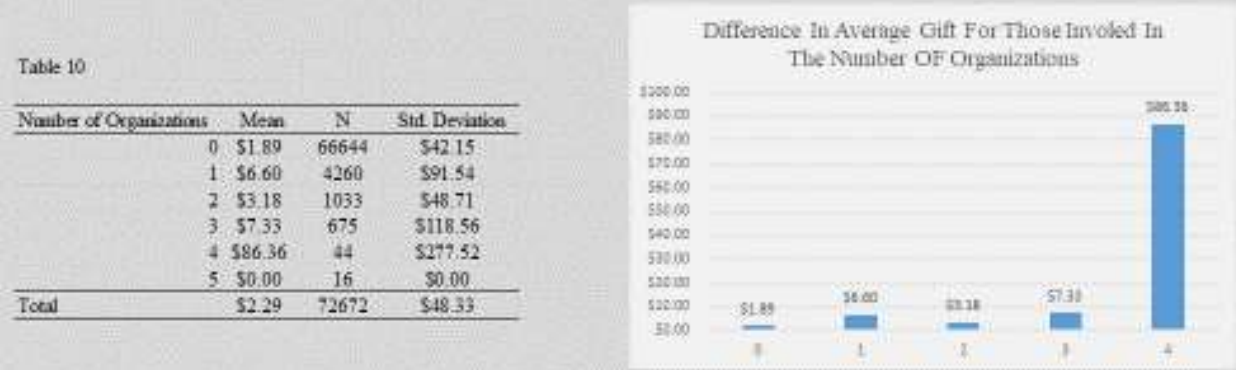

These results suggested the more organizations a donor was in the potential for the amount of their gifts to be larger than other donors.

A descriptive statistic analysist was run to determine what the average gift was among those who were not in organization and those who were in one or more student organizations. The results found the average mean for give size by number of student organizations. Results were as follows: Organization had a mean average gift of $\$ 1.89$, in one organization had a mean average gift of \$6.60, in two organizations had a mean average gift of \$3.18, in three organizations had a mean average gift of $\$ 7.33$, and in four organizations had a mean average gift of $\$ 86.36$. These results suggested the more organizations a donor was in the potential for the amount of their gifts to be larger than other donors. 


\section{Findings}

- Probing Sub-Question: Why do Millennials give at Midwest University?

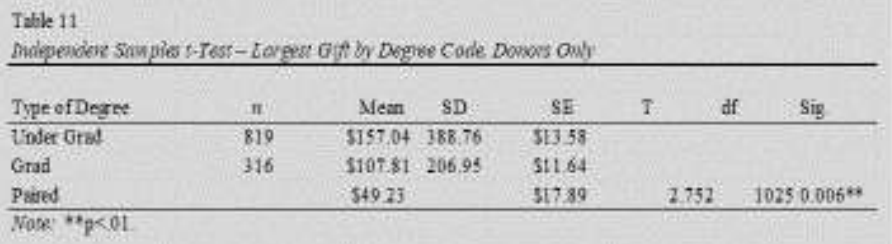

Average Give by Degree Tvpe, Donors Only
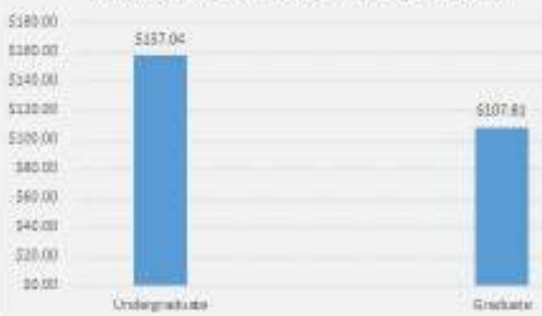

These results suggested that individuals who had an undergraduate degree had the potential to give a higher average then those with graduate degrees.

A paired samples $t$-test was conducted for the two groups of degree types who were donors subtest. The test compared average donation among the two groups and found on average, individuals with graduate degrees gave a lower average gift $(M=\$ 107.81, S E=\$ 11.64)$ than did individuals with undergraduate degrees $(M=\$ 157.04, S E=\$ 13.58), t(1025)=2.752, p<.05$ resulting in a statistical significant difference among average donations when comparing the two degree types. These results suggested that individuals had an undergraduate degrees had the potential to give a higher average then those with graduate degrees. 


\section{Findings}

- Probing Sub-Question: Why do Millennials give at Midwest University?

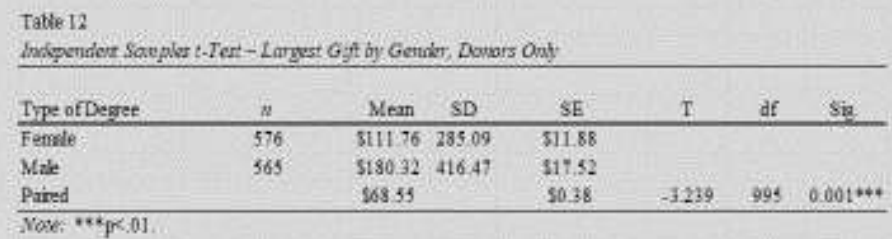

Takie 12

\begin{tabular}{|c|c|c|c|c|c|c|c|}
\hline Thpe ofDergee & $n$ & Mem & SD & SE & I & df & $\mathrm{Sin}$ \\
\hline Fenvile: & 576 & 811176 & 28509 & $\$ 11.88$ & & & \\
\hline Mak & 565 & $\$ 180.32$ & 416.47 & $\$ 17,52$ & & & \\
\hline Pared & & 56859 & & 50.38 & -1239 & 995 & 0.001044 \\
\hline
\end{tabular}

These results suggested males had the potential to give a higher average than females.
Average Gift by Gender, Donors Only

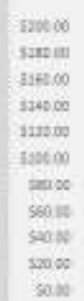
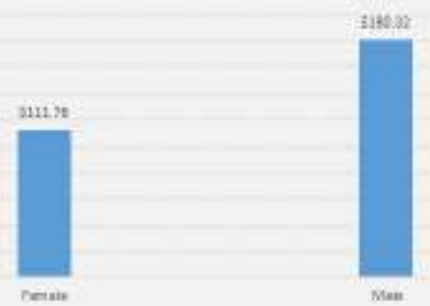

A paired samples $t$-test was conducted for gender of donors subtest. The test compared average donation among the two groups and found, on average, females gave a lower average gift $(M=\$ 111.76, S E=\$ 11.88)$ than did males $(M=\$ 180.32, S E=\$ 17.52), t(995)=-3.239, p<.05$ resulting in a statistical significant difference among average donations when comparing the two genders. These results suggested males had the potential to give a higher average than females. 


\section{Findings}

- Probing Sub-Question: Why do Millennials give at Midwest University?

\begin{tabular}{|c|c|c|c|c|c|c|c|}
\hline Ipe of Degree & $n$ & Mean & SD & SE & I & df & Siz. \\
\hline $\mathrm{N}_{0} \mathrm{Otg}$ & 979 & 5128,79 & 32358 & 510.34 & & & \\
\hline Athktics Ors & 162 & $\$ 24796$ & 50783 & $\$ 39.90$ & & & \\
\hline Paired & & $\$ 11919$ & & $\$ 41.22$ & -2.891 & 183 & $0.004 * 4$ \\
\hline
\end{tabular}

Tatie 13

These results suggested that donors who were athletes as students had the potential to give a higher average than those who were not athletes as a student.
Athletics Org Dosnors vs Donors

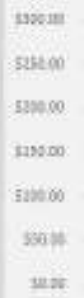

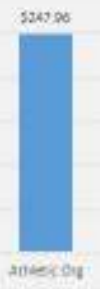

A paired samples $t$-test was conducted for donors who were in athletics against donors who were not in athletics while a student subtest. The test compared average donation among the two groups and found, on average, those who were not athletes as students gave a lower average gift $(M=\$ 128.79, S E=\$ 10.34)$ than did donors who were athletes as a student $(M=\$ 247.96$, $S E=\$ 39.90), t(183)=-2.891, p<.05$ resulting in a statistical significant difference among average donations when comparing non athlete again an athlete donor. These results suggested that donors who were athletes as students had the potential to give a higher average than those who were not athletes as a student. 


\section{Themes That Emerged}

Communication Preference

Affinity Gravitation

Event Interest

Gift Interest

Engagement Rationale 


\section{Findings}

- Probing Sub-Question: Why do Millennials give at Midwest University?

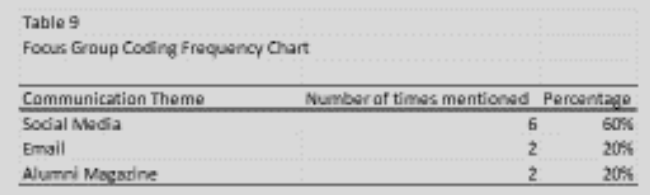

Table 9

Focus Group Coding Frequency Chart

\begin{tabular}{lcc}
\hline Affinity Theme & Number of times mentioned & Percentoge \\
\hline Univeristy Brand & 4 & $31 \%$ \\
Athletics & 2 & $15 \%$ \\
Family Culutre & 7 & $54 \%$ \\
\hline
\end{tabular}

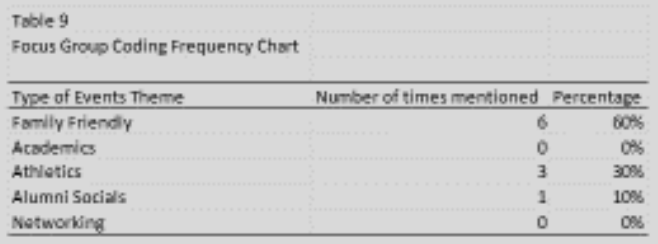

\section{Communication Theme Quotes:}

"It's hard. I would say email would be the best, because that's where I get a lot of bills, that's where I get a lot of notifications. I'm programmed to check that. Social media, I'll take healthy breaks from that if needed. Especially lately. It's something that can be hit and miss. I get information there, but I definitely keep a control on it. And there really isn't a lot that comes in the mail."

"I think it depends on what it's for. So if it's for sending the magazine, for instance, I wouldn't want a digital version of the magazine. I like that being physical as well. But when it comes to the alumni groups that are getting together, like I was talking about, in the St. Louis area, that's something I would rather be through Facebook or a way that's a little bit easier to have quick answers to questions, which I guess email could do that as well, but it's a little bit more interactive through a social media platform of some kind for those get together and opportunities. So I think it just depends on what the situation is or what the communication is for."

"Yeah. I agree. I think, with the magazine, or even anything, it's just kind of updates on certain things that you definitely want people to see, because I'm the same way of, there's a lot of stuff that I'll go back and see something that pop up, someone comments on something a month ago on Facebook, and you're like, "Oh, I didn't realize that happened." So the social media can be hit and miss. If it's something that you want more of an immediate response, then yeah, email. I check it like a hundred times a day so that's the quickest and best probably." 
"I would also say email probably first and then social media. And in some of the more in depth articles and stuff that are in the alumni magazine, I like those too. So I think all three of those have a good place for communicating to the alumni."

\section{Affinity Theme Quotes:}

"I can start that one if you want. I would say the community. The community is something that, I'm a recent graduate, like I said, 2017, and I loved everything about my experience in Northwest. I was one of those students."

"I would say family. I remember that more than anything. The community itself. I liked the town of Maryville, I think they really embrace the school, and not just Maryville, but the whole region. I also liked how well the campus is landscaped and maintained. It's beautiful. Just really fortunate to be able to have such a nice campus. And of course, there's a lot of good people on campus too that make it the way it is."

"Yeah, maybe it's cliché to say too, because I feel like athletics kind of beats at the death, the family part, but I really think that's a lot of reasons why they do get certain recruits in over there, but then also on the other side. I had a cousin and then some family went to Northwest, but they were aunts and uncles in a different family and they had been gone for 10 years by the time I got there. I was from a small school and didn't have anybody else from my school there at the time, and so regardless of where I went, I was a little bit nervous as an 18 year old going somewhere else, even though I wasn't very far away. But it just did feel like you're embraced by everybody right away and I really enjoyed it and, looking back, it's kind of like, nowhere else you'd really want to be. So even though we got a little bit sick of Maryville and near the end, we still ended up moving back a couple of years after we left. But no, we really liked it."

"And yeah, it's kind of just the tight bond there, of Maryville and Northwest. I had a buddy that I worked with in St. Joe that had no ties to Northwest, except through just me talking to him, and I got him a Bearcat in my AA championship shirt. And he was out in the Caribbean somewhere on a boat ride on his honeymoon and there was another couple there and they're like, "Hey, we graduate from Northwest in '09." And it's crazy, you see people from all over. My parents are the same way. Just a shirt I get them and they were in a random place, not around here, and there's Northwest people everywhere and they always come together. So I think that's something that's really, really cool."

"That's what I was going to say. I studied in Greece, I studied abroad for one of my masters through a different school, and there was somebody there in their office who they're a Northwest undergraduate who was working in Greece, so super cool. And I would agree with everything too, that community piece. My husband's in athletics and we'll go to other towns and there'll be like, "Good luck to like the Bearcats." You would never have that happen in Northwest. No one's going to tell the other team good luck in our community. I mean, we'll care for them, but we're not going to be like, "Oh, we hope you do well." And he always says, if he can bring athletes on campus, they're going to come here. Because once they feel that environment, which you've talked about how beautiful, how much people care, how involved, he can get a recruit to come 
just from having that experience. Now, if they don't come on campus, it's something about that atmosphere that we have."

"And that the community really is for our students. Like they're on the same page. I mean, every now and then, I don't know, you might get a noise disturbance or whatever it is, but like overall, our community is for the college, and you don't see that everywhere. That reciprocal relationship and working together. And then I would just say too, the awesome things my students do. I'm super proud of our alumni and what they're doing, and so I use those alumni stories in my classroom. I'll try to start like, "Hey, let me tell you about what so and so is doing." Just to kind of encourage them too, because they're in their class like, "Oh, am I ever going to graduate? I'm not going to see the end of this." And I want them to know, "No, here's some things you can do with your degree and keep going and be proud of our alumni too." So I'm just really proud of some of the great things that people have gone on to do."

"And the people aspect of it too, again. At times I feel like Northwest gets this view of, they're like Nebraska football fans or KU basketball fans. Some people from the outside are like the Bearcat fans are so pretentious because there's so much winning and there's so much success and kind of goes to everybody's heads. But a couple of years ago, whenever Sioux Falls, South Dakota hosted the Elite Eight for men's basketball, and it was the first men's basketball championship, Northwest admin had beat up on Augustana a few different times and they were the host school for the Elite Eight overall, even though they won a championship the year before, the Bearcats had still knocked them off and it kind of became a good rivalry."

\section{Type of Events Theme Quotes:}

"I like our social media platforms that we have, and, of course, I like our chapter gatherings and socials and of course when you're really good at athletics, it's always fun to have gatherings at those events as well.

I forgot the exact name you just gave for it, but the chapter meetings that are like more centralized to specific locations, I live over in the St. Louis area, and I know that there is a St. Louis alumni group that is fairly active, they sent out a couple emails about getting together to meet up, and that's not something I've been able to take advantage of yet."

"We lived in St. Joe for a while and they always have, especially in the fall, they had a big party and I knew a couple of guys and they'd invite me, but my wife and I always felt like we would be so much younger than everybody, like man, "Maybe we get in there and it's a little uncomfortable." So I love the idea of gatherings, and especially if we can find a way to get, keep those younger generations also coming in with the older ones that are obviously very committed to Northwest."

"I would say it's almost the cliche answer, but like things like homecoming and the family weekends, those big events on campus that are going to be something, especially for someone like me who is five hours away, that's more enticing to come up than just maybe like a random game here or there. And also, obviously, when we get to the championships and things like that, 
those are the things that I want to be a part of as well. So for me, it's those bigger are bigger events, on campus."

"I think the huge events that, like he was mentioning, a family weekend, homecoming, some of the bigger games, not just a random one here or there, and I think too, the championships, the alumni does a great job of getting some of those gatherings together and opening it up at a local restaurant or a bar and saying, "Everybody come on in and chat a little bit before heading over to the game."

"And then an underrated one, too, was the Yuletide Feast, which I think just about every year they ended up selling out. The only bad part of it is, I think, playoff football's right around that time, there's usually a basketball game too. Probably not this year though. But yeah, that's a great one too that I think you get a lot of community members and not just specifically Northwest alumni or students or this or that, but that one kind of brings in folks from the outside. So anything like that, that you can have on campus that I think people are really excited for." 


\section{Findings}

- Probing Sub-Question: Why do Millennials give at Midwest University?

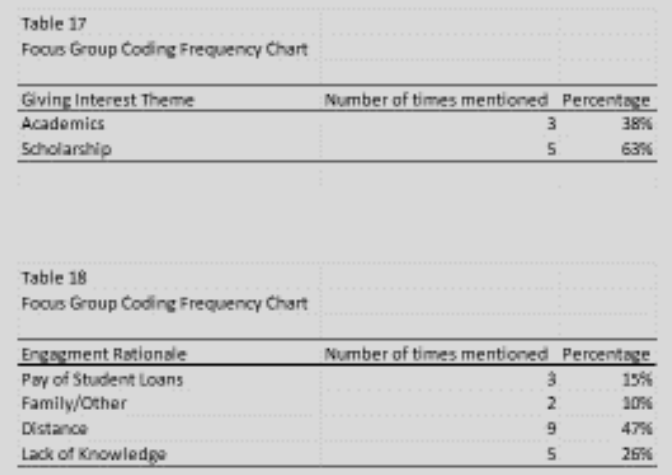

\section{Giving Interest Theme Quotes:}

"I like knowing where the donation goes. I work on campus, so I've been more inclined to give to like Pay It Forward for the food pantry or a specific scholarship that I've seen benefit my students. So probably more the basic level things have motivated me to give or want to help that situation."

"I would agree. Whenever I was in school, one semester, I got the Adoptive Bearcat Scholarship from people I didn't know and I thought that was the coolest thing ever. So things like scholarships, but then also what my background was in when I was at Northwest Missouri State, radio, TV, if you know that there are certain upgrades that need to be made or certain things that we didn't have when I was there that could benefit students. Little things like that you know that could help that profession-based learning aspect."

"Yeah. And not to just repeatedly say the same things, but I think that is really important, at least for myself too. That was kind of what I thought through ahead of time is that I like knowing where it's going directly and being able to select, if there's multiple options, on knowing this is going to directly go to a student in the form of an endowed scholarship, for instance, or if it's going to be something that's more, I want to fund this organization on campus that I was part of because it meant a lot to me when I was a student. I think those would be motivating factors, too, just knowing that it's going to go towards something that I really care about directly."

"And I would say the exact same thing that everyone else has. I think giving it to areas that you have interest in, it really just means a lot. And at the same time, some of the things that given to you, like the Bearcat scholarship, I think that's also nice too. The Adoptive Bearcat." 


\section{Engagement Rationale Theme Quotes:}

"I'm from a lower SES background, so I'm not first generation college, but I have student loans. And so I think since I worked from Northwest, it seems interesting to sort of be paying off my loans, trying to meet my goals of being at least middle-class, which yeah, you know, but then also giving to where I'm working when I'm not quite making it yet. So I think that class mentality also of knowing to give, how, what, sort of a culture of norms, I guess. That was a weird answer. But I would say, in my mind, when I've paid off my student loans for my education, I would be more likely to give for others so maybe they won't have as many loans or have more opportunities."

"Yeah. I was kind of thinking along the same lines too, of, whether it's a student loan or for instance, we have a three year old, put him through daycare and all that stuff and all those expenses right now too and hopefully we get him off into kindergarten and not worrying about that stuff anymore, but some of the little expenses, we're still kind of getting our footing. And I guess as adults, even though I'm 31, I should probably have that already. So little things like that. Just kind of those other expenses right now while we're trying to build up for retirement and et cetera, early on in adult life are things right now that set me back. Because we talk about, can we do this? Can we do that? Can we give them that? And right now we're pumping the brakes on a lot of that, but yeah, hopefully in the next few years, those are things that can be alleviated for us."

"Yeah. And another side of it too, kind of like what he was saying, is that, for instance, us personally, we have our first child on the way. And so that would be something that we are planning for financially as well. And so I would just say the general topic of financial ability would be one of those. And then also going along with the Sarah said is that I still have student loans out myself, and so being able to pay off all of those and getting myself and my wife both on that same page of, we are financially independent or be able to start giving back to the university. Because that's something that I know is definitely on our minds, but it's something we're not able to do right now."

"And I would say the finances, as long as I'm stable with my finances, I don't mind giving back. But at the same time there's a lot of things that pop up. So even like myself, I'm single with no kids, and that does allow me to give back, probably more here recently, but it's the same time everyone has things that come up that costs a lot sometimes. So I think it just comes back to the finances."

"We've always had other things going on at the same time, the same weekends. But that's something I definitely am interested in and would love to be a part of because over in St. Louis, I'm about five hours from campus, so it's not as easy to go pick up and go to a game on a weekend if that's something even though we want to."

"We lived in St. Joe for a while, and they always have, especially in the fall, they had a big party and I knew a couple of guys and they'd invite me, but my wife and I always felt like we would be 
so much younger than everybody, like man, "Maybe we get in there and it's a little uncomfortable."

"I think the social media is great for, especially, that up to date what's going on and what's happening. And I might be a little bit different in this aspect. I feel like we get so much junk mail in general. You know what, if there's was a letter that came in, I know we get the alumni magazine, what, once, twice a year, along with that, but heck we got a letter from Northwest Alumni Relations saying, "All right, this is what's going on, this is what we have coming up." I mean, I'd be happy to open up an envelope and read something actually in my hand.“

\section{Findings}

- Probing Sub-Question: Why do Millennials give at Midwest University?
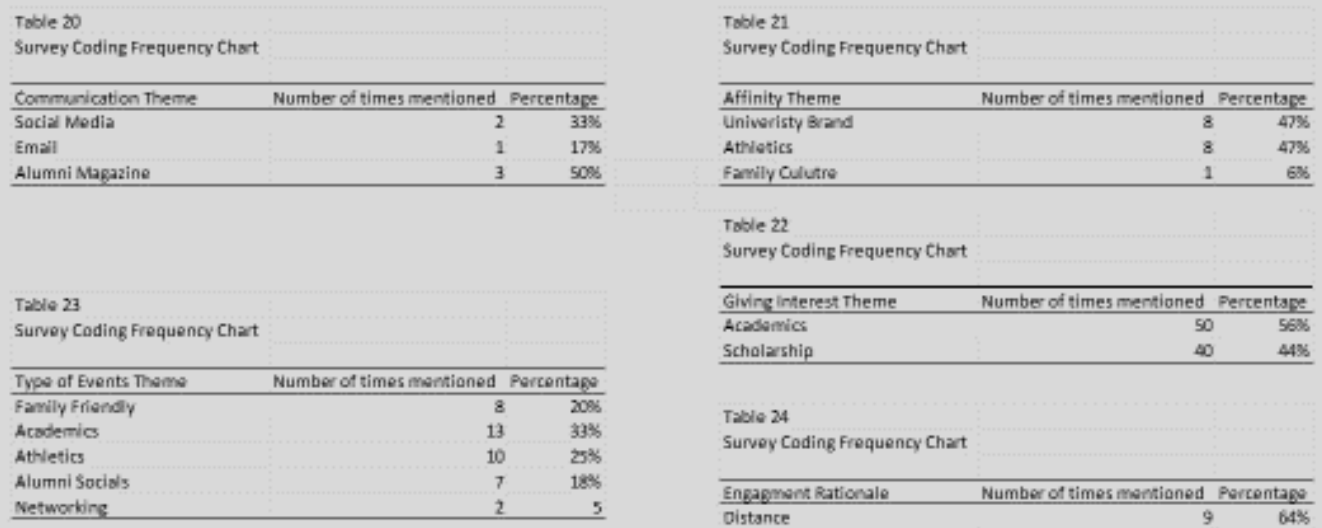

Table 22

Survey Coding Frequency Chart

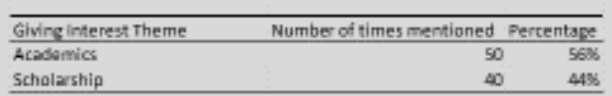

Table 24

Survey Coding Frequency Chart

\begin{tabular}{lcc}
\hline Engagment Rationale & Number of times momtioned Porcentass \\
\hline Oistance & 9 & $64 \%$ \\
Lack of Knowiedge & 5 & $36 \%$ \\
\hline
\end{tabular}

\section{Communication Theme Quotes:}

"I think this survey is the first time I have been contacted by the Alumni Association, so basically I think you could improve on a lot."

"I like the presence the Alumni Association has on social media and through the print magazine. This is how I stay most aware of what is going on and where I experience the most visibility of the association. Everything communicated digitally and in print is engaging, looks professional, and makes me proud to be a Northwest Alumni."

"I enjoy the periodic Alumni magazine that is published. Otherwise, I don't have much interaction with the Association. Once in a while I get calls from students during fundraising campaigns, but that has been the extent of the personal interaction I've had." 
"I like reading about the successes of students and alumni."

"Texting about how we can engage with future students."

"Honestly, I don't think I have ever really been contacted by the Northwest Alumni Association except to make a donation."

"Would also like to have a newsletter!"

"Great to stay connected, but would be cool if there was a platform for groups of every 5 or 10 years can post updates, gatherings for alumni of a particular age to connect, and more (2000-2004, 2005-2008, etc.). Enjoy seeing all alumni, but it's easy to get lost in the shuffle of older generations."

\section{Affinity Theme Quotes:}

"I like that membership is free."

"Sporting events tend to bring me back."

"The only events I would have any interest in are with the Art Department."

"After the pandemic, I'd love to hear about student presentations, such as theater, art, and perhaps any lectures or presentations open to alumni or the public."

"I return to campus frequently, to participate in Mock Interview Day, the Professional Advisory Team meeting, and as a guest speaker for various classes or clubs."

"I used to visit more often. I'd consider Homecoming or something similar perhaps when my son is a bit older."

"Special Family Events on weekends."

"A reunion of fellow peers, teachers, and administrators."

"I really loved Happy Garden, so I'd totally come to town for that."

"Faculty, events, homecoming."

"Football games or special events."

"Homecoming or connecting with classmate's reunion."

"Football games."

“Alumni events within my specific department." 
"A reunion of fellow peers, teachers, and administrators."

\section{Giving Interest Theme Quotes:}

"Help out with scholarship for students would be fabulous."

"Not one thing. The state of Missouri closed the Missouri Academy of Science, Mathematics and Computing. That was my school and Northwest just happened to host it."

\section{Type of Events Theme Quotes:}

"The positives are the events they put together with the sporting events."

"Hosting family events like Worlds of Fun, Zoo, baseball games, etc. Having more of these types of events would be an improvement."

"I like the events in my area!"

"I would come back for a reunion, but otherwise, I live out of state - it is difficult to travel back just to visit!"

"Alumni gatherings, class reunions, games, events, family days, etc."

"Not many events in a Maryville that are not part of athletic events."

"Golf Tournaments."

"I return to campus frequently to participate in Mock Interview Day, the Professional Advisory Team meeting, and as a guest speaker for various classes or clubs.

Career Day, speaking to classes/organizations, and athletic events."

"I would love to know about different ways to get involved."

"More information about regional association opportunities for people who no longer live in Maryville. Networking opportunities in areas outside of Maryville would be great."

"It would be nice to have some targeted opportunities for those of us who are not in that immediate area occasionally. For example: there are $3 \mathrm{NW}$ alumni (counting me) in the immediate area where I am located and we are all within easy driving distance of Duke."

\section{Engagement Rationale Theme Quotes:}

"Negative is there doesn't seem to be a lot of coordination between the school and the individual chapters." 
"I am an alumni who is a long distance from Missouri (on the East Coast). I love seeing all the activities and things going on, but feel disconnected because they require you to be there in the Missouri/Kansas/Iowa/Nebraska area."

"I think the only thing I know about the Alumni Association is that you ask for money."

"I only get contacted when you want money."

"I don't like being called and asked for \$."

"I feel very disengaged from NWMS, honestly. I feel like I was never "in" the alumni even though I am one. Most of that is one me."

"Dislike: The only time I get contacted is when they want my donation."

"My fraternity not being kicked off." 


\section{Collective Findings}

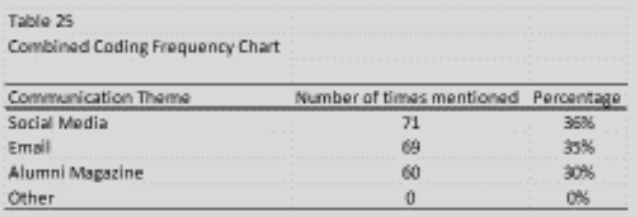

Table 26

Combined Coding Frequency ourt

\begin{tabular}{lcc}
\hline Affinity Theme & Number of times montioned & Porcentago \\
\hline Univeristy Brand & 12 & $40 \%$
\end{tabular}

athiletics

$\frac{10}{8}$

Table 27

Combined Coding Frequency Chart

\begin{tabular}{lcc}
\hline Type of Events Theme & Number of times mentioned & Percentage \\
\hline Family Friendly & 71 & $34 \%$ \\
Acasomics & 69 & $33 \%$ \\
Atwietics & 60 & $29 \% 5$ \\
Alumni Socials & 8 & $4 \% 5$ \\
Notworking & 2 & 1 \\
\hline
\end{tabular}

\section{Themes That Emerged}

\section{Communication Preference}

"I like the presence the Alumni Association has on social media and through the print magazine."

"I would also say email probably first and then social media."

"So, if it's for sending the magazine, for instance, I wouldn't want a digital version of the

magazine."

"I enjoy the periodic Alumni magazine that is published." 


\title{
Themes That Emerged
}

\section{Affinity Gravitation}

\author{
"Sporting events tend to bring me back." \\ "I used to visit more often. I'd consider Homecoming or something similar." \\ "Football games or special events." \\ "Alumni events within my specific department." \\ "I would say the community." \\ "I would say family." \\ "And that the community really is for our students."
}

\section{Themes That Emerged}

\section{Event Interest}

"I like our chapter gatherings and socials and, of course, when you're really good at athletics, it's always fun to have gatherings at those events as well."

"I forgot the exact name you just gave for it, but the chapter meetings that are like more centralized to specific locations."

"Homecoming and the family weekends."

Family weekend, homecoming, some of the bigger games, not just a random one here or there, and I think too, the championships."

"I like the events in my area!" 


\section{Collective Findings}

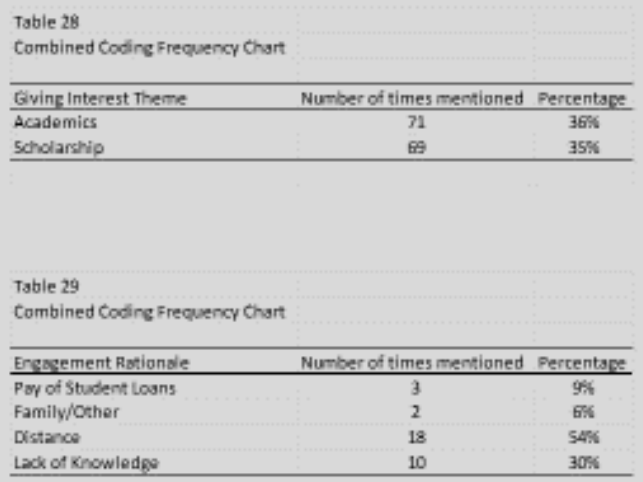

\section{Themes That Emerged}

\section{Areas to which Make a Donation}

"I like knowing where the donation goes. I work on campus, so I've been more inclined to give to like Pay It Forward for the food pantry or a specific scholarship that I've seen benefit my students. So probably more the basic level things have motivated me to give or want to help that situation."

"I think giving it to areas that you have interest in, it really just means a lot."

"Help out with scholarship for students would be fabulous." 


\title{
Themes That Emerged
}

\section{Engagement Rationale}

\author{
"I only get contacted when you want money." \\ "I am an alumni who is a long distance from Missouri (on the East Coast)." \\ "I have student loans." \\ "Us, personally, we have our first child on the way." \\ "And I would say the finances, as long as I'm stable with my finances, I don't mind giving back."
}

\section{Discussion}

- Is their a connection between type of degree and one's ability to give? Results shown that those with a higher degree give a higher average amount.

- The Millennial generation is a large generation span. Findings concluded that those born from 1980 to 1989 are different from those who were born from 1990 to 2004 due to how much they were giving.

- Those involved as a student in either organizations or athletic organizations gave a larger amounts compared to those that were not involved.

- Male and female do give differently. This research shown that males give larger amounts the females. However its important to note that this was also a limitation of the study as the institution researched coded donors to credit males when marred to a female who was also an alumni.

- Giving to areas that individuals have connection with rose to the top for priorities to support. However, descriptive statistics shown that Millennials were giving at high rates to unrestricted areas and not specific designated areas. 


\section{Scholarly Recommendations}

- Future research is needed on communication and engagement preference by early to late Millennial birth grouping years (1980 to 1989 and 1990 to 2004).

- Future research is needed on communication and engagement preference by degree type (undergraduate and graduate degree) when looking at the Millennial population.

- Future research is needed on types of activities Millennial population (zero to five activities) were involved in. From those activities, what produced the most donors and highest average gift.

- Future research on if there was a connection between students who received scholarships and became a donor to areas of scholarships, athletics, and academic areas.

\section{Practitioner Recommendations}

- Bring more events to regional areas in which alumni are living.

- Incorporate more of family culture brand into all marketing and communication for alumni engagement and fundraising.

- Build in more family friendly events into alumni engagement programming.

- Email is not dead; keep using this as a way to disperse communication.

- Provide more resources to social media and alumni magazine for the Millennial population.

- Change call to action to more academic priorities and the needs for scholarships and direct student benefit.

- Evaluate non donors and determine how many were involved in organizations and how many to be potential included in future solicitations and engagement opportunities. 


\section{References}

Barber, K.D. (2012): A study of almani engagetnent and satisfaction as related to alumui voluteerism and plilarthropy. Valdosta (Georgia): Graduate Scloool Valdosta State University.

Charles, C. M. \& Mertler, C. A. (2002), Introduction to educational research (4th ed.). Boston, MA: Allyu and Bacon

Chou, S. Y, (2012), Millewuials in the workplace: A coniceptual analysis of millemuials' leaderstup and followership styles. Interwational Jotrnal of Himan Resource Studies, 2(2).

Conoor, H., Shaw, S., \& Faithurst, D. (2008). Engaging a new generation of gradiates. Educationt training.

Creswell. J. W. (2014). Reseanch design, qualitative: Qmantitatine, qualitathe and wired methods approxaches: (4th ed). Thousand Oaks, CA Sage.

Dreaner, N. D, \& Huehls, E. (2014). Fundraising and institutional advancenent: Theory, practice, and new paradignts. Rontledge. Emerson, R. M. (1976). Social exchnge theory. Ammual Review of Sacrology, 2(1), 335-

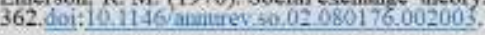

Frey, W. (2018). The millennial generation: A demographic bridge to America's diverse finure. Brookings.

Hanley Semelbaner, K. (2015), The Next Generation of Philanthropic Giving in West Michigan and Beyond. SPNHA Review, $14(1), 6$. Hummel. R. (2010). Factors influencing alumni connection aud conamitment. (Doctoral dissertation, University of Lethbridge). Available from ProQuest Dissertations and Theses database. (UMI No. MR68767. ProQuest document ID 822408775)

Keller. M.J.C. (1982) An analysis of ahumi dowor and nora-donor characteristics at the University of Montevallo (Alabamn). Doctoral dissertation, University of Alabama, Tuscaloosa, AL.

\section{References}

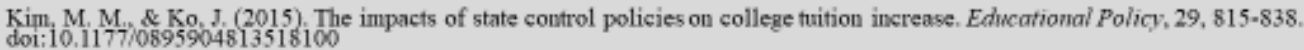

Krueger, R. A., Casey, M. A., (2015). Focus groups: A practical guide for appliedresearch. Thousand Oaks, CA. Sage Publications. Lee, J., Lim. C. \& Kim, H. (2017). Development of an instructional design model for flipped learning in higher education. Educational
Technology Research and Development, 65(2), $427-453$.

Merriam, S. B., \& Tisdell, E. J. (2015), Quahtative research: A guide to design and implementation. John Wiley \& Sons.

Monaco, M., \& Martin, M. (2007). The millennial student: A new generation of leamers. Athletic Training Education Journal, 2(2), 4246.

Monks. J. (2003, April). Patterns of giving to one's alma mater among young graduates from selective institutions, Economics of Edication Review, 22(2), 121-130.

Scott, N., \& Seglow, J. (2007), Altruism. New York, NY: Open University Press.

Snijders, I., Wijnia, L., Rikers, R. M., \& Loyens, S. M. (2019). Alumni loyalty drivers in higher education. Social Psychology of Education, 22(3), 607-627.

Stranss, W. (2005). Talling about their generations: Making sense of a school environment made up of Gen-Xers and Millenuials. School Ä̈nintstrator, 62(8), 10-14

Stranss, W. \& Howe, N. (1991), Generations: The history of America's future, 1584 to 2069. William Morrow \& Co.

Weerts, D. J. \& Ronca, J. M. (2007). Profiles of supportive almuni: Donors, volunteers, and those who "do it all," International Journal of Edicational Adiancement, $7(1), 20-34$.

Volin, J. (2016). The relationship between undergraduate student involvement and subsequent alumni engagement. 


\section{Thank You}

Robert J. Machovsky

University of Missouri-Columbia

rmachov@nwmissouri.edu 


\title{
SECTION FIVE
}

\section{CONTRIBUTION TO SCHOLARSHIP}

\section{Target Journal}

The target journal for publication is The Journal of Education Advancement \& Marketing. The journal was listed in Cabells' Directories of Publishing Opportunities and was considered a highly respected and trusted journal for the advancement and alumni engagement industry.

\section{Rationale for this Target}

The Journal of Education Advancement \& Marketing was a major professional journal publishing in-depth, peer-reviewed articles and case studies on advancement, development, alumni relations, fundraising, marketing and communications for educational institutions. Content is written by and for professionals in the field with no advertising or sales pitches.

\section{Outline for Proposed Contents}

\author{
Abstract \\ Statement of the Problem \\ Purpose of the Study \\ Research Question \\ Conceptual Framework \\ Social Exchange \\ Alumni Engagement \\ Millennial Characteristics \\ Limitations of Study \\ Delimitations of Study \\ Assumptions \\ Design Controls \\ Key Terms \\ Methods \\ Participants \\ Procedures \\ Data Analysis \\ Results \\ Discussion \\ Future Research \\ Implications for Scholarly \\ Implications for Practitioners \\ References
}




\title{
Plan for Submission
}

Who: The Journal of Education Advancement \& Marketing

When: Fall 2020

How: Website

https://www.henrystewartpublications.com/jeam

\section{Essence of Social Exchange Through Alumni Engagement of Millennials and their Alma Matters}

\begin{abstract}
This study investigated the donor and alumni engagement and perceptions of the "Millennial" generation and descriptive statistics of the population (born between 1980-2004) at a rural Midwest University. Data were obtained from a University database containing demographic (i.e., gender, race, birth year, donor status, donation amount, activities involved in while in school), on Millennial alumni at the University. Data were analyzed by a variety of techniques that included descriptive statistics, Independent $t$-Test, deployment of a survey, and focus group. The quantitative findings concluded that Millennials who were born from 1980 to 1989 contributed larger average gifts then Millennials who were born from 1990 to 2004. Additionally, the research discovered that Millennials who were involved in organizations gave larger donations than those who were not in student organizations. The qualitative findings concluded that the Millennial population provided evidence of areas and reason on why they support the institution when connected to making a donation and the various aspects that affect one's ability due to communication preferences, affinity, areas to support, and financial ability. An understanding for professionals and researchers to be educated on how to better fundraise/engage with the Millennial generations within higher education will allow for universities and colleges to rely on this generation in the years to come.
\end{abstract}

Keywords: millennial generation, donor, alumni, affinity and alumni engagement

\section{Statement of the Problem}

Each year, fundraising professionals at universities developed fundraising and engagement activities with a range of constituents who engaged with universities in the past or have yet to continue that relationship (Weerts \& Hudson, 2009). At the time of this study, there was a lack of research regarding information that determined the specific alumni engagement practices needed when considering future fundraising campaigns and segmentation criteria towards individuals born from 1980 to 2004, known henceforth as "Millennials." Definitions for 
this group included additional years within 1980 to 2004. For this study, Millennials were categorized by being born from 1980 to 2004 (Stein, 2013; Feiertag \& Berge, 2008; Howe \& Strauss, 2000; Rainer \& Rainer, 2011). With limited time and budget, institutions' alumni relations professionals needed to strategically examine who and how they were messaging to younger alumni to improve engagement activity (Drezner \& Huehls, 2014). As Millennials became the next generation of donors and volunteers at the Midwest University studied (Hanley Semelbauer, 2015), the lack of institutional knowledge in fundraising, engagement practices, personal preference with this population, and demographics needed to be evaluated.

\section{Purpose of the Study}

This study sought to fill the gap about what Millennial engagement looked like within higher education. The university studied was referred to as the "Midwest University" throughout the remainder of the study. This study provided demographic information about whom from the Millennial alumni generation from the Midwest University was giving back, and provided a blueprint about which engaged alumni the institution should have communicated and concentrated on differently in future communications pieces, such as direct mail solicitations and individual approaches like personalized fundraising asks. The significance of this study was to minimize the scholarship gap in the literature and professional practice of alumni engagement to Millennials.

Current and past donors, such as alumni, friends, parents, and students who have demonstrated financial interest in engaging with the Midwest University, were referred to as "donors" for the remainder of the study from fiscal years 2015 through 2019 from the Midwest University was the main focus of this research. The researcher examined variables, such as total giving history, age, class year, and gender. Additionally, this study identified perceptions of why 
Millennials engaged with Midwest University. The research question that guided this study was, "What does Millennial alumni engagement look like at a rural Midwest university?"

This study intended to fill the gap in knowledge and research by building a better understanding of what was needed for Millennials to stay engaged with Midwest University when looking at financial resources (Saratovsky \& Feldmann, 2013; McAlexander, Koenig \&

DuFault, 2016; McCellan, 2016). Connolly and Blanchette (1986) identified additional economic variables, such as job, age, grandchildren, and spouse's career, as other factors that influenced engagement for those born from 1980 through 2004. However, in this study, the only institutional data collected was class year, gift amount, age, gender, and selected fiscal years. Additionally, qualitative research methods were conducted to help understand the Millennial perception of why and how they chose to engage with higher education institutions.

\section{Research Questions}

Due to the necessity of higher education institutions needed to rely more on private sources of funding and higher levels of engagement among their alumni (Oliff et al., 2013), it was pertinent to understand emerging constituents. This explanatory sequential mixed-methods study sought to answer the overarching question: What does Millennial alumni engagement look like at a rural Midwest university?

Probing questions driving this study included:

1) Who are the Millennials that give at the University?

2) Why do these Millennials give to the University?

To understand the qualitative nature of the phenomenon, a survey and semi-structured focus group (see Appendix A) was used answer the overarching research question of how do 
Millennial alumni prefer to stay engaged with Midwest University. See Appendix A for additional probing questions that assisted in answering this question.

\section{Conceptual Underpinnings}

This explanatory sequential mixed-methods study was guided by the conceptual underpinnings of the social exchange perspective, alumni engagement, and Millennial characteristics. When looking at demographics that identified Millennials who chose to engage with the university in which they graduated from, one must first have understoud why alumni and friends would want to connect with the institution by making a philanthropic gift or any additional engagement possibilities. Understanding a person's social exchange needs allowed the researcher to understand why individuals chose to give back and/or engage with this school (Radcliffe, 2011; Dodge, 2016). Additionally, understanding typical alumni engagement and Millennial characteristics were imperative in guiding this study.

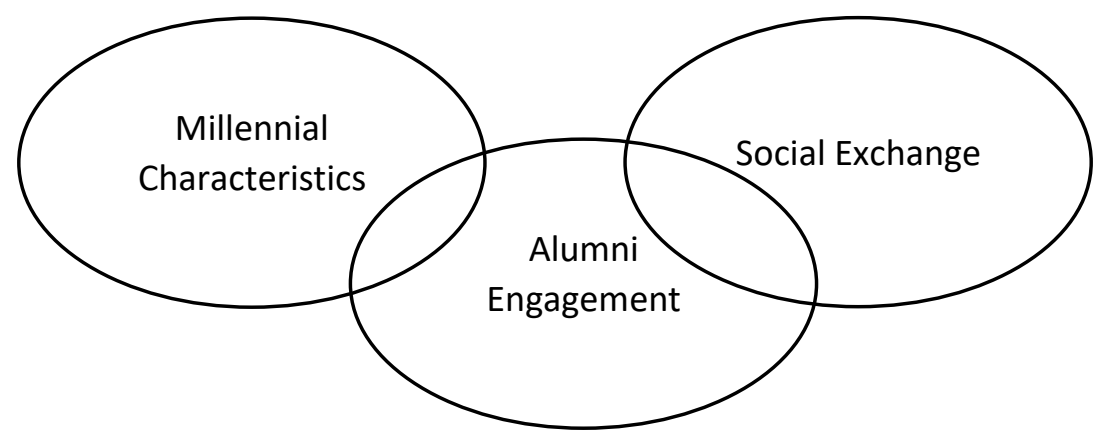

Figure 8. Conceptual Underpinnings

\section{Social Exchange}

Blau (1964) defined the social exchange theory as a concept of exchanging relationships, as a social exchange phenomenon in which the product of exchanged relationships, with each other and a social reward environment that established trust and social bonds. Additionally, this theory provided the following assumption: Individuals engaged in activities to achieve goals with 
the understanding that there was a cost for the continued relationship (Blau, 1964). Blau's (1964) development of the social exchange theory (SET) provided insight on organizational behavior and integrated a variety of frames, references, and methods that explained or debunked the phenomenon of social satisfaction and interaction (Emerson, 1976). Blau's (1964) simple definition of social exchange was "limited to action that was contingent, and mutually rewarding processes involving 'transaction' or simply 'exchange"” (Emerson, 1976, p. 336). To provide an even more simplistic lens on SET.

This study was further supported by the works of researchers, Weerts and Ronca (2007), to substantiate social exchange and its importance as a critical conceptual underpinning. In their research, Weerts and Ronca (2007) used the social exchange concept to explain why alumni stayed connected to their alma mater based on the attitudes and characteristics that people had towards their institutions. This further confirmed the reasoning of using the social exchange concept in this study and understanding why a specific population chose to engage and develop a continued relationship with an entity in which they are associated (Weerts \& Ronca, 2007).

\section{Alumni Engagement}

Many factors could have had an effect on alumni engagement and ranged from a variety of approaches and reasons (Drew-Branch, 2011). Factors, such as student engagement, alumni satisfaction, and affinity towards the institution, emerged as identifiers for more significant alumni engagement in the study. When considering alumni participation further, one study determined there was a variety of different methods that made an individual connected to his or her alma mater (Osborn et al., 2015). Another study found that alumni who received university publications and materials had a higher probability of making a gift than those who did not accept or receive similar information (Taylor \& Martin, 1995). An additional study reported that 
the most significant predictor of alumni engagement potential was institutional programming that focused on alumni activities, along with further communication aspects including a multiple alumni affinity programs, such as alumni chapters and volunteer opportunities (Harrison, 1995). Global financial stability was another area that revealed several vital findings that supported its effect on alumni engagement predictability (Davis, 2019). A survey conducted in 2008 reported that $22 \%$ of individuals over the age of 60 did not make a gift due to the downturn of the economy (Hall, 2008). This $22 \%$ represented a large population of the Baby Boomers who were hit the hardest with decreases to retirement and investment portfolios (Hall, 2008). Specifically, this study identified three areas: (a) donor engagement, (b) global financial stability, and (c) alumni loyalty.

\section{Millennial Characteristics}

Understanding the Millennial population by looking at the characteristics most exhibited was essential when considering this generation (Oblinger, 2003; Purani, Kumar, \& Sahadev, 2019). A wealth of information existed regarding this population and its characteristics. The work of Farrel and Hurt (2014) provided a variety of features that accounted for this population, such as multi-tasking abilities, poor communication skills, and the requisite of technology (Feirtag \& Berge, 2008). Additional characteristics, such as generous, optimistic, structured, and collaborative, were cited by the works of Elam, Stratton and Gibson (2007). Looking at the literature available on this population allowed additional framework about connecting with this population from a philanthropic stand-point. 


\section{Limitations of Study}

Limitations for the study included the fact that the data only analyzed the past three years of Millennials' donations at Midwest University within the uncontrolled group of participants at the time of this study. Additionally, the data was not always revealing the correct primary donor, as many alumni, friends, and spouses made gifts on alumni's behalf, which resulted in the donor credit being assigned to the spouse and not to the actual alumnus, which often led to inaccurate donor coding with males getting the gift credit over females. Another limitation was the data was only extracted from one university, which limited the ability to find national trends.

\section{Delimitations of Study}

There was a delimitation associated with the study which was, this study only examined one school, the Midwest University. The economy and financial health of the country impacted the data during the past three years. Additionally, this study took place during the COVID-19 pandemics, which could have altered participants responses while taking the surveys and participating in the focus group sessions. An additional factor that could have had an impact on giving results was that the national trend consisted of the majority of higher-end donors who were over the age of 65 and represented 17\% of all donors below age 50 (Sargeant \& McKenzie, 1999). These individuals were the highest age group within the last recession and could have affected financial contributions during 2017, 2018, and 2019 fiscal years (Sargeant \& McKenzie, 1999).

\section{Assumptions}

Findings from this research would be beneficial to practitioners at the participating institutions along with providing insight and knowledge to higher education fundraising alumni engagement progression. Staff would benefit from knowing the breakdown between genders and 
about how their donor bases were represented. Knowing donor demographics would allow for the strategic approaches to be the benchmark against peer institutions, along with providing a matrix that established accountability for performance and best practice. Fundraising professionals, especially annual giving staff, needed to review marketing and segmenting strategies moving forward. Targeted segmenting strategies with age, graduation year, last gift amount, and gender would provide more reliable and higher yields when reviewing performance and return on investment.

Finally, practitioners at the participating institution should have considered expanding this research by identifying other donor parameters, such as academic major, involvement, donor wealth capacity, and occupation. When reviewing additional information, practitioners would make a better estimate on proper dollar amounts to be solicited from potential donors, along with a metric for finding and reviewing potential donors.

\section{Design Controls}

The researcher implemented design controls to keep the focus of research and result in a narrow focus (Creswell, 2014). This was done by only looking at a sample set of Millennial data that encompassed the following demographics: (a) gender, (b) giving amount, (c) fiscal year, (d) activities, (e) email address, (f) type of degree, (g) race, and (h) age.

\section{Definition of Key Terms}

For clarification and educational purposes, terms used in this study have been defined. The following terms were:

Fiscal Year (FY). Fiscal year operated from July 1 to June 30 and was a year as reckoned for taxing or accounting purposes (Midwest University, 2020). 
Current Donor. Anyone who made a gift within the fiscal year (Midwest Foundation, 2020).

Past Donor. Anyone who had made a gift in previous fiscal years but not the current fiscal year (Midwest Foundation, 2020).

Segments. Organization of constituent records for solicitation using a variety of fundraising approaches (Midwest University, 2020).

Designation. In a selected area, the donations were directed for a specific project (Midwest University, 2020).

Annual Fund. A division within the institutional advancement department that organized all annual solicitation appeals to restricted and unrestricted designations.

Institutional Advancement. A division within a university that directed and coordinated all fundraising efforts (Midwest University, 2020).

Alumni. A graduate or former student of a specific school, college, or university (Dictionary.com, 2020).

Friends. Anyone who donated to the university and were not alumni (Midwest University, 2020).

Average Gift. To calculate the average gift amount, two numbers were needed: (a) total donation revenue and (b) total gifts received. Divide donation revenue (x) by the number of gifts (y), and average gift was generated (Fundraising Report Card, 2016).

Affinity. Liking to a specific group or university representation (Merriam-Webster, n.d.). Alumni Engagement. The level of attraction, connection, affection, and influence an alumnus had with their alma mater over time (Toyn, 2020).

Millennials. Individuals born from 1980 to 2004 (Howe \& Strauss, 2012). 


\section{Methods}

This explanatory sequential mixed-methods study explored the demographics of Millennials who chose to engage with the alumni program at a moderately selective rural Midwest university and understood the phenomenon of Millennial giving. The mixed-methods study design combined quantitative and qualitative data within the study that allowed the researcher to understand the aspects under review (Creswell, 2014). The researcher relied on both numerical data (Charles \& Mertler, 2002), and "an inquiry process of understanding the meaning of individuals or groups" (Creswell, 2014, p. 4). The researcher collected the data in phases, which allowed him to continually reflect and to sort comments into themes and categories known as the constant comparative method (Kruger \& Casey, 2015; Merriam \& Tisdell, 2015). This gave the researcher the opportunity to consider changes in the data to increase the quality of the data being collected (Krueger \& Casey, 2015). Figure 2 provided the order of phases the mixed-methods study evaluated during the collection and study of data.

Midwest University was a rural public university located in a city of less than 15,000 residents (Midwest University, 2020). Due to its rural location, students came from a variety of backgrounds that included rural, city, and urban environments during their high school years (Midwest University, 2020). Midwest University was approximately 100 miles from a large metropolitan city center with a population of more than one million. Midwest had an enrollment of approximately 7,000 students that consisted of a traditional student body with a large concentration of Caucasian students at more 88\% (Midwest University, 2020). The 12\% of minority student population ethnicities included Black, Asian, and Hispanic as the recognized primary minority groups (Midwest University, Student demographic sec.). Additionally, the average class size at Midwest University was 27, the student-to-faculty ratio was 22-to-1, and 
laptops and textbooks were included in the tuition (Midwest University, 2020, facts sec.). From an alumni perspective, Midwest University reported more than 70,000 alumni and friends, and an endowment of $\$ 25.6$ million that provided more than $\$ 900,000$ in scholarships, as published in 2018 on the Midwest University facts website. Midwest University's Foundation reported more than 5,600 donors in 2018 (Midwest University, 2020, Midwest Facts, Facts sec.).

Midwest University prided itself on "student success - every student, every day" (Midwest University, Mission sec., para. 1). Additionally, it identified student retention as one of the main areas of focus due to a decline in enrollment over the past few years (Midwest University, 2018). University programs and services, such as the Student Success Center, were

charged in assisting students with their needs to help keep retention strong at Midwest University and the graduation rate above peer institutions (Midwest University, 2018, Facts sec.).

Midwest University was associated with a separate nonprofit organization that worked through the vice president of external relations and the executive director of the Midwest Foundation. The Foundation did not report to the Board of Regents, university president, or the vice president of external relations and executive director of the Midwest Foundation (Midwest University, 2020). Instead, the Foundation was comprised of a group of alumni and friends of the University and served as Board of Directors and governed itself. The Foundation was again a separate entity from the University but operated in the benefit of the University by raising private dollars for various university initiatives and projects.

\section{Participants}

The participants for this study were graduates of Midwest University who were born from 1980-2004 and known as the Millennial Generation. A random sampling approach was utilized to shorten the list of alumni reviewed in the study and allowed the researcher to establish 
a controlled setting "so that the true influence of the independent variable on the dependent can be determined" (Creswell, 2014, p. 53). The list of participants was pulled from a database known as Raiser's Edge, a constituent management software used within the Midwest University Advancement division that stored and tracked records. Names were removed from the list and replaced with a unique numeric identifier and then randomly selected to be included in the study (Creswell, 2014). The data information consisted of: (a) gender, (b) giving amount, (C) fiscal year, (d) activities, (e) email address, (f) type of degree, (g) race, and (h) age. Additionally, the participants donated to the intended institution within the fiscal years of (FY19, FY18, FY17, FY16, and FY15) and engaged with the university by taking advantage of one or more of its many volunteer opportunities.

\section{Data Collection Tools}

After the Institutional Review Board (IRB) was approved, the researchers requested the data and accessed the information in an archival manner by extracting the information in an Excel file format with the following headers: (a) gender, (b) giving amount, (c) fiscal year, (d) activities, (e) email address, (f) type of degree, (g) race, and (h) age. To protect the participants and to allow for complete anonymity, the researcher coded each participant with a unique individual number that was not aligned or distinguishable to personal records or any identifiable information that would determine the participants' identities (Creswell, 2014). This anonymity protected the participants from political repercussions on important ethical pieces of research, as denoted by Seidman. Additionally, the researcher stored data on a password protected server that was locked in an office when the researcher was not present.

Additionally, the researcher organized and distributed a survey that randomly selected Millennials from the Midwest University pool of available participants by email, dispersing 
through the Midwest University email system. In selection of participants and design, the researcher followed design and measurement validity to insure the selection and distribution of the survey adhered to a trustworthiness of followed protocols (Fink, 2017). The study was used to obtain or to secure a series of engagement questions with the university (see Appendix A). The survey was conducted through Qualtrics, a recognized and trusted vendor in survey production and deployment (Molnar, 2019). For triangulation, a semi-structured focus group also was organized and conducted during the data collection process to collect deeper and richer data (Kruger \& Casey, 2015). Participants in the focus group were randomly selected by odd numbers in the original data set of alumni Millennials from Midwest University. Additionally, the focus group consisted of four participants (Kruger \& Casey, 2015) being asked a series of questions; (see Appendix B for participant consent form structure and questions of the focus group.)

\section{Data Analysis}

To answer the research questions, the researcher conducted the following analysis of the data that was compiled from both methodologies of quantitative and qualitative study approaches by using what the Explanatory Sequential Mixed-Methods approach (Creswell, 2014). From this approach, the researcher conducted quantitative research first and analyzed the results. Creswell (2014) affirmed that a mixed-methods approach allowed for the investigation to combine or to integrate the research collected from qualitative and quantitative study approaches to build a deeper and richer understanding of the subject being reviewed. To answer the overarching research question, the researcher compiled descriptive statistics that provided a summary on the following demographics: (a) gender, (b) giving amount, (c) graduation year, (d) activities, (e) email address, (f) types of degree, (g) race, and (h) age. 
The researcher then conducted the qualitative portion of the study to build on the findings and results uncovered from the quantitative collection (Creswell, 2014). The dependent variables for this were: (a) gender, (b) giving amount, (c) activities, (d) email address, (e) types of degree, (f) race, and (g) age, and the independent variable was: (a) graduation year. Finally, the researcher used Microsoft Excel to randomly select participants who were used in the descriptive statistics and Independent Samples $t$-Test analysis portion of the study.

Additionally, a survey was conducted to help determine why Millennial-born alumni form Midwest University preferred to stay engaged with the university. The survey taken by Midwest University Millennial alumni consisted of a series of open and closed questions along with the inclusion of questions that the respondent answered by using a Likert Scale (see Appendix B). In the data analysis part of research, the researcher created themes or categories from the survey and focus group data, along with using an Axial coding method, that allowed for themes and coding structures to be constructed and used for implementation (Merriam \& Tisdell, 2015). This approach would also meet the needs and standards to be reviewed in an organized qualitative study. Additionally, this led to an open coding practice that allowed the researcher to categorize words and themes (Merriam \& Tisdell, 2015; Picardi \& Masick, 2013).

\section{Results}

The purpose of this study was to investigate the demographics and perceptions of Millennials who were donors and their preferences when it came to engaging with their University. The qualitative portion of the study consisted of statistical test that included the following: (a) descriptive summary statistics, (b) $t$-Test, and (c) Anova. Each of these test allowed for the researcher to answer the overarching research question and propping research questions. 


\section{Quantitative Findings}

Of the sample $(n=72,672)$ the gender breakdown was 31,992 males and 40,644 females.

Table 3 shows the gender breakdown of the Millennial population at Midwest University. Table 1 show the breakdown of Millennial male and female participants in the study.

Table 1

Alumni Gender

\begin{tabular}{cll}
\hline Gender & Frequency & Percent of Total \\
\hline Female & 40644 & 55.9 \\
Male & 31992 & 44 \\
Unknown & 28 & 0 \\
\hline Total & 72672 & 100 \\
\hline
\end{tabular}

When looking at ethnicity the breakdown included: 284 alumni who identified as American Indian/Alaska Native, 1,488 alumni identified as Asian, 1,964 alumni identified as Black, Non-Hispanic, 352 alumni identified as Hispanic, 244 alumni identified as Multi-race, 36 alumni identified as Native Hawaiian or Pacific Islander, 1488 alumni identified as Non Resident Alien, 572 alumni identified as Unknown, and 55.064 alumni identified as White, Non-Hispanic.

Table 2 show the breakdown of the Millennial population by ethnicity.

Table 2

Alumni Ethnicity

\begin{tabular}{lll}
\hline Ethnicity & Frequency & Percent of Total \\
\hline American Indian/Alaska Nat. 284 & 0.46 \\
Asian & 1488 & 2.42 \\
Black, Non-Hispanic & 1964 & 3.19 \\
Hispanic & 352 & 0.57 \\
Multi-race & 244 & 0.40 \\
Native Hawaiian or Pac. Isl. & 36 & 0.06 \\
Non Resident Alien & 1488 & 2.42 \\
Unknown & 572 & 0.93 \\
White, Non-Hispanic & 55064 & 89.55 \\
\hline
\end{tabular}


Two separate groups of birth years were analyzed of the Millennial population. The first group of birth years was individuals born from 1980-1989. This group represented 39,568 of the population analyzed or $54.45 \%$. The second group of birth years was individuals born from 1990-2004. This group represented 33,104 of the population analyzed or $45.55 \%$. Table 3 show the breakdown between the Millennial population born from 1980 - 1989 and 1990 - 2004 at Midwest Univeristy.

Table 3

Alumni as Early or Late Millennials

\begin{tabular}{cll}
\hline Millennial Status & Frequency & Percent of Total \\
\hline Born from 1980-1989 & 39568 & 54.45 \\
Born from 1990-2004 & 33104 & 45.55 \\
\hline
\end{tabular}

The different in alumni degrees was also analyzed among the Millennial population. The alumni degree holders were separated by those who had undergraduate degrees from those who had graduate degree. When analyzing the undergraduate degree alumni holders consisted of 58,956 or $81.3 \%$ of the population. While graduate degree alumni holders consisted of 13,572 or $18.7 \%$ of the population. Table 4 show the breakdown of type of degree among Millennial's at Midwest University.

Table 4

Alumni Degree Codes

\begin{tabular}{cll}
\hline Codes & Frequency & Percent of Total \\
\hline Undergraduate Degree & 58956 & 81.3 \\
Graduate Degree & 13572 & 18.7 \\
Total & 72528 & 100 \\
\hline
\end{tabular}

The data reviewed consisted alumni information from the following fiscal years: FY16, FY17, FY18, and FY19. Each year had the following breakdown for records analyzed. The 
FY16 had 18,168 or $25 \%$ of the population, FY17 has 18,168 or $25 \%$ of the population, FY18 had 18,168 or $25 \%$ of the population, and FY19 has 18,168 , or 25 percent of the population. Table 5 show the breakdown of Millennial individuals records in the fiscal years of 16, 17, 18 and 19.

Table 5

Alumni Millennial Data by Fiscal Year

\begin{tabular}{cll}
\hline Fiscal Year & Frequency & Percent of Total \\
\hline FY16 & 18168 & 25 \\
FY17 & 18168 & 25 \\
FY18 & 18168 & 25 \\
FY19 & 18168 & 25 \\
Total & 72672 & 100 \\
\hline
\end{tabular}

The following statistical analysist test included the following: descriptive summary statics and independent sample $t$-Test to help answer the overarching researching question and additional probing questions. Proving demographic information of the population study provided the research to make available the following descriptive summary and $t$-Test statistics of: (a) frequency, (b) percentage, (c) cumulative percentage, (d) mean, (e) standard deviation (SD), (f) standard error of the mean (SE), (g) t-score (T), (h) degree of freedom (df), and (i) significance (Sig).

When looking at Millennial donors from a demographic perspective. 71,531 , or $98.4 \%$ were not considered donors as they had not ever made a gift to the University during the time spam of FY16-FY19. However, 1,141 individuals in this study had made a donation representing $1.5 \%$ of the population. Table 6 show the breakdown of Millennials who gave versus those that did not give from the data reviewed for the study. 
Table 6

Millennial Alumni Who Gave

\begin{tabular}{cll}
\hline Gave Anything & Frequency & Percent of Total \\
\hline No Give & 71531 & 98.43 \\
Gave & 1141 & 1.57 \\
\hline
\end{tabular}

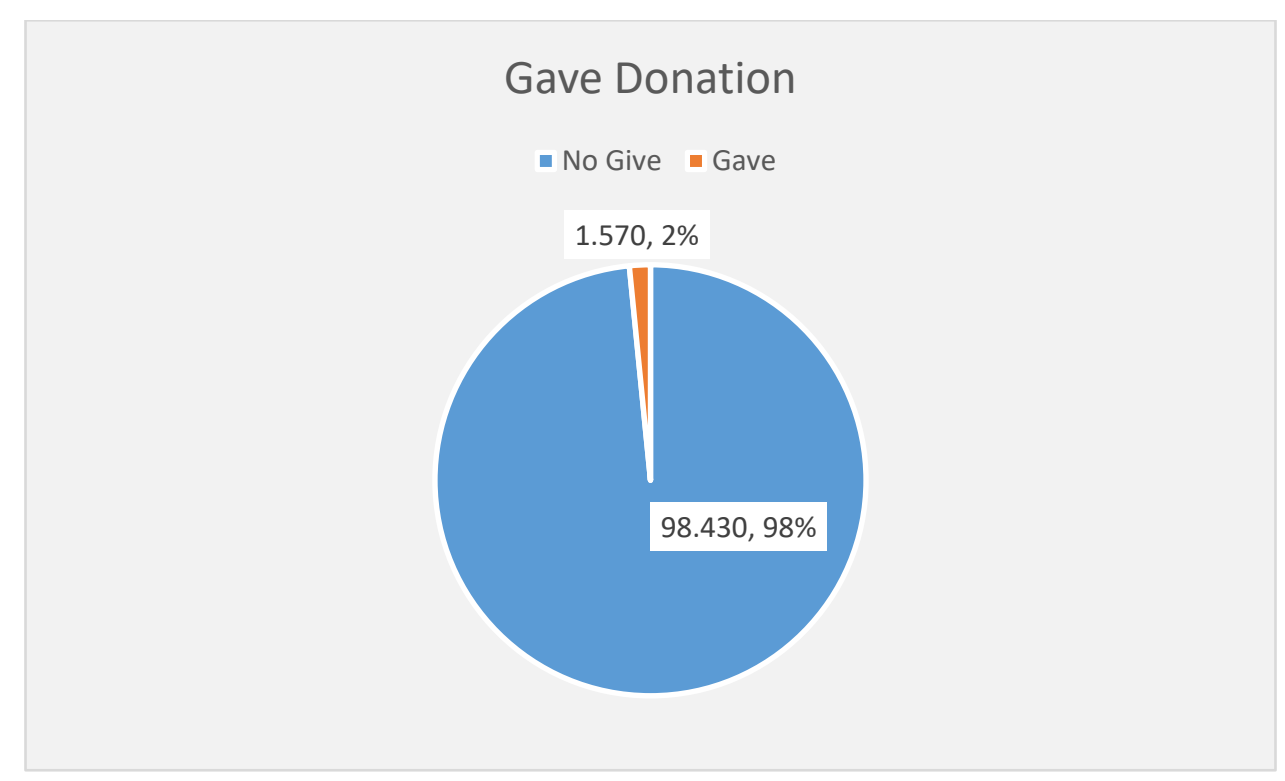

Figure 9. Breakdown of Millennial alumni who gave versus those that did not give from the data reviewed for the study.

To further breakdown the 1,141 donors, the researcher analyzed the type of areas the donor Millennial population was giving too. The following are the designation themes donors were giving too: scholarships had 135 donors representing $11.8 \%$ of the donors, athletics had 261 donors representing $22.9 \%$ of the donors, unrestricted designations had 536 donors representing $47 \%$ of donors, academics had 56 donors representing $4.9 \%$ of the donor base, and other had 153 donors representing $13.4 \%$. The other designation category included designations of student 
organizations and areas that donors participated in as a student. Table 7 show the breakdown of Millennial donor gift by area.

Table 7

Donor Gift Area Breakdown

\begin{tabular}{lcc}
\hline Designation Area & Frequency & Percent of Total \\
\hline Scholarships & 135 & 11.8 \\
Athletics & 261 & 22.9 \\
Unrestricted & 536 & 47 \\
Academics & 56 & 4.9 \\
Other & 153 & 13.4 \\
\hline Total & 1141 & 100 \\
\hline
\end{tabular}

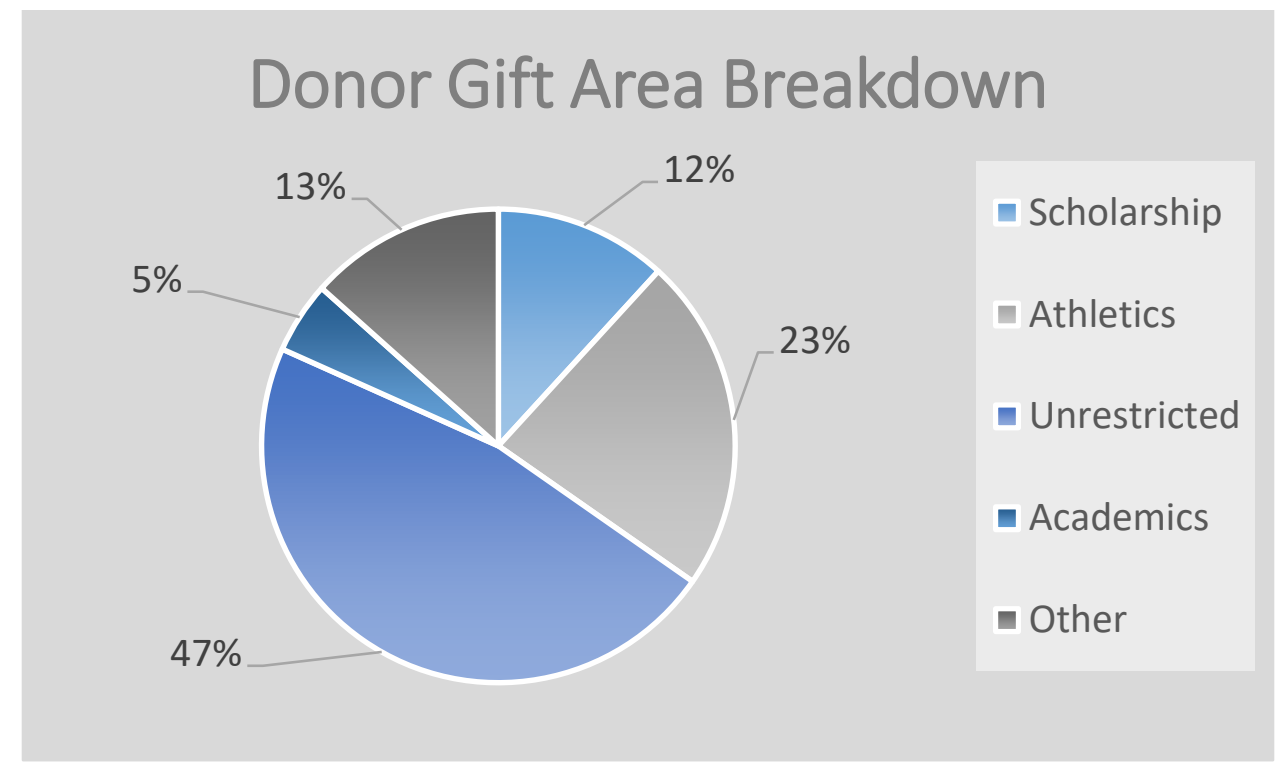

Figure 10. Breakdown of Millennial donor gift by area.

A paired samples $t$-test was conducted for the two groups of birth years of donors subtest. The test compared average donation among the two groups and found on average: individuals born from 1990 to 2004 gave a lower average gift $(M=\$ 90.19, S E=\$ 10.00)$ than did individuals born from 1980 to $1989(M=\$ 170.08, S E=\$ 14.51)$. Also, $t(1137)=4.53, p<.05$ resulted in a statistical significant difference among average donations when comparing the two birth year groups. These results suggested individuals born from 1980 to 1989 had the potential to 
contribute at higher averages than those alumni born from 1990 to 2004 . Table 8 show the average gift difference between Millennial's born from 1980 - 1989 and 1990 - 2004.

Table 8

Independent Samples t-Test - Largest Gift by Early or Late Millennial Status, Donors Only

\begin{tabular}{|c|c|c|c|c|c|c|c|}
\hline Millennial Status & $n$ & Mean & $\mathrm{SD}$ & $\mathrm{SE}$ & $\mathrm{T}$ & $\mathrm{df}$ & Sig. \\
\hline Born in 1980-1989 & & 793 & $\$ 170.08$ & $\$ 408.69$ & $\$ 14.51$ & & \\
\hline Born in 1990-2004 & & 348 & $\$ 90.19$ & $\$ 186.49$ & $\$ 10.00$ & & \\
\hline Paired & & $\$ 79.89$ & & $\$ 17$ & 24.53 & 1137 & $.000 * * *$ \\
\hline
\end{tabular}

Note: $* * * \mathrm{p}<.001$

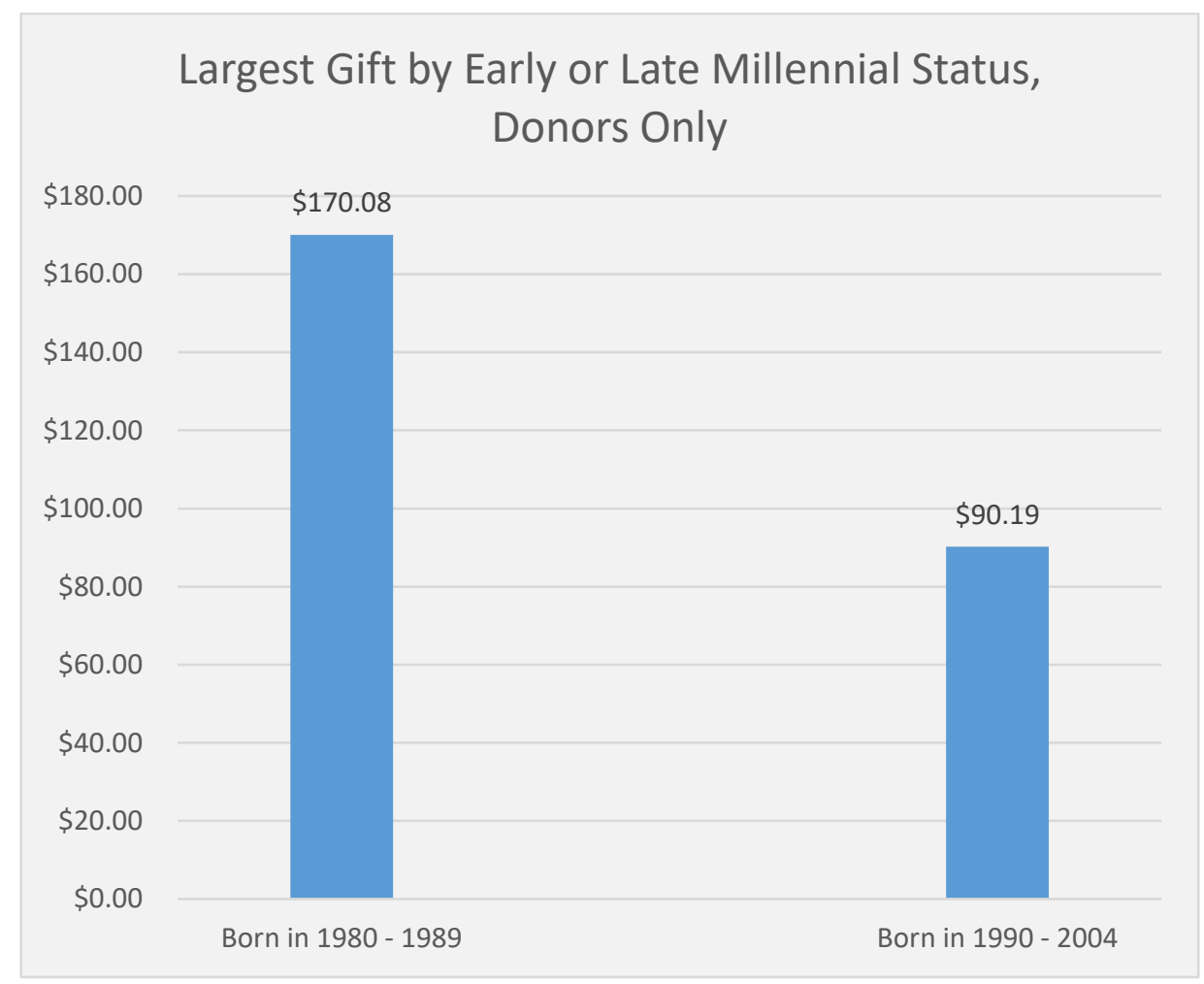

Figure 11. Average gift different between Millennial's born from 1980-1989 and 1990-2004.

A paired samples $t$-test was conducted for donors who were organizations versus those donors who were not in organizations. The test compared average donation among the two groups and found, on average, individuals who gave and were not in student organizations while in college had a lower average gift $(M=\$ 141.70, S E=\$ 13.44)$ than did donors who were in 
organizations as student $(M=\$ 150.50, S E=\$ 16.81), t(1139)=0.414, p>.05$ resulting in not a statistical significant difference among average donations when comparing the two groups. Although, not significant, these results suggested individuals who were in organizations as students donated larger gifts than those who were not in student organizations. Table 9. Show difference in average gift among donors who were in an organization versus donors who were not in an organization as student.

Table 9

Independent Samples t-Test - Largest Gift by Org. Participation, Donors Only

\begin{tabular}{clllllll}
\hline Participated in Org & $n$ & Mean & SD & SE & T & df & Sig. \\
\hline Org & 520 & $\$ 150.50$ & $\$ 383.40$ & $\$ 16.81$ & & \\
No Org & 621 & $\$ 141.70$ & $\$ 335.01$ & $\$ 13.44$ & & \\
Paired & & $\$ 8.80$ & & $\$ 21.27$ & 0.414 & 1139 & 0.679 \\
\hline
\end{tabular}

Note: Not statistically significant.

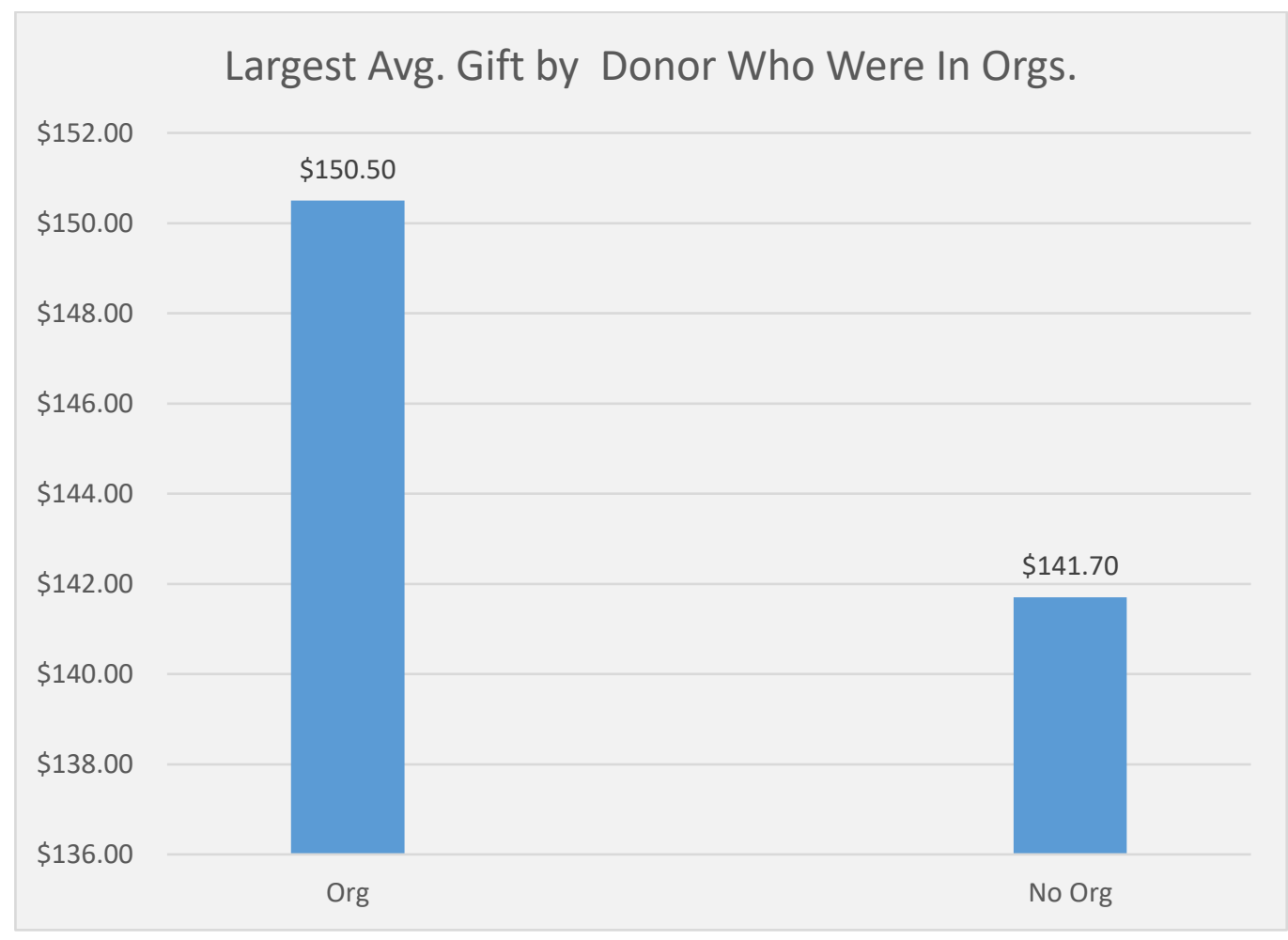


Figure 12. Difference in average gift among donors who were in an organization versus donors who were not in an organization as student.

A descriptive statistic analysist was conducted to determine what the average gift was among those who were not in organizations and those who were in one or more student organizations. The results found the average mean for "give size" by number of student organizations. Results were as follows: 0 organization had a mean average gift of $\$ 1.89$, one organization had a mean average gift of $\$ 6.60$, two organizations had a mean average gift of $\$ 3.18$, three organizations had a mean average gift of $\$ 7.33$, and four organizations had a mean average gift of $\$ 86.36$. These results suggested that the more organizations in which alumni participated, the potential for the amount of their gifts were larger than other donors. Table 10 show the difference among all Millennials in the study and average gift based on number of organizations involved in.

Table 10

Mean Largest Gift by Number of Organizations Participated

\begin{tabular}{ccc}
\hline Number of Organizations & Frequency & Mean Largest Gift \\
\hline 0 & 66644 & $\$ 1.89$ \\
1 & 4260 & $\$ 6.60$ \\
2 & 1033 & $\$ 3.18$ \\
3 & 675 & $\$ 7.33$ \\
4 & 44 & $\$ 86.36$ \\
\hline
\end{tabular}




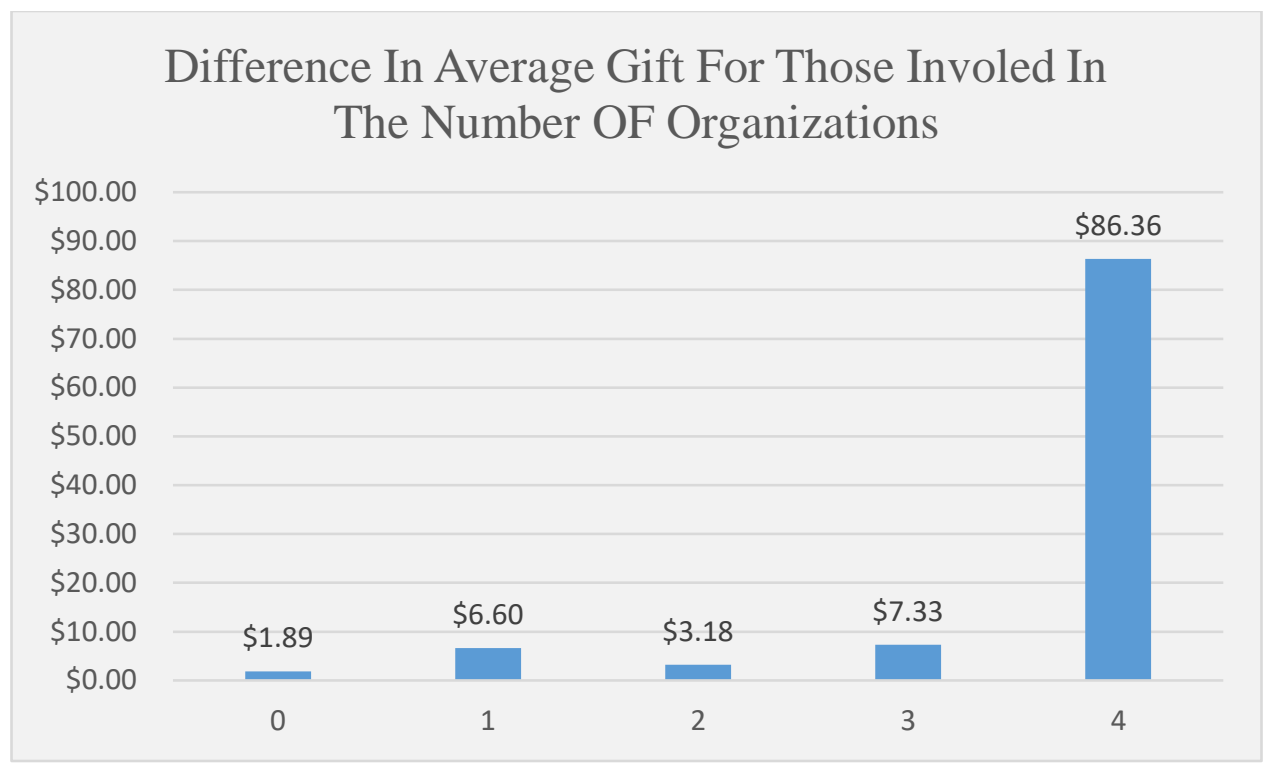

Figure 13. Difference among all Millennials in the study and average gift based on number of organizations involved in.

A paired samples $t$-test was conducted for the two groups of degree types who were donors subtest. The test compared average donations among the two groups and found, on average, individuals with graduate degrees gave lower average gifts $(M=\$ 107.81, S E=\$ 11.64)$ than did individuals with undergraduate degrees $(M=\$ 157.04, S E=\$ 13.58), t(1025)=2.752$, $p<.05$ resulting in a statistical significant difference among average donations when comparing the two degree types. These results suggested that individuals who had an undergraduate degrees had the potential to give a higher average give than those with graduate degrees. Table 11 show the different in average gift among donors based on degree type.

Table 11

Independent Samples t-Test - Largest Gift by Degree Code, Donors Only

\begin{tabular}{clllllll}
\hline Degree Code & $n$ & Mean & SD & SE & T & df & Sig. \\
\hline UG & 819 & $\$ 157.04$ & $\$ 388.76$ & $\$ 13.58$ & & \\
Grad & 316 & $\$ 107.81$ & $\$ 206.95$ & $\$ 11.64$ & & \\
Paired & & $\$ 49.23$ & & $\$ 17.892 .752$ & 1025 & $0.006 * *$ \\
\hline
\end{tabular}

Note: $* * \mathrm{p}<.01$ 


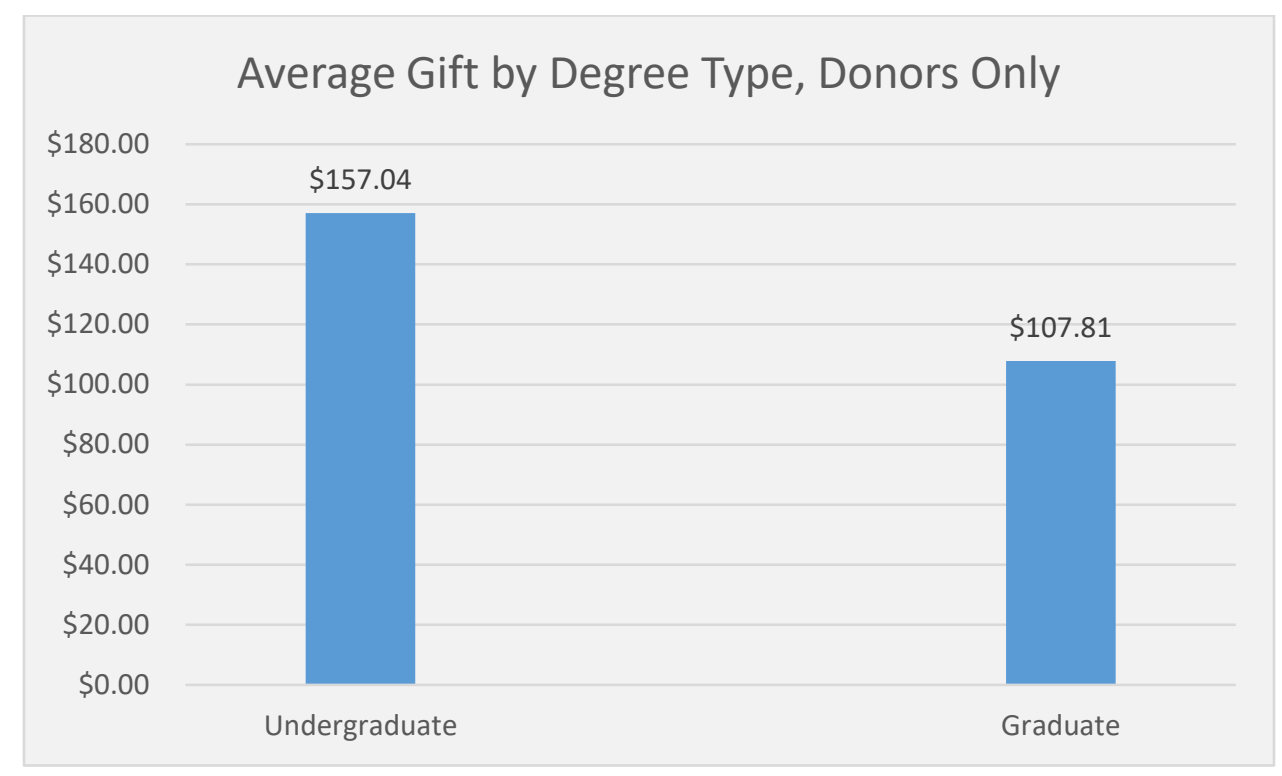

Figure 14. Different in average gift among donors based on degree type.

A paired samples $t$-test was conducted for gender of donors subtest. The test compared average donation among the two groups and found, on average, females gave a lower average $\operatorname{gift}(M=\$ 111.76, S E=\$ 11.88)$ than did males $(M=\$ 180.32, S E=\$ 17.52), t(995)=-3.239, p<.05$, resulting in a statistical significant difference among average donations when comparing the two genders. These results suggested that males had the potential to give higher averages give than females. Table 12 show the average gift difference among male and female Millennial's in the study.

Table 12

Independent Samples t-Test - Largest Gift by Gender, Donors Only

\begin{tabular}{clllllll}
\hline Gender & $n$ & Mean & SD & SE & T & df & Sig. \\
\hline Female & 576 & $\$ 111.76$ & $\$ 285.09$ & $\$ 11.88$ & & \\
Male & 565 & $\$ 180.32$ & $\$ 416.47$ & $\$ 17.52$ & & \\
Paired & & $\$ 68.55$ & & $\$ 0.38$ & -3.239 & 995 & $0.001 * * *$ \\
\hline
\end{tabular}

Note: $* * * \mathrm{p}<.001$ 


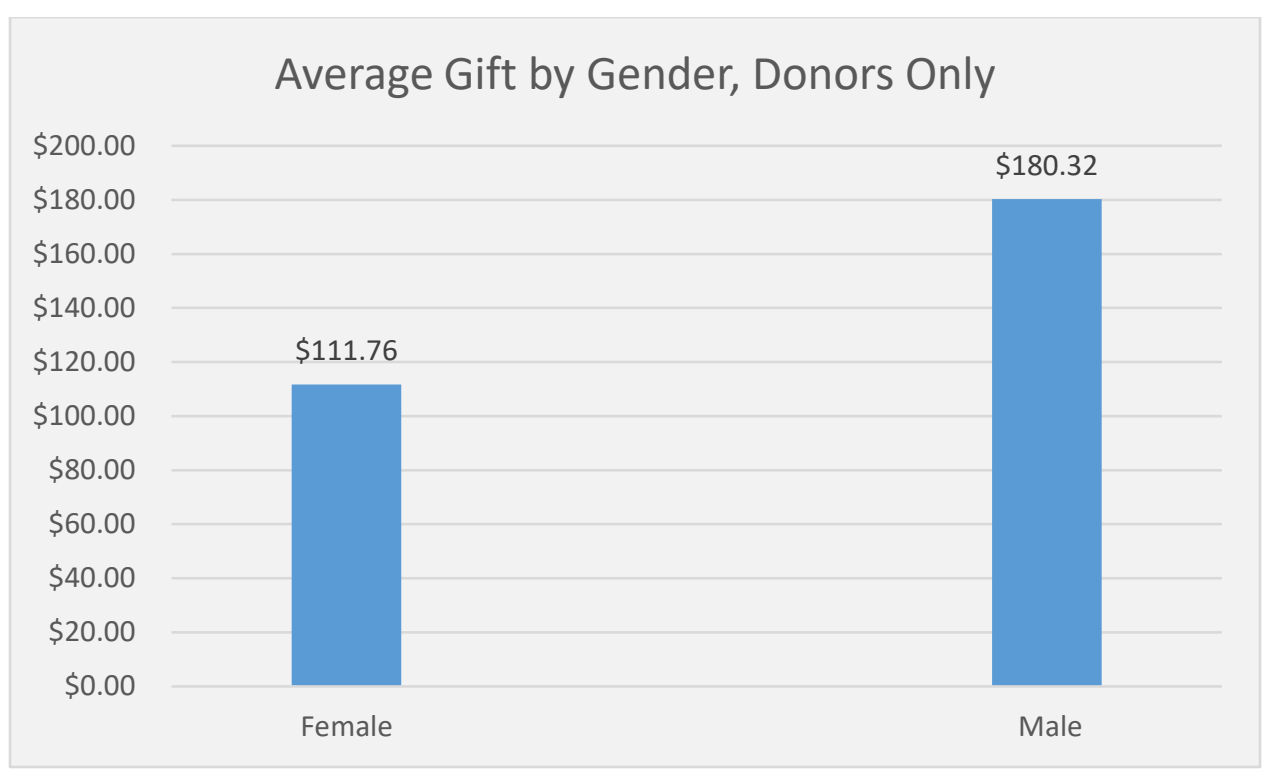

Figure 15. Average gift difference among male and female Millennial's in the study.

A paired samples $t$-test was conducted for donors who were in athletics against donors who were not in athletics while a student subtest. The test compared average donation among the two groups and found, on average, those who were not athletes as students gave lower average gifts $(M=\$ 128.79, S E=\$ 10.34)$ than did donors who were athletes as students $(M=\$ 247.96$, $S E=\$ 39.90), t(183)=-2.891, p<.05$ resulting in a statistical significant difference among average donations when comparing non athlete again an athlete donor. These results suggested that donors who were athletes as students had the potential to give at higher averages gift than those who were not athletes as students. Table 13 show the average gift of donors who were in athletics versus donors who were not in athletics.

Table 13

Independent Samples t-Test - Largest Gift by Athletic Org. Participation, Donors Only

\begin{tabular}{clllllll}
\hline Gender & $n$ & Mean & SD & SE & T & df & Sig. \\
\hline No Org & 979 & $\$ 128.79$ & $\$ 323.58$ & $\$ 10.34$ & & \\
Org & 162 & $\$ 247.96$ & $\$ 507.83$ & $\$ 39.90$ & & \\
Paired & & $\$ 119.17$ & & $\$ 41.22-2.891$ & 183 & $0.004^{* *}$ \\
\hline
\end{tabular}

Note: $* * \mathrm{p}<.01$ 


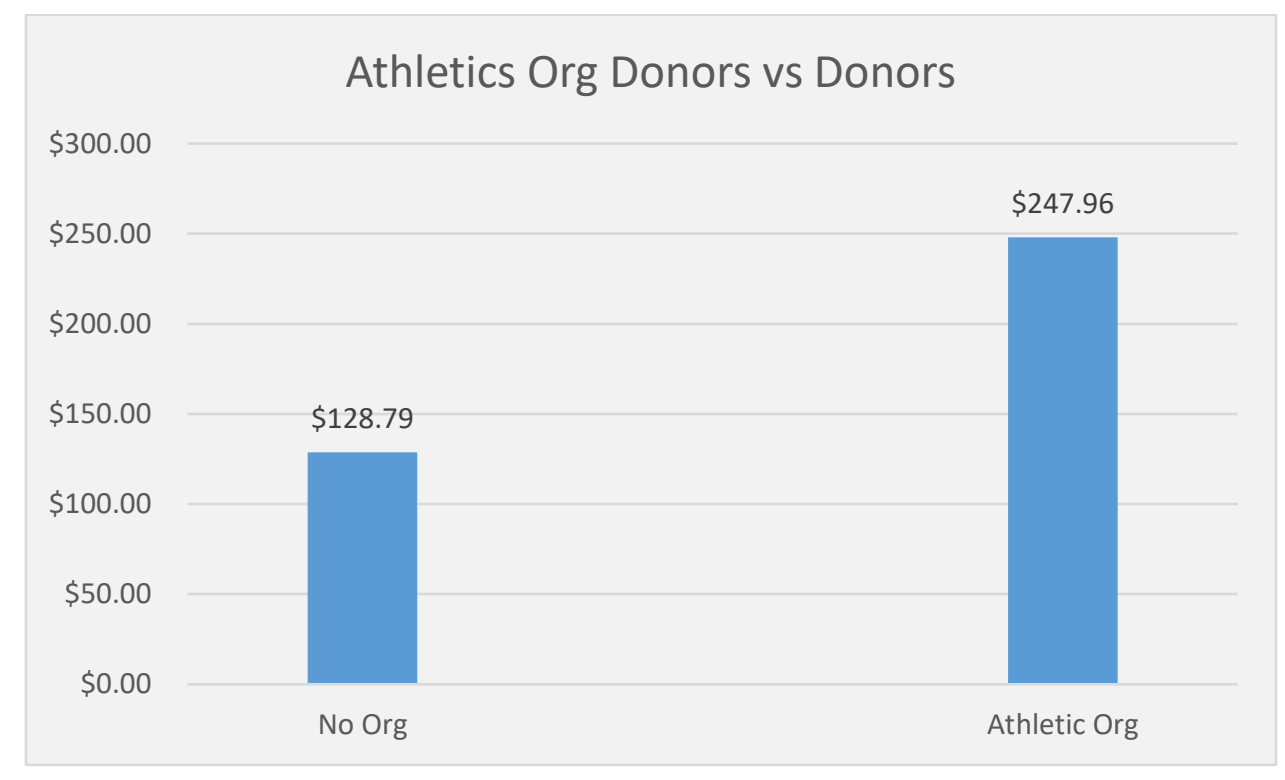

Figure 16. Average gift of donors who were in athletics versus donors who were not in athletics.

\section{Qualitative Findings}

The purpose of this study was to investigate the demographics and perceptions of Millennials who were donors and their preferences when it came to engaging with their University. The qualitative portion of the study consisted of one focus group that included four individuals, one female and four males. Additionally this portion of the study conducted a survey that had 129 responses from a pool of randomly selected potential participants. Analysis and coding of themes were initiated from both the survey and focus group and the following themes emerged: (a) communication, (b) affinity, (c) type of events, (d) giving interest, (e) no giving interest, (f) and why not engaged. Table 1 provided themed categories that were uncovered during the analysis procedure. 
Table 14

Themes About Communication, Affinity, Type of Events, Giving Interest, No Giving Interest and Why Not Engaged

\begin{tabular}{|c|c|c|}
\hline Theme & Frequency & Categories \\
\hline Communication & 200 & $\begin{array}{l}\text { Social Media preference } \\
\text { Email preference } \\
\text { Alumni Magazine preference }\end{array}$ \\
\hline By Affinity & 30 & $\begin{array}{l}\text { University Brand } \\
\text { Athletics } \\
\text { Family Culture }\end{array}$ \\
\hline Type of Events & 210 & $\begin{array}{l}\text { Family Friendly } \\
\text { Academics } \\
\text { Athletics } \\
\text { Alumni Socials } \\
\text { Networking }\end{array}$ \\
\hline Giving Interest & 140 & $\begin{array}{l}\text { Academics } \\
\text { Scholarships }\end{array}$ \\
\hline Engagement Rationale & 33 & $\begin{array}{l}\text { Paying off student loans } \\
\text { Family/Other } \\
\text { Distance } \\
\text { f knowledge }\end{array}$ \\
\hline
\end{tabular}

\section{Communication}

The communication theme was an area the researcher was interested in learning more about from the participants from the survey and focus group. Communication preferences provided by the research participants gave the research several common themed preferences that emerged. These themed communication preferences included, social media, email and the alumni 
magazine. Participants reported a variety of feedback and comments that provide evidence to the themes collected. One participant shared the following:

I like the presence the Alumni Association has on social media and through the print magazine. This is how I stay most aware of what is going on and where I experience the most visibility of the association. Everything communicated digitally and in print is engaging, looks professional, and makes me proud to be a Northwest Alumni.

Additionally, several participants talked about the importance to social media and alumni magazine to help keep them informed with the University. One participant explained that they would not want a digital version of the alumni magazine as they enjoy having something physical to have while reading the stories Another research participant said, . Alumni Magazine was another communication preference that emerged from participants responses. One individual shared that magazine is still their preference in receiving communication by saying "Yeah. I agree. I think, with the magazine, or even anything, it's just kind of updates on certain things that you definitely want people to see." Social media was a common preference among participants however one individuals indicated that it would be nice to have a platform for alumni to connect with each other that the Alumni Association would manage by saying,

"Great to stay connected, but would be cool if there was a platform for groups of every 5 or 10 years can post updates, gatherings for alumni of a particular age to connect, and more (2000-2004, 2005-2008, etc.). Enjoy seeing all alumni, but it's easy to get lost in the shuffle of older generations."

Overall, the use of email, social media and alumni magazine came through as communication preferences under the communication theme.

\section{By Affinity}


Affinity was another theme that emerged among the survey results and focus group from the participants responses. The researcher looked for themes that explained why alumni like Midwest Univeristy. Within the affinity theme, the researcher found university brand, athletics, and family culture to be areas that highlighted responses from participants. Participants shared what they liked most about the university with several individual referencing athletics. One participant said, "Football games or special events" such as National Championship appearances is what makes Midwest Univeristy such a special place. This was supported by another individual saying that "sporting events" keep him connected with the Univeristy. Another area within affinity that participants mentioned was the family culture. One participated shared:

I would say family. I remember that more than anything. The community itself. I liked the town of Maryville, I think they really embrace the school, and not just Maryville, but the whole region. I also liked how well the campus is landscaped and maintained. It's beautiful. Just really fortunate to be able to have such a nice campus. And of course, there's a lot of good people on campus too that make it the way it is.

Other participants shared their feelings about the family culture by explaining that they enjoy coming back to traditions such as Homecoming and athletics events. These examples provided the researcher an understanding of the family culture that continued to be brought up by participants.

University brand was another key notion the researcher collected from the communication themed responses. Within the University brand, the researcher combined responses together that provided evidence of what the school was known for, such as the alumni pride in the school and with the graduates. One participant shared, "I'm just really proud of some of the great things that people have gone on to do." The affinity theme allowed the researcher to pull feedback from participants on what they like most about the university. 


\section{Type of Events}

The type of events theme was created due to the statements participants made in response to what events they enjoy attending. The researcher was interested in learning about what events participants enjoyed and what events would make them more engaged as an alum. Types of events that emerged throughout the study were: (a) family friendly events, (b) academic events, (c) athletic events, and (d) alumni socials. To highlight a response on events, one participant shared:

I think the huge events that, like he was mentioning, a family weekend, homecoming, some of the bigger games, not just a random one here or there, and I think too, the championships, the alumni does a great job of getting some of those gatherings together and opening it up at a local restaurant or a bar and saying, "Everybody come on in and chat a little bit before heading over to the game'.

Another participant shared:

More information about regional association opportunities for people who no longer live in Maryville. Networking opportunities in areas outside of Maryville would be great." Both examples of response were great at it showed the researcher that participants in the study are interested with events that bring Millennial back together with other alumni that they know. Additionally, several participants shared that reunions would be something they are interested in coming back to Northwest for or meeting up with other alumni at various regional locations around the country. This information provided the researcher that regional alumni chapters and reunions of classes are types of events that Millennial Alumni are interested in. Additionally participant respondents talked about the importance of coming back to Northwest for things they 
feel connected too such as Homecoming, athletic events and reunions that revolved around those that were in their academic department or class. To support this find, one participant shared,

"I would say it's almost the cliché answer, but like things like homecoming and the family weekends, those big events on campus that are going to be something, especially for someone like me who is five hours away, that's more enticing to come up than just maybe like a random game here or there. And also, obviously, when we get to the championships and things like that, those are the things that I want to be a part of as well.

So for me, it's those bigger are bigger events, on campus."

The researcher found themes again in responses that showed evidence of events Millennial alumni enjoy along with specific examples of what this population would like to see more of when looking at events in the future.

\section{Engagement Rationale}

The researcher was interested in learning what the Millennial population would be interested in supporting when making a donation along with understanding why this group would choose not make a donation to the Univeristy. Additionally, the researcher asked questions that help him understand why an individual in the group would choose not to come back to campus or engage with the Univeristy at a future events. The following themes emerged under the engagement rationale theme. The themes that emerged were, paying off student loans, family/other, distance and lack of knowledge where highlighted from participant responses. The two areas that participants shared that they were interested in giving to were scholarships/directly supporting a student and academics. A response that highlighted the scholarship/directly support a student one person said, 
"I think giving it to areas that you have interest in, it really just means a lot. And at the same time, some of the things that given to you, like the Bearcat scholarship, I think that's also nice too. The Adoptive Bearcat."

Another participant responded, "I like knowing where the donation goes. I work on campus, so I've been more inclined to give to like Pay It Forward for the food pantry or a specific scholarship that I've seen benefit my students. So probably more the basic level things have motivated me to give or want to help that situation."

The researcher was also interested in learning why alumni would choose not to make a donation to the university. Feedback collected indicated that students loans and family other financial commitments would hinder them in making a donation. One participant said,

"And I would say the finances, as long as I'm stable with my finances, I don't mind giving back. But at the same time there's a lot of things that pop up. So even like myself, I'm single with no kids, and that does allow me to give back, probably more here recently, but it's the same time everyone has things that come up that costs a lot sometimes. So I think it just comes back to the finances."

To provide another example of why someone may not give, one participant shared:

I would just say the general topic of financial ability would be one of those. And then also going along with the other participants said is that I still have student loans out myself, and so being able to pay off all of those and getting myself and my wife both on that same page of, we are financially independent or be able to start giving back to the university. 
Another area the researcher was interested in learning more about was why a alumni choose not to engage with the university by not attending the an event or visiting campus. Participants provided a variety of reasons in the focus group and survey. The two themes reasons why not engaged where those of distance from campus and lack of knowledge of what is happing on campus. One participant said, "I am an alumni who is a long distance from Missouri (on the East Coast). I love seeing all the activities and things going on, but feel disconnected because they require you to be there in the Missouri/Kansas/Iowa/Nebraska area." While another research participant said:

I think the social media is great for, especially, that up to date what's going on and what's happening. And I might be a little bit different in this aspect. I feel like we get so much junk mail in general. You know what, if there's was a letter that came in, I know we get the alumni magazine, what, once, twice a year, along with that, but heck we got a letter from Northwest Alumni Relations saying, "All right, this is what's going on, this is what we have coming up." I mean, I'd be happy to open up an envelope and read something actually in my hand.

Communication continued to be an issue on why alumni feel like they are not engaged. Several research participants shared that they feel they are only contacted when we want money. One participants said, "I think the only thing I know about the Alumni Association is that you ask for money." While another participant shared, "I only get contacted when you want money." Both examples provided evidence that communication or type of communication also can have effect on one's ability to give.

\section{Discussion}

The purpose of this research was to do an analyze on the existing data of Millennials at Midwest University with collecting feedback from research participants on their opinions on how 
to improve engagement with the university. This study examined the specific descriptive statistics, independent tTest and opinions of individuals born from 1980 to 2004 . The analysis of Millennial alumni was extracted from data from a survey and focus group which allowed for the facts and perceptions of this group to be understood and to be known.

The information provided by both the quantitative data analysis and qualitative analysis allowed for a variety of information to come to the service. From this information, the researcher was able to provide recommendation to the program and to future scholarly work that connected to this research. The researcher was able to collect key findings and provided the information back to the program director and submitted academic findings to accredit nonprofit journal for alumni engagement and fundraising.

\section{Future Research}

The researcher proposed both scholarly recommendations and practitioner recommendations. Both sets of recommendations are intended to provide better evidence and direction on best practices to engage with the Millennial generation in higher education. The set of scholarly recommendation included the following:

- Future research is needed on communication and engagement preference by early to late Millennial birth grouping years (1980 to 1989 and 1990 to 2004).

- Future research is needed on communication and engagement preference by degree type (Undergraduate and Graduate Degree) when looking at the Millennial population.

- Future research is needed on types of activities Millennial population (zero to four activities) were involved in. From those activities what produced the most donors and highest average gift. 
- Future research on if there was a connection between students who received scholarships and became a donor to areas of scholarships, athletics, and academic area.

The set of practitioner recommendations include the following:

- Bring more events to regional areas that alumni are living in.

- Incorporate more of family culture brand into all marketing and communication for alumni engagement and fundraising.

- Build in more family friendly events into alumni engagement programing.

- Email is not dead; keep using this as a way to disperse communication.

- Provide more resources to social media and alumni magazine for the Millennial population.

- Change call to action to more academic priorities and the needs for scholarships and direct student benefit.

- Evaluate non donors and determine how many were involved in organizations and how many to be potential included in future solicitations and engagement opportunities. 


\section{References}

Blau, P. (1964). Exchange and power in social life. New Your, John Wiley \& Sons.

Charles, C. M., \& Mertler, C. A. (2002). Introduction to educational research (4 $^{\text {th }}$ ed.). Boston, MA: Allyn and Bacon.

Connolly, M. S., \& Blanchette, R. (1986). Understanding and predicting alumni giving behavior. New Directions for Institutional Research, 1986(51), 69-89.

Creswell, J. W. (2014). Research design, qualitative: Quantitative, qualitative and mixed methods approaches: (4th ed). Thousand Oaks, CA: Sage.

Davis, D. (2019). Understanding annual giving \& what motivates young alumni to give to their alma mater: A mixed methods study.

Dodge, L. E. (2016). Alumni giving and social exchange: a study of alumni giving behavior. In Facilitating Higher Education Growth through Fundraising and Philanthropy (pp. 294-323). IGI Global.

Drew-Branch, V. (2011). Student engagement, alumni satisfaction, and alumni donations at a public four year institution: An analysis of how the undergraduate experience influences alumni donations. West Virginia University. ProQuest Dissertations and Theses, 68. Retrieved.

Drezner, N. D., \& Huehls, F. (2014). Fundraising and institutional advancement: Theory, practice, and new paradigms. Routledge.

Elam, C., Stratton, T., \& Gibson, D. D. (2007). Welcoming a new generation to college: The Millennial students. Journal of College Admission, 195, 20-25.

Emerson, R. M. (1976). Social exchange theory. Annual Review of Sociology, 2(1), 335-362. doi: $10.1146 /$ annurev.so.02.080176.002003. 
Farrel L., \& Hurt A. (2014). “Training the Millennial Generation: Implications for Organizational Climate”, Journal of Organizational Learning and Leadership, 12 (1), 47-60.

Feiertag, J. \& Berge, Z. L. (2008). Training generation N: How educators should approach the Net Generation. Education + Training, 50(6), 457-464.

Fink, A. (2017). How to conduct surveys: A step-by-step guide. Thousand Oaks, CA. Sage Publications.

Fundraising Report Card, (2016) 3 simple fundraising metrics for nonprofits (and how to calculate them). Retrieved from, Fundraising Report Card https://fundraisingreportcard.com/fundraising-metrics-for-nonprofits/

Hanley Semelbauer, K. (2015). The next generation of philanthropic giving in West Michigan and beyond. SPNHA Review, 11(1), 6.

Harrison, W. B. (1995). College relations and fundraising expenditures: Influencing the probability of alumni giving to higher education. Economics of Education Review 14(1), 73-84.

Howe, N., \&L Strauss, W. (2000). Millennials rising: The next great generation. NY, Vintage Books.

Krueger, R. A., Casey, M. A., (2015). Focus groups: A practical guide for applied research. Thousand Oaks, CA. Sage Publications.

McAlexander, J. H., Koenig, H. F., \& DuFault, B. (2016). Millennials and boomers: Increasing alumni affinity and intent to give by target market segmentation. International Journal of Nonprofit and Voluntary Sector Marketing, 21(2), 82-95. 
McClellan, C. (2016). Miami University: A case study of young alumni programs. Journal of Education Advancement \& Marketing, 1(2), 144-155.

Merriam, S. B., \& Tisdell, E. J. (2015). Qualitative research: A guide to design and implementation. John Wiley \& Sons.

Molnar, A. (2019). SMARTRIQS: A Simple Method Allowing Real-Time Respondent Interaction in Qualtrics Surveys. Journal of Behavioral and Experimental Finance, 22, $161-169$.

Oblinger, D. (2003). Boomers gen-xers millennials. EDUCAUSE Review, 500(4), 37-47.

Northwest Missouri State University. (n.d.) Various university web pages. Retrieved from https://www.nwmissouri.edu/facts/

https://www.nwmissouri.edu/alumni/giving/index.htm

https://www.nwmissouri.edu/alumni/advancement/index.htm

Oliff, P., Palacios, V., Johnson, I., \& Leachman, M. (2013). Recent deep state higher education cuts may harm students and the economy for years to come. Center on Budget and Policy Priorities, 19.

Osborn, D., Alkezweeny, J., \& Kecskes, K. (2015). Beyond the university: an initiative for continuing engagement among alumni. Metropolitan Universities.

Picardi, C. A., \& Masick, K. D. (2013). Research methods: Designing and conducting research with a real-world focus. Sage Publications.

Purani, K., Kumar, D. S., \& Sahadev, S. (2019). e-Loyalty among millennials: Personal characteristics and social influences. Journal of Retailing and Consumer Services, 48, 215-223. 
Radcliffe, S. (2011). A study of alumni engagement and its relationship to giving behaviors, Master's Theses, Bucknell University. Retrieved from http://digitalcommons.bucknell.edu/masters_theses/

Rainer, T. S., \& Rainer, J. W. (2011). The Millennials: Connecting to America's largest generation. Nashville, TN. B \& H Books.

Sargeant, A., \& McKenzie, J. (1999). The lifetime value of donors: Gaining insight through CHAID. Fundraising management, 30(1), 22-27.

Saratovsky, K. D., \& Feldmann, D. (2013). Cause for change: The why and how of nonprofit millennial engagement. John Wiley \& Sons.

Seidman, I. (2013). Interviewing as qualitative research: A guide for researchers in education and the social sciences. Teachers College Press.

Stein, J. (2013). Millennials: The me me me generation. Time magazine, 20, 1-8.

Taylor, A. L., \& Martin, J. C. (1995). Characteristics of alumni donors and nondonors at a research I, public university. Research in Higher Education, 36(3), 283-302.

Toyn, G. (2020, February 16). Alumni \& advancement: Agree on definition of engagement.

Weerts, D., \& Hudson, E. (2009). Engagement and institutional advancement. New Directions for Higher Education, 147, 65-74. 


\section{SECTION SIX}

\section{SCHOLARLY PRACTITIONER REFLECTION}

My educational journey through the doctoral program has allowed for me to grow as a student, leader, and learner from the knowledge and insights I have gained over the last several years. Obtaining my EdD has ignited my desire to want to make change for the organizations I serve and has strengthened my voice on issues and policies I agree or disagree with. The pillar of leadership theory and practice were leading themes evaluated throughout the program. Through the last three years, I have been challenged with what I am reading, writing and processing when related to new ideas and complex issues from all different types of lenses. My overall understanding of leadership and how I have the ability to use that leadership to make change for the better is a profound lesson that I will take with me throughout the rest of my life.

\section{Dissertation Influenced Practice as Educational Leader}

Northouse (2016) explained that leaders exhibit a variety of traits that make them an effective leader. The skill sets that stand out to me as a leader include being a change agent, building trust, the ability of clear and open communication among team members, having experiences and opportunities learned from each other and the need and importance of critical reflection, and establishing trusting dialogue with those whom I work with. Gill (2010) explained that it was the importance of leaders to learn from their surroundings, people they worked with, and personal experiences to be able to acclimate to the culture for the best success. 


\section{Leadership Theory and Practice}

\section{Scholarly Background}

As a leader, I infuse a great deal of trust and communication with everything to help me initiate building successful professional relationships with others and productive teamwork (Bruffee, 1999). Daniel Goleman (2011) explained that leaders should use what he called “emotional intelligence," which included using the five traits of self-awareness, self-regulation, motivation, empathy, and social skills to build strong relationships (p. 3). As a leader, I see the importance of developing relationships that are strong and create a climate for those around me to have the ability to be themselves and use their voice freely without fear of retaliation. Building authentic relationships with colleagues that foster open and honest discussions and sharing of information freely has been the ideal climate (Taylor, 2009). Creating this type of environment that encourages positive social interactions within the work culture also aids in building an atmosphere where trust and communication can flourish (Levi, 2017).

\section{Learning and Growing from Experiences}

I see myself as someone who can reflect on where I have been in my experiences and acknowledge the importance of each learnable moment. Continuous self-examination has allowed me to assess and to challenge assumptions that I may have had, which ultimately led to what Mezirow and Taylor (2009) described as a transformative process to learning. As a leader, I want to be able to act based on facts and truths instead of personal bias, feelings, or judgments of others. To be able to do this, a leader must use a combination of previous experiences and data to make change within the organization, Datnow and Park (2014) called this form of leadership “data-driven leadership" (p. 18). Zettelmeyer (2015) also supported the use of data but explained 
that leaders needed to be able to decipher the good data from the bad data, which he called “working knowledge of data science," (p.47).

As a leader at a university, I support and value an environment that encourages ongoing learning amongst its employees. This type of culture is what Gill (2010) explained, as the responsibility of the organization and its employees together. I have realized that many situations have provided opportunities for additional learning and self-development. However, before any learning can commence, all employees, including the leaders, should understand clearly the outcomes the group is trying to achieve (Gill, 2010). Additionally, leaders within an organization should foster an environment that allows employees to experience, conceptualize, and interact with the organization (Hoggan, 2015). Hoggan elaborated on to explain that individuals need to have three phases of learning outcomes for transformative learning to be initiated. Depth, breadth, and relative stability were essential in the learning outcomes employees and leaders considered when implementing opportunities for individuals to learn and to grow within organizations (Hoggan, 2015).

\section{Ability to Create Change}

When reviewing my ability to be a change agent, I examined the different environments in which I have had the opportunity to make a difference. My community, workplace, and higher education were all areas as a leader, learner, and citizen where I can and will lead improvements for the better. Taylor (2009) explained that there were three necessary elements needed in any teaching and learning moment: (a) individual experiences, (b) critical reflection, and (c) dialogue. To be a change agent, a leader needed to have the ability to connect and to teach others by using these elements to create an environment where learning and change were possible. However, to create change, one first needs to have a reliable compass of ethics. Rest 
(1986) supported the need for high ethical practices by explaining that leaders should use the four moral behavior skill sets of; moral sensitivity, moral judgment, moral focus, and moral character to be able to carry out strong ethical behaviors consistently. Strong values in identity, commitment, and civic agency were additional traits that have been cited by the works of Kochahar-Bryant (2017), who explained leaders can be ethical change agents when they fuse community-based knowledge with scholarly work to better themselves and the ones around them.

\section{Application to Professional Practice}

Personal experiences are the cornerstone to what leaders bring to the table to tackle issues that allow for change to be possible (Northouse, 2016). Prior experience enabled individuals to use first-hand knowledge to situations and ideas to stimulate new approaches or new ways of thinking (Taylor, 2009). Taylor (2009) supported the idea that leaders' experiences shared with others for transformational learning to occur (Merriam \& Bierema, 2014). Providing environments where people wanted to look for answers and solutions to help make a difference was the climate in which I have preferred to create and to work in.

Taking time to review and reflect on thoughts and knowledge was what Taylor (2009) explained was essential for leaders to be successful. As a leader, I tend to do a great deal of writing to help me organize my thoughts on projects and goals. Taylor (2009) explained this helped individuals organize and make sense of their reflections. I have found this approach one of the most helpful and successful processes to do when initiating and evaluating change. When promoting change, communicating, and talking with others were additional actions to demonstrate as a leader. Creating an environment where open dialogue allowed individuals to put their experiences and reflections together to generate action into agendas that made change 
possible (Taylor, 2009). However, the critical thing to understand has been for communication to assist in making a difference, leading by experience, and active reflection must have been present in the environment.

\section{Content and Context of Learning}

Adults are constantly learning (Merriam \& Bierema, 2014; Nonaka, 1994). As a matter of fact, I just accessed the Internet to learn the quickest route for my family's summer vacation. With technology, multiple resources are readily available for acquiring knowledge with minimal effort. Learning today seems to occur almost without thoughtful intention, as society has adapted to the wealth of knowledge conveniently at our fingertips. Whether to achieve a specific goal, to research a particular topic, or to learn about current events, access to new knowledge simply requires motivation to learn (Merriams \& Bierema, 2014). Adults, just like students, have diverse learning styles (Gill, 2010).

\section{Learning Styles}

Gill (2010) suggested understanding your own personal style of learning to better assist others in learning how to learn. I prefer to learn by watching or listening, and then doing. When learning the Cha Cha Slide for an upcoming middle school dance, I preferred to watch a video and play it repeatedly, while I practiced simultaneously. I appreciate coaching that provides guidance along the way, but if I do not tackle the task myself, I do not grasp the concept as well. A few months ago, I needed to execute a unique report on our district's computer program, PowerSchool, for a work-related task. I asked the secretary for assistance and, knowing my personal learning style, she coached me through the process on my computer. I made all the clicks with her instructing me through the process. I have found forcing myself to jump in and to 
learn a new task has been the best way for me to remember how to complete the task again in the future. Perhaps a variation of this learning approach will be transferable to others in the field.

As an educational leader, it is crucial to recognize followers have different learning styles (Gill, 2010). There is no one-size-fits-all approach to learning (Gill, 2010); followers should be exposed to different learning methods (Gill, 2010). Not only does this appeal to the diverse learning approaches of the followers, it also provides instructional strategies for teachers to consider incorporating into the classroom. Teachers, too, must be sensitive to the different learning styles in the classroom.

\section{Establishing a Culture of Learning}

Effective organizations establish a culture of learning (Gill, 2010). During my past 10 years in education, I have encountered a strong learning culture and a weak learning culture. From my experience, the leadership sets the tone for the level of adult learning that takes place within an organization. Under quality leadership, I participated in individual learning activities, partner and team collaboration, discussions in various settings, whole organization learning, and structured professional development opportunities. During school years with weak leadership, if any learning occurred at all, it took place in isolation with self-interest being the only motivator. I think adult learning is important in all organizations, but essential in education.

How does an organization create an effective learning environment? First and foremost, I think leaders who understand the importance of adult learning is key. In addition, for teachers to be receptive to adult learning in an organization, they must respect the leader. In my opinion, no one wants to learn from someone they do not respect. Leaders must be willing to not only communicate the importance of ongoing learning, but to create time and space for learning 
opportunities (Ettling, 2012). Effective leaders who support and encourage adult learning provide structured activities and allow time for collaboration in various forms (Ettling, 2012). Also, followers should serve as resources to each other and encourage one another's growth. Leaders, in effective learning organizations, served as role models by listening to others and by being open to new ideas. In a successful adult learning environment, trust has been established between the leader and followers, and a candid dialogue existed between all staff members without reservations.

Leaders must communicate how taking risks was acceptable in learning. Failure is a great learning method. Learning from mistakes allows us to continuously perfect our craft. In my first year of administration, I struggled with phone calls from frustrated parents which was a reoccurring event for any administrator. It took repeated practice for me to understand that often times parents just wanted to be heard. Sometimes parents needed to express their frustrations before they can accepted and processed the problems. Typically, the situation frustrates the parent, and it has nothing to do with me personally. After several failed attempts of handling phone calls of this nature, I learned to be more patient and to listen. With feedback from my supervisor and personal reflection upon my past failed attempts, I have learned to take my time with parents who were upset.

Feedback and reflection were crucial factors in adult learning (Gill, 2010). I consider feedback essential in facilitating adult learning; adults need to be made aware of strengths and weaknesses. I think it is beneficial in an organization to gain feedback from multiple sources, if possible. In my experience, open, honest, and direct communication in individual settings with teachers has prompted reflection and growth, as well as great follow-up conversations. Throughout my entire adult life, I have blossomed from feedback. It can be reassuring, 
motivating, thought-provoking, and tremendously useful in encouraging constant growth and development. Conversations may be somewhat awkward or difficult, if there is no established relationship. I strive to build relationships before having tough conversations. Once followers know you care and truly have not only their best interest, but the organization's best interest in mind, conversations are more comfortable.

\section{Conclusion}

My biggest takeaway from the cohort experience has been that I have been stretched to consider all ideas from various perspectives. I have grown from working with professionals who have different experiences. My appreciation for diversity in all settings, not just workplace issues, has multiplied. In everyday life, I now naturally consider situations from different angles. Careful attention to various perspectives has given me balance and a foundation for making decisions in a fair and equitable manner.

Thinking back on President Harry S Truman's quote, "It is amazing what you can accomplish if you do not care who gets the credit" (McKee, 2016, p. 51), my way of thinking has transitioned from an individual to a holistic perspective. Quite honestly, my selfish ways and biases have been exposed. The cohort experience has humbled me to be a valuable member of a team with no need for individual recognition. In the end, it did not matter who completed each individual task. The people and the process were important. Quality leadership and successful organizations has been about collaboration and teamwork. What makes a difference was how the team worked together to move the organization to a higher level of functioning. 


\section{References}

Affinity. (2020). Merriam-Webster. Retrieved from https://www.merriamwebster.com/dictionary/affinity

Alumni. (2020). Dictonary.com. Revised from https://www.dictionary.com/browse/alumni

Atchley, R C. (1989) The Continuity Theory of Normal Aging. The Gerontologist.; 29:18390.

Austin, T. L., Clark, L. C., \& Sigmar, L. S. (2018). Practical Persuasive Communication: The Evolving Attitudes of the iGeneration Student. e-Journal of Business Education and Scholarship of Teaching, 12(3), 14-33.

Baade, R. A., \& Sundberg, J. O. (1996a). Fourth down and gold to go? Assessing the link between athletics and alumni giving. Social Science Quarterly, 77, 789-803.

Barber, K.D., (2012): A Study of Alumni Engagement and Satisfaction as Related to Alumni Volunteerism and Philanthropy. Valdosta, (Georgia): Graduate School Valdosta State University.

Bass, B. M., \& Riggio, R.E (2006). Transformational leadership. Mahwah, NJ: Lawrence Erlbaum Associates, Inc

Blau, P. (1964) Exchange and power in social life. NY: John Wiley \& Sons.

Bolman, L., \& Deal, T. E. (2013). Artistry choice \& leadership reframing organizations (5th ed.). San Francisco, CA: Jossey-Bass.

Broido, E. M. (2004). Understanding diversity in millennial students. New Directions for Student Services, 2004(106), 73-85.

Cha, I., and W. Neilsen (2001): 'Is Competition Among Charities Bad?,' Texas A\&M University Working Paper Series No. 0116. 
Caboni, T. C., \& Proper, E. (2007). Dissertations Related to Fundraising and Their Implications for Higher Education Research. Online Submission.

Cates, D. W. (2011). Undergraduate alumni giving: A study of six institutions and their efforts related to donor participation. (Doctoral dissertation). Available from ProQuest LLC. (3455392).

Charles, C. M., \& Mertler, C. A. (2002). Introduction to educational research (4 $^{\text {th }}$ ed.). Boston, MA: Allyn and Bacon.

Chou, S. Y. (2012). Millennials in the workplace: A conceptual analysis of millennials' leadership and followership styles. International Journal of Human Resource Studies, 2(2).

Cobban, A.B. (1975). The Medieval Universities: Their Development and Organization. London: Methuen \& Co. Ltd.

Connolly, M. S., \& Blanchette, R. (1986). Understanding and predicting alumni giving behavior. New Directions for Institutional Research, 1986(51), 69-89.

Connor, H., Shaw, S., \& Fairhurst, D. (2008). Engaging a new generation of graduates. Education+ training.

Cook, W. B., \& Lasher, W. F. (1996). Toward a theory of fund raising in higher education. Review of Higher Education, 20, 33-51.

Coolman, J. (2011). The science behind alumni engagement. CASE Currents, Alumni Relations. Creswell, J. W. (2014). Research design, qualitative: Quantitative, qualitative and mixed methods approaches: (4th ed). Thousand Oaks, CA: Sage.

Dagher, V. (2014). Talking philanthropy with millennials. The Wall Street Journal. 
Davis, D. (2019). Understanding annual giving \& what motivates young alumni to give to their alma mater: A mixed methods study.

DeVaney, S. A. (2015). Understanding the millennial generation. Journal of Financial Service Professionals, 69(6).

Dimock, M. (2019). Defining generations: Where Millennials end and Generation Z begins. Pew Research Center, 17, 1-7.

Diehl, A. G. (2007). The relationship between alumni giving and receipt of institutional scholarships among undergraduate students at a public, land-grant institution. Unpublished doctoral dissertation, Pennsylvania State University, State College.

Dodge, L. E. (2016). Alumni Giving and Social Exchange: A Study of Alumni Giving Behavior. In Facilitating Higher Education Growth through Fundraising and Philanthropy (pp. 294-323). IGI Global.

Drew-Branch, V. (2011). Student Engagement, Alumni Satisfaction, And Alumni Donations at a Public Four Year Institution: An Analysis of how the Undergraduate Experience Influences Alumni Donations. West Virginia University. ProQuest Dissertations and Theses, 68. Retrieved from http://search.proquest.com/docview/ 898950350? accountid $=14640$

Drezner, N. D. (2011). Philanthropy and fundraising in American higher education, 37 Number (2). John Wiley \& Sons.

Drezner, N. D. (2018). Alumni engagement in higher education: A matter of marketing and leveraging social identities. Competition in Higher Education Branding and Marketing (181-195). Palgrave Macmillan, Cham. 
Drezner, N. D., \& Huehls, F. (2014). Fundraising and institutional advancement: Theory, practice, and new paradigms. Routledge.

Drucker, P. F., Goleman, D., \& George, B. (2011). HBR's 10 Must Reads on Leadership (with featured article" Why Should Anyone Be Led By You," by R. Goffee \& G. Jones). Harvard Business Press.

Elam, C., Stratton, T., \& Gibson, D. D. (2007). Welcoming a new generation to college: The Millennial students. Journal of College Admission, 195, 20-25.

Emerson, R. M. (1976). Social exchange theory. Annual Review of Sociology, 2(1), 335-362. doi:10.1146/annurev.so.02.080176.002003.

Eppli, M. (2015). The impact of demographics and millennials on commercial real estate. Working paper.

Farrel L. and Hurt A. 2014. "Training the Millennial Generation: Implications for Organizational Climate", Journal of Organizational Learning and Leadership, 12 (1): 47- 60

Feiertag, J. \& Berge, Z. L. (2008). Training generation N: How educators should approach the Net Generation. Education + Training, 50(6), 457-464.

Fink, A. (2017). How to conduct surveys: A step-by-step guide. Thousand Oaks, CA. Sage Publications.

Foreman, B. (2020, March 20) Here are the U.S. universities that have closed due to Coronavirus. Retrieved from, Edscoop https://edscoop.com/universities-closed-duecoronavirus-2020/

Frey, W. (2018). The millennial generation: A demographic bridge to America's diverse future. Brookings. 
Fundraising Report Card, (2016) 3 simple fundraising metrics for nonprofits (and how to calculate them). Retrieved from, Fundraising Report Card https://fundraisingreportcard.com/fundraising-metrics-for-nonprofits/

Galvan, J. L., \& Galvan, M. (2017). Writing literature reviews: A guide for students of the social and behavioral sciences.

Gagliardi, J., Parnell, A., \& Carpenter-Hubin, J. (2018). The analytics revolution in higher education. Change: The Magazine of Higher Learning, 50(2), 22-29.

Garvey, J. C., \& Drezner, N. D. (2013). Advancement staff and alumni advocates: Cultivating LGBTQ alumni by promoting individual and community uplift. Journal of Diversity in Higher Education, 6(3), 199.

Gill, S. 2010, Developing a learning culture in non-profit organizations, Sage, Thousand Oaks, California.

Gottfried, M. A., \& Johnson, E. L. (2006). Solicitation and donation: An econometric evaluation of alumni generosity in higher education. International Journal of Educational Advancement, 6(4), 268-281.

Grace, K. S. (1997). Beyond fundraising: New strategies for non-profit innovation and investment. The NSFRE/Wiley Fund Development Series. New York, NY: Wiley.

Hanley Semelbauer, K. (2015). The Next Generation of Philanthropic Giving in West Michigan and Beyond. SPNHA Review, 11(1), 6.

Harrison, W. B. (1995). College relations and fundraising expenditures: Influencing the probability of alumni giving to higher education. Economics of Education Review 14(1): 73-84. 
Harrison, W. B., Mitchell, S. K., \& Peterson, S. P. (1995). Alumni donations and colleges’ development expenditures: Does spending matter? American Journal of Economics and Sociology, 54(4), 397-412.

Harvard University Fact Book. (2005-06), Office of Budgets, Planning and Institutional Research, President and Fellows of Harvard College. Retrieved from https://oir.harvard.edu/files/huoir/files/harvard fact book 2005-2006.pdf

Hobbs, H. L. (2017). A qualitative study of millennials in the workplace: Gaining their long-term employment in news media firms in north Alabama (Doctoral dissertation).

Holthouser, A. (2020, March 25) Help! Should I raise money during a pandemic (and how)? Network for Good https://www.networkforgood.com/nonprofitblog/help-should-i-raisemoney- during-a-pandemic-and-how/

Homans, G. (1961). Social behavior: Its elementary forms. NY: Harcourt Brace Jovanovich, 13.

Horseman, A. M. (2011). The effects of new media on alumni engagement among millennials: A case study of the University of Kentucky College of Health Sciences Alumni.

Howe, N., \&L Strauss, W. (2000). Millennials rising: The next great generation. New York: Vintage Books.

Hrywna, M. (2013, July 1). Giving beat GDP before inflation. The Nonprofit Times. Retrieved from http://www.thenonprofittimes.com/wpcontent/uploads/2013/07/7-1-

\section{SR GivingUSA.pdf}

Hummel, R. (2010). Factors influencing alumni connection and commitment. (Doctoral dissertation, University of Lethbridge). Available from ProQuest Dissertations and Theses database. (UMI No. MR68767, ProQuest document ID 822408775) 
Hurst, F. M. (2008). Philanthropic giving preference differences: Nontraditional and traditional alumni at Northern Arizona University. (Doctoral dissertation). Retrieved from the ProQuest Dissertations and Theses database. (3321618)

Internal Revenue Service (2020, April 28) IRS TAX TIP 2001-31. Retrieved from https://www.irs.gov/pub/irs-news/at-01-31.pdf

Kanady, J. (2015). An examination of alumni engagement at Rowan University. Theses and Dissertations. 525.

Kaplan, A.E. (2017). 2011 Voluntary support of education. New Your, NY: Council for Aid to Education. 2000 and Beyond: Charitable and Social Change Giving in The New Millennium," Fund Raising Management 30 (May 1999): 28-31.

Kaplan, A. E. (2018). 2017 voluntary support of education survey.

Keller, M.J.C. (1982) An analysis of alumni donor and non-donor characteristics at the University of Montevallo (Alabama). Doctoral dissertation, University of Alabama, Tuscaloosa, AL.

Kennett, D. A. (1980). Altruism and economic behavior: Developments in the theory of public and private redistribution. American Journal of Economics \& Sociology, 39, 183-198.

Kim, M. M., \& Ko, J. (2015). The impacts of state control policies on college tuition increase. Educational Policy, 29, 815-838. doi:10.1177/0895904813518100

Knapp, L. G., Kelly, J. E., Whitmore, R. W., Wu, S., Gallego, L. M., \& Broyles, S. G. (2002). Enrollment in Postsecondary Institutions, Fall 2000 and Financial Statistics, Fiscal Year 2000. NCES Report 2002-212. Available at http://nces.ed.gov/pubs2002/pubsearch.

Kotz, P. E. (2016). Reaching the Millennial Generation in the Classroom. Universal Journal of Educational Research, 4(5), 1163-1166. 
Krueger, R. A., Casey, M. A., (2015). Focus groups: A practical guide for applied research. Thousand Oaks, CA. Sage publications.

Langley, J. A. (2010, July 18). Listening-really listening-to alumni. Retrieved from The Chronicle of Higher Education [Online]: http://chronicle.com/article/ListeningReally/66318/

Lee, J., Lim, C., \& Kim, H. (2017). Development of an instructional design model for flipped learning in higher education. Educational Technology Research and Development, 65(2), 427-453.

Levi, D. (2015). Group dynamics for teams. Thousand Oaks, CA: Sage Publications.

Lewis, C. (2019). "Next Generation" Givers: Implications for Nonprofit Engagement (Doctoral dissertation, University of San Francisco).

Li, A. Y., \& Zumeta, W. (2015). State support for higher education. In The Palgrave international handbook of higher education policy and governance (pp. 463-482). Palgrave Macmillan, London.

Liu, Y. (2006). Determinants of private giving to public colleges and universities. International Journal of Educational Advancement, 6, 119-140.

Lunenburg, F. C. (2012). Organizational structure: Mintzberg's framework. International journal of Scholarly, Academic, Intellectual Diversity, 14(1), 1-8.

Magyar Nemzeti Bank. (2020, April, 28), Defining financial stability, Retrieved from https://www.mnb.hu/en/financial-stability/defining-financial-stability

McAlexander, J. H., Koenig, H. F., \& DuFault, B. (2016). Millennials and boomers: Increasing alumni affinity and intent to give by target market segmentation. International Journal of Nonprofit and Voluntary Sector Marketing, 21(2), 82-95. 
McCaffery, P. (2010). The higher education manager's handbook: effective leadership and management in universities and colleges. Routledge.

McClellan, C. (2016). Miami University: A case study of young alumni programs. Journal of Education Advancement \& Marketing, 1(2), 144-155.

Merriam, S. B., \& Bierema, L. L. (2014). Adult learning: Linking theory and practice. San Francisco, CA: Jossey-Bass.

Merriam, S. B., \& Tisdell, E. J. (2015). Qualitative research: A guide to design and implementation. John Wiley \& Sons.

Mesch, D. J., Rooney, P. M., Steinberg, K. S., Denton, B. (2006). The effects of race, gender, and marital status on giving and volunteering in Indiana. Nonprofit and Voluntary Sector Quarterly, 35(4), 565- 587.

Molnar, A. (2019). SMARTRIQS: A Simple Method Allowing Real-Time Respondent Interaction in Qualtrics Surveys. Journal of Behavioral and Experimental Finance, 22, 161-169.

Monaco, M., \& Martin, M. (2007). The millennial student: A new generation of learners. Athletic Training Education Journal, 2(2), 42-46.

Monks, J. (2003, April). Patterns of giving to one's alma mater among young graduates from selective institutions, Economics of Education Review. 22(2), 121-130.

Morgan, R. A. (2014). Factors that lead Millennial alumni to donate to their alma mater. Carbondale: Southern Illinois University.

Northouse, P. G. (2016). Leadership: Theory and practice. Sage publications.

Northwest Missouri State University. (n.d.) Various university web pages.

https://www.nwmissouri.edu/facts/

https://www.nwmissouri.edu/alumni/giving/index.htm 
https://www.nwmissouri.edu/alumni/advancement/index.htm

Oblinger, D. (2003). Boomers gen-xers millennials. EDUCAUSE Review, 500(4), 37-47.

Okunade, A. A., Wunnava, P. V., \& Walsh Jr, R. (1994). Charitable giving of alumni: micro-data evidence from a large public university. American Journal of Economics and Sociology, 53(1), 73-84.

Oliff, P., Palacios, V., Johnson, I., \& Leachman, M. (2013). Recent deep state higher education cuts may harm students and the economy for years to come. Center on Budget and Policy Priorities, 19.

Osborn, D., Alkezweeny, J., \& Kecskes, K. (2015). Beyond the university: an initiative for continuing engagement among alumni. Metropolitan Universities.

Picardi, C. A., \& Masick, K. D. (2013). Research methods: Designing and conducting research with a real-world focus. Sage Publications.

Purani, K., Kumar, D. S., \& Sahadev, S. (2019). e-Loyalty among millennials: Personal characteristics and social influences. Journal of Retailing and Consumer Services, 48, 215-223.

Pyöriä, P., Ojala, S., Saari, T., \& Järvinen, K. M. (2017). The millennial generation: a new breed of labor?. Sage Open, 7(1), 2158244017697158.

Radcliffe, S. (2011). A study of alumni engagement and its relationship to giving behaviors, Master's Theses, Bucknell University, [online at]:

Phttp://digitalcommons.bucknell.edu/masters_theses/

Rainer, T. S., \& Rainer, J. W. (2011). The Millennials: Connecting to America's largest generation. B \& H Books: Nashville, TN.

Remley, D. (1996). Relationship marketing: Guaranteeing the future. Nonprofit World, 14, 13.

Roeckelein, J. E. (Ed.). (2006). Elsevier's dictionary of psychological theories. Elsevier. 
Rosentiel, T. (2019). Portrait of the Millennials. Pew Research Center. Retrieved from. https://www.pewresearch.org/2010/03/11/portrait-of-the-millennials/

Sargeant, A., \& McKenzie, J. (1999). The lifetime value of donors: gaining insight through CHAID. Fund raising management, 30(1), 22-27.

Saratovsky, K. D., \& Feldmann, D. (2013). Cause for change: The why and how of nonprofit millennial engagement. John Wiley \& Sons.

Scott, N., \& Seglow, J. (2007). Altruism. New York, NY: Open University Press.

Seidman, I. (2013). Interviewing as qualitative research: A guide for researchers in education and the social sciences. Teachers college press.

Skari, L. A. (2014). Community college alumni: Predicting who gives. Community College Review, 42(1), 23-40.

Shefska, Z (2020, February 16) Fundraising metrics, Nonprofit metrics https://fundraisingreportcard.com/fundraising-metrics-for-nonprofits/

Snijders, I., Wijnia, L., Rikers, R. M., \& Loyens, S. M. (2019). Alumni loyalty drivers in higher education. Social Psychology of Education, 22(3), 607-627.

Specter, J. K. (2012). Enhancing alumni engagement: Tradition-building at the University of Delaware. University of Delaware.

Stein, J. (2013). Millennials: The me me me generation. Time magazine, 20, 1-8.

Statistics Canada. (2007). Labor force projections for Canada, 2006- 2031. Canadian Economic Observer, June 2007.

Strauss, W. (2005). Talking about their generations: Making sense of a school environment made up of Gen-Xers and Millennials. School Administrator, 62(8), 10-14.

Strauss, W., \& Howe, N. (1991). Generations: The history of America's future, 1584 to 2069. William Morrow \& Co. 
Strout, E. (2007, July). Courting female donors. Chronicle of Higher Education, 53(44), A21A22

Sweeney, R. (2006). Millennial behaviors and demographics. Newark: New Jersey Institute of Technology, 12(3), 10.

Swift, J. S. (1999). Cultural closeness as a facet of cultural affinity. International Marketing Review.

Taylor, A. L., \& Martin, J. C. (1995). Characteristics of alumni donors and no donors at a research I, public university. Research in Higher Education, 36(3), 283-302.

Taylor, P., Keeter, S. (2010.). The Millennial count, Washington, DC: Pew Research Center: Retrieved from: http://www.pewsocialtrends.org/2020,04/19/millennials-confidentconnectedopen-to-change/.

The Change Leader, Inc. (2020, April 29) Scenario, risk and budget planning: is your university's fall term toast? The Change Leader, Inc. https://thechangeleader.com/scenario-risk-and-budget-planning-is-your-universitys-fall-termtoast/

Thomas, J. A., \& Smart, J. (2005). The relationship between personal and social growth and involvement in college and subsequent alumni giving. Paper presented at the annual meeting of the Association for Institutional Research, San Diego, CA.

Toyn, G. (2020, February 16). Alumni \& Advancement: Agree on Definition of Engagement.

Tsiotsou, R. (2007). An empirically based typology of intercollegiate athletic donors: High and low motivation scenarios. Journal of Targeting, Measurement and Analysis for Marketing, 15(2), 79- 92.

Tulgan, B. (2013). Meet Generation Z: The second generation within the giant" Millennial" cohort. Rainmaker Thinking, 125. 
Underwood, A. (2014). Keeping your friends close: Toward a relationship management model for young alumni donor stewardship at Grinnell College and Macalester College. Retrieved from the University of Minnesota Digital Conservancy. http://hdl.handle.net/11299/166757.

Vervoort, A., \& Gasman, M. (2016). An exploration of giving among gay male college alumni. Journal of Education and Training Studies, 4(5), 123-138.

Volin, J. (2016). The relationship between undergraduate student involvement and subsequent alumni engagement.

Waters, R. D., \& Tindall, N. T. (2011). Exploring the impact of American news coverage on crisis fundraising: Using media theory to explicate a new model of fundraising communication. Journal of Nonprofit \& Public Sector Marketing, 23(1), 20-40.

Wedgeworth, R. (2000). Donor relations as public relations: Toward a philosophy of fundraising.

Weerts, D., \& Hudson, E. (2009). Engagement and institutional advancement. New Directions for Higher Education, 147, 65-74.

Weerts, D. J., \& Ronca, J. M. (2007). Profiles of supportive alumni: Donors, volunteers, and those who "do it all." International Journal of Educational Advancement, 7(1), 20-34.

Whitford, E. (2020, April 6); Colleges continue to churn through refund plans. Inside Higher Education. Retrieved from https://www.insidehighered.com/news/2020/04/06/collegesannounce-room-and-board-refund-plans-students-are-asking-more

Wiepking, P., \& Bekkers, R. (2012). Who gives? A literature review of predictors of charitable giving. Part Two: Gender, family composition and income. Voluntary Sector Review, 3(2), 217-245. 
Zainudin, M. I. B., Ali, A. A. E. B. R., Fadzil, A. S. A., Sarin, M. F., Zaki, N. A. S. B. A., Othman, A. K., \& Hassan, F. H. (2018). Halal Brand Personality and Brand Loyalty among Millennials Modest Fashion Consumers in Malaysia: A Conceptual Paper.

Zhang, Q., Ning, K., \& Barnes, R. (2016). A systematic literature review of funding for higher education institutions in developed countries. Frontiers of Education in China, 11(4), 519-542.

$\underline{\text { https://blog.alumniaccess.com/alumni_engagement_definition_attraction_connection_aff }}$ $\underline{\text { ection_influence }}$ 
Appendix A

Alumni Engagement Survey

Participant Informed Consent Form for Online Survey

\section{Midwest Alumni Association Alumni Engagement Survey}

\section{Consent Form for Midwest Alumni and Friends Engagement Survey Evaluation}

You are invited to participate in a web-based online survey about your engagement interest with the Midwest University Alumni Association. This survey is being conducted by Bob Machovsky, a doctoral student from the University of Missouri-Columbia in conjunction with Midwest University and its Alumni Association. It should take approximately 10 minutes to complete.

\section{PARTICIPATION}

Participation in this survey is voluntary. You may refuse to take part in the research or exit the survey at any time without penalty. You are free to decline to answer any particular question you do not wish to answer for any reason.

\section{BENEFITS}

There are no direct benefits from participating in this research study. However, your responses may help us learn more about the program and hopefully come up with ways to improve your experience and/or the experience of future alumni engagement opportunities.

\section{RISKS}

The possible risks or discomforts of the study are minimal. You may feel a little uncomfortable answering personal or sensitive survey questions.

\section{CONFIDENTIALITY}

Responses will remain anonymous. No one will be able to identify you or your answers, and no one will know whether or not you participated in the study.

\section{CONTACT}

If you have questions at any time about this study or the procedures, you may contact my Chair Advisor, Dr. Nissa Ingraham via phone at 660.562.1776 and via email at nissi@ nwmissouri.edu.

Consent question I consent to participate

\section{Yes}

No 
Appendix B

Online Survey

\section{NORTHWEST ALUMNI}

Midwest Alumni Engagement Survey

Your Midwest Alumni Association would like to know how better to get you involved in future engagement opportunities. This brief survey will help the Alumni Association create programming and engagement opportunities that better fit your needs and wants.

Communication (4 questions)

1. What communications are you currently reading from us? (Select all that apply)

\section{Alumni Magazine}

\section{Facebook Post}

Twitter Post

Emails sent from Alumni Association

Other: 
2. How often do you visit the Midwest Alumni Website?
Very Frequently
Frequently
Infrequently
Never

3. Would you like to receive information about future events by text message?
Yes
No

4. What do you like or dislike about the Midwest Alumni Association? What could we improve?

Engagement Opportunities (5 questions)

5. How often do you visit campus?

Multiple times per year

At least once per year

About every 3-5 years

It has been more than 5 years

6. What would motivate you to come back to campus? 
7. Are you interested in attending a regional Alumni and Friends Chapter events in your area?

Yes

No

8. When you visit campus, what is the reason? (Check all that apply)

\section{Sporting Event}

Attend a special event like Homecoming or the Alumni Awards Banquet

Meet up with friends

Visit Faculty and Staff

Recruit Potential Employees

Other 
9. Based on the statements listed, please indicate how strongly you agree or disagree with them.

\begin{tabular}{|c|c|c|c|c|c|}
\hline & Strongly agree & $\begin{array}{l}\text { Somewhat } \\
\text { agree }\end{array}$ & $\begin{array}{l}\text { Neither agree } \\
\text { nor disagree }\end{array}$ & $\begin{array}{l}\text { Somewhat } \\
\text { disagree }\end{array}$ & $\begin{array}{l}\text { Strongly } \\
\text { disagree }\end{array}$ \\
\hline $\begin{array}{l}\text { Would like to } \\
\text { help the } \\
\text { University } \\
\text { recruit future } \\
\text { Bearcats }\end{array}$ & & & & & \\
\hline $\begin{array}{l}\text { Interested in } \\
\text { learning more } \\
\text { about } \\
\text { networking } \\
\text { opportunities } \\
\text { with other } \\
\text { Bearcats }\end{array}$ & & & & & \\
\hline $\begin{array}{l}\text { Getting involved } \\
\text { in the Alumni } \\
\text { Association }\end{array}$ & & & & & \\
\hline $\begin{array}{l}\text { Mentoring a } \\
\text { current } \\
\text { Northwest } \\
\text { student }\end{array}$ & & & & & \\
\hline $\begin{array}{c}\text { Attending a } \\
\text { Northwest } \\
\text { Sporting Event }\end{array}$ & & & & & \\
\hline $\begin{array}{l}\text { Attend or help } \\
\text { with organizing } \\
\text { a Northwest } \\
\text { Alumni Social }\end{array}$ & & & & & \\
\hline $\begin{array}{l}\text { Serving on an } \\
\text { academic } \\
\text { advisory board }\end{array}$ & & & & & \\
\hline
\end{tabular}

\section{Philanthropy}

10. I have made a donation to Northwest.

\section{Yes}

No 
11. What would motivate you to give to Midwest?

Scholarships

Supports a special project

If a classmate reached out to me

If my company I worked for matched my gift

Volunteer opportunities

12. Please share any opportunities you see for Alumni engagement opportunities

13 Please indicate your gender

Male

Female

Another gender identity

Prefer not to respond 
14 Please select your age group

$22-25$

26-29

$30-33$

$34-37$

38 or older

Prefer not to respond

15 What year did you graduate from Northwest?

2003

2004

2005

2006

2007

2008

2009

2010

2011

2012 
2013

2014

2015

2016

2017

2018

2019

2020

Other 


\section{Appendix C}

\section{Participant Informed Consent Form for Focus Group Evaluation}

$\mathrm{I}$, (please print), agree to participate

in a focus group study on your engagement interest with the Midwest University Alumni Association. This is survey in being conducted by Bob Machovsky a doctoral student in the Educational Leadership and Policy Analysis program from the University of Missouri-Columbia in conjunction with Midwest University and its Alumni Association. I understand the following guidelines:

1.Participation in this survey is voluntary. You may refuse to take part in the research or exit the survey at any time without penalty. You are free to decline to answer any particular question you do not wish to answer for any reason.

2. There are no direct benefits from participating in this research study. However, your responses may help us learn more about the program and hopefully come up with ways to improve your experience and/or the experience of future Commit to be Fit members.

3. The possible risks or discomforts of the study are minimal. You may feel a little uncomfortable answering personal or sensitive survey questions.

4. Responses will remain anonymous. No one will be able to identify you or your answers, and no one will know whether or not you participated in the study.

5. If you have questions at any time about this study or the procedures, you may contact my Chair Advisor, Dr. Nissa Ingraham via phone at 660.562.1776 and via email at nissai @nwmissouri.edu or Bob Machovsky via email at rmachov@nwmissouri.edu or phone 573.465.2179 Date 


\section{Appendix D Continued \\ Interview/Focus Group Questions}

\section{General Information}

- Please share your current age, sex and relationship status with Midwest University (major and year of graduation).

- Do you considered yourself to be engaged with Midwest University since you graduated?

- What year did you graduate?

\section{Motivation}

- What would motivate you to give back to Midwest University?

- What types of causes would you like to support at Midwest University?

\section{Alumni Engagement}

- How would you like to stay engaged with Midwest University?

- What is your communication preference that Midwest University use when communicating with you?

- If not engaged with the Midwest, why do you think that is?

\section{Alumni Affinity/Social Engagement}

- What are some of things you are most proud of at Midwest University?

- What are some activities or events you would come back to at Midwest University?

- If your peers were engaged with Midwest University would that make your more likely to be engaged? 


\section{Appendix E}

Executive Summary

ESSENCE OF SOCIAL EXCHANGE THROUGH ALUMNI ENGAGEMENT OF

MILLENNIALS AND THEIR ALMA MATER

\section{Statement of the Problem}

As Millennials become the next generation of givers and volunteers at the Midwest University studied, the lack of institutional knowledge in fundraising, engagement practices, personal preference with this population, and demographics should be evaluated.

\section{Purpose of the Study}

The purpose of this study seeks to fill the gap in knowledge about what Millennial engagement looks like within higher education at a rural Midwest University.

This Mixed-Methods study aims to fill the gap in the research that is currently in existence. No previous research studies on Millennial alumni engagement at Midwest University has been done.

\section{Conceptual Framework}

- $\quad$ Social Exchange as defined by Peter Blau (1964)

- Perceptions on Value (Thomas \& Smart; Radcliffe, 2011; Skari,2014)

- Alumni Engagement (Hummel, 2010; Barber, 2013; Volin, 2016))

- Factors that Affect Engagement (Hummel, 2010; Barber, 2013; Volin, 2016)

- Millennial Characteristics Strauss \& How (1991)

- Preference in Communication

- Gender Diversity

\section{Design of the Study}

Explanatory Sequential Mixed-Methods Study- "Is a design in which the researcher converges or merges quantitative and qualitative date in order to provide a comprehensive analysis of the research problem.” (Creswell. 2014, p.15).

Descriptive Statistics Analysis of Millennials - A summary of the following demographics: a) gender, b) giving amount, c) fiscal year, d) activities, e) email address, f) type of degree, g) race, and h) age (Creswell, 2014).

Focus Groups - Conducted with alumni of Midwest University (Krueger \& Casey, 2015).

Surveys - Sent to alumni at Midwest University. Surveys have proven to be an effective technique to gain feedback from stakeholders, (Fink, 2017).

\section{$\underline{\text { Research Question }}$}

What Does Millennial Alumni Engagement Look Like at a Rural Midwest University?

\section{$\underline{\text { Research Sub-questions }}$}

1) Who are the Millennials that give at the University?

2) Why do these Millennials give to the University? 


\section{Limitations}

- Data only analyzes the past three years of giving.

- Data integrity, records of alumni are not always updated with correct information.

- Data is only looking at one university and may not accurately reflect the perceptions and characteristics of the Millennial population.

\section{Delimitations}

- This study only looks at one university's Millennial population.

- The economy and financial health of the country could have impacted the data over the past three years.

- Majority of donors are not in the target population.

\section{Significance of the Study}

This study was significant because it provided advancement practitioners and fundraising professionals within higher education an opportunity to understand how to better engage with Millennial alumni more effectively and efficiently in the future fundraising and engagement efforts. This research provided a greater understanding and knowledge to university advancement divisions and practitioners in building better engagement plans and fundraising efforts with this subgroup. The ability for advancement and fundraising professionals to identify best practices on engaging with the Millennial population will also provide a stronger foundation for alumni engagement and fundraising efforts for years to come. 


\section{Appendix F}

Institutional Review Board

University of Misscaut-Columbi

FWA Number: 00002876

IRB Registration Numbers: 00000731,00009014
482 McRleynolds $\mathrm{Hall}$

Columbia, MO 6521 573-882-318:

irbeminsouriedu

June 05, 2020

Principal Imvertigator: Robert J. Machovsky (MU-Student)

Department: Bducational Lendership-EDD

Your IRB Application to project entifled ESSENCE OF SOCIAI. EXCHANGE THHOUGH ALUMNI ENGAGEMENT OE MILI.ENNINIS AND THEIR AL.MA MATERS was reviewed and approved by the MU Institutional Review Board according to the terms and conditions described below:

\begin{tabular}{|c|c|}
\hline IRB Project Number & 2024163 \\
\hline IRB Review Number & 265990 \\
\hline $\begin{array}{l}\text { Initial Application } \\
\text { Approval Date }\end{array}$ & June 05,2020 \\
\hline IRB Expiration Date & June 05, 2021 \\
\hline Level of Review & Exempt \\
\hline Project Seatus & Active-Exempt \\
\hline Exempt Categories & 45 CFR $46.104 d(2)(1)$ \\
\hline (Revised Common Rule) & 45 CFR $46.104 d(4)$ (ii) \\
\hline Bisk Level & Minimal Risk \\
\hline Approved Documents & $\begin{array}{l}\text { A sturvey Consent form will be provided prior to any participant taking } \\
\text { the survey. } \\
\text { Conseat form for Focus group participation. Participants will receive } \\
\text { consent form prior to focus group participation. } \\
\text { Questions for Focus Group. The researcher will ask the following } \\
\text { questions in this document during the Focus Group session. } \\
\text { An online survey that will be sent to the Northwert Millennial } \\
\text { population via email. The survey will be conducted through Qualtrice. } \\
\text { I will use this in my email to recruit alumni for my survey. } \\
\text { I will use this in my email to recruit alumni for my focus group. } \\
\text { Looking to have } 3 \text { to } 8 \text { individuals participate. }\end{array}$ \\
\hline
\end{tabular}

The principal invertigator (PI) is responsible for all aspects and conduct of this study. The $\mathrm{Pl}$ must comply with the following conditions of the approval:

t. CoWD-19Specife Information

Enroliment and study related procedures must remain in compliance with the University of Missouri regulations related to interaction with human participants following guidance at research miseouriedulabout/oovid-19.info.phe

In addition, any reatarting of in-person research activities must comply with the policies and guiding principles provided at research.minsourl.edu/about/research-restart.php, including

appropriate approvals for return to work authorization for individuals as well as human subject research projects.

2. No subjects may be imvolved in any study procedure prior to the IRB approvil date or after the expiration date.

3. All changes must be IRB approved prior to implementation utilizing the Brempe Amendment Form.

4. The Annual Exempt form must be sabmitted to the IRB for review and approval at least 30

days prior to the project expiration date to keep the study active or to close it.

5. Maintain all research records for a period of seven yeara from the projoct completion date.

If you are offering subject payments and would like more information about rescarch participant paymenta, please click bere to view the MU Business Policy and Procedure: hittoifl.

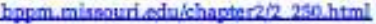

If you have any questions or concerns, pleave contact the MU IRB Office at 573-882-3181 or email to muresearchirthmissouri.edu.

Thank you,

MU Institutional Review Board 


\section{Appendix G}

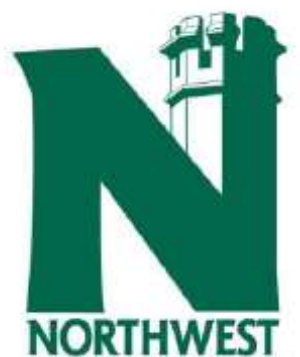

MISSOURI STATE UNIVEREITY

Institutional

Review

Board

Vice President for Finance 117 Administration Buliding 660.562 .1440 office 660.562 .1400 tax
Northwest focuses on student success every student, every day.

Date: 11 June 2020

IRB Project \#: 1920-080

Primary Investigator: Robert Machovsky

Project Title: Essence of Social Exchange Through Alumni Engagement of Millennials and their Alma Maters

The Institutional Review Board has secondarily approved your research proposal as exempt.

You may collect data according to the procedures you describe in your proposal.

You are required to submit a status report to the IRB Chair on several occasions. The status report form is available on the IRB website?

- If your methodology changes, you must file a status report within 10 days.

- If negative incidents pertaining to human participants occur, you must file a status report within 10 days.

- Upon completion of your project, you must file a status report.

Please contact us at IRBNWMS@nwmissouri.edu if you have any questions or concerns, and please include your IRB Project number in all correspondence.

Thank you for your interest in research at Northwest Missouri State University. We wish you the best with your important research.

Regards,

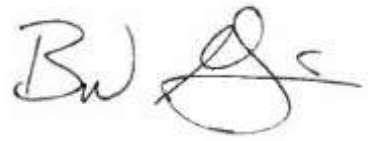

Dr. Bradlee W. Gamblin

Chair, Institutional Review Board AY2019-20 


\section{Vita}

The author of this explanatory sequential mixed-methods study Robert Machovsky started his career at University of South Dakota. He earned a bachelor's degree in Allied Health and a master of science degree in Higher Education Leadership from Northwest Missouri State University. With over 20 years of higher education fundraising and alumni engagement experience, Machovsky currently serves as the Director of Alumni Relations and Annual Giving at Northwest Missouri State University. Robert is currently completing a Doctorate in Educational Leadership and Policy Analysis form the University of Missouri, Columbia. 